\title{
Transient Earth system responses to cumulative carbon dioxide emissions: linearities, uncertainties, and probabilities in an observation-constrained model ensemble
}

\author{
M. Steinacher ${ }^{1,2}$ and F. Joos ${ }^{1,2}$ \\ ${ }^{1}$ Climate and Environmental Physics, Physics Institute, University of Bern, 3012 Bern, Switzerland \\ ${ }^{2}$ Oeschger Centre for Climate Change Research, University of Bern, 3012 Bern, Switzerland \\ Correspondence to: M. Steinacher (steinacher@climate.unibe.ch)
}

Received: 5 June 2015 - Published in Biogeosciences Discuss.: 2 July 2015

Revised: 16 January 2016 - Accepted: 22 January 2016 - Published: 23 February 2016

\begin{abstract}
Information on the relationship between cumulative fossil $\mathrm{CO}_{2}$ emissions and multiple climate targets is essential to design emission mitigation and climate adaptation strategies. In this study, the transient response of a climate or environmental variable per trillion tonnes of $\mathrm{CO}_{2}$ emissions, termed TRE, is quantified for a set of impact-relevant climate variables and from a large set of multi-forcing scenarios extended to year 2300 towards stabilization. An 1000member ensemble of the Bern3D-LPJ carbon-climate model is applied and model outcomes are constrained by 26 physical and biogeochemical observational data sets in a Bayesian, Monte Carlo-type framework. Uncertainties in TRE estimates include both scenario uncertainty and model response uncertainty. Cumulative fossil emissions of $1000 \mathrm{Gt} C$ result in a global mean surface air temperature change of $1.9^{\circ} \mathrm{C}$ ( $68 \%$ confidence interval (c.i.): 1.3 to $2.7^{\circ} \mathrm{C}$ ), a decrease in surface ocean $\mathrm{pH}$ of 0.19 (0.18 to 0.22$)$, and a steric sea level rise of $20 \mathrm{~cm}$ (13 to $27 \mathrm{~cm}$ until 2300). Linearity between cumulative emissions and transient response is high for $\mathrm{pH}$ and reasonably high for surface air and sea surface temperatures, but less pronounced for changes in Atlantic meridional overturning, Southern Ocean and tropical surface water saturation with respect to biogenic structures of calcium carbonate, and carbon stocks in soils. The constrained model ensemble is also applied to determine the response to a pulse-like emission and in idealized $\mathrm{CO}_{2}$-only simulations. The transient climate response is constrained, primarily by long-term ocean heat observations, to $1.7^{\circ} \mathrm{C}\left(68 \%\right.$ c.i.: 1.3 to $\left.2.2^{\circ} \mathrm{C}\right)$ and the equilibrium climate sensitivity to $2.9^{\circ} \mathrm{C}\left(2.0\right.$ to $\left.4.2^{\circ} \mathrm{C}\right)$. This
\end{abstract}

is consistent with results by CMIP5 models but inconsistent with recent studies that relied on short-term air temperature data affected by natural climate variability.

\section{Introduction}

How multiple climate targets are related to allowable $\mathrm{CO}_{2}$ emissions provides basic information to design policies aimed to minimize severe or irreversible damage from anthropogenic climate change (Steinacher et al., 2013). The emission of carbon dioxide from burning of fossil fuels is by far the most dominant driver of the ongoing anthropogenic climate change and of ocean acidification (IPCC, 2013; Gattuso et al., 2015). The increase in a broad set of climate variables such as atmospheric carbon dioxide $\left(\mathrm{CO}_{2}\right), \mathrm{CO}_{2}$ radiative forcing, global air surface temperature, or ocean acidification depends on cumulative $\mathrm{CO}_{2}$ emissions (Allen et al., 2009; IPCC, 1995). It is thus informative to quantify the link between cumulative, total $\mathrm{CO}_{2}$ emissions, and different climate variables. It is advantageous to represent a climate target, such as the United Nations' $2{ }^{\circ} \mathrm{C}$ global mean surface air temperature target, in terms of allowable total $\mathrm{CO}_{2}$ emissions because this is an easily communicable emission mitigation goal. While the link between cumulative $\mathrm{CO}_{2}$ emissions and global mean surface air temperature has been extensively studied (IPCC, 2013), relatively little attention has been paid to the relationship between cumulative $\mathrm{CO}_{2}$ emissions and other impact-relevant variables such as ocean acid- 
ification or sea level rise (Zickfeld et al., 2012; Herrington and Zickfeld, 2014). However, considering the link to emissions for other variables and from the global to the regional scale appears important as many impact-relevant changes are not directly related to global mean surface air temperature.

It is also important to quantify the uncertainty in these links with $\mathrm{CO}_{2}$ emissions by using probabilistic, observation-constrained approaches or multi-model ensembles. This enables one to establish a budget for the amount of allowable carbon emissions if a given climate target or a set of targets is to be met with a given probability. Such budgets in probabilistic terms have been established for surface air temperature, but only recently for a set of multiple climateimpact-relevant variables (Steinacher et al., 2013).

A climate target that is currently recognized by most world governments (United Nations, 2010) places a limit of $2{ }^{\circ} \mathrm{C}$ on the global mean warming since preindustrial times. An objective of the recent Paris agreement (United Nations, 2015 ) is to hold "the increase in the global average temperature to well below $2{ }^{\circ} \mathrm{C}$ above pre-industrial levels and to pursue efforts to limit the temperature increase to $1.5^{\circ} \mathrm{C}$ above pre-industrial levels". This target emerged from the international negotiation process following the United $\mathrm{Na}$ tions Framework Convention of Climate Change (United Nations, 1992) that entered into force in 1994. However, the United Nations Framework Convention of Climate Change has multiple objectives. It calls for the avoidance of dangerous anthropogenic interference within the climate system as well as allowing for ecosystems to adapt naturally to climate change, ensuring food production, and enabling sustainable economic development. These objectives cannot be encapsulated in one single target, e.g., a global mean surface air temperature target, but may require multiple targets. These may be specific for individual regions and components of the climate system, which includes the atmosphere, hydrosphere, biosphere, and geosphere and their interactions (United Nations, 1992). For example, targets may include bounds for sea level rise, ocean acidification, and ocean warming that threatens marine ecosystem functioning and services (IPCC, 2014; Gattuso et al., 2015; Howes et al., 2015). Ocean acidification is, like global warming, progressing with anthropogenic $\mathrm{CO}_{2}$ emissions but, unlike global warming, largely independent of the emissions and atmospheric abundance of non- $\mathrm{CO}_{2}$ forcing agents. It is thus expected that the quantitative link to cumulative $\mathrm{CO}_{2}$ emissions is different for ocean acidification variables, e.g., surface ocean $\mathrm{pH}$, than for global mean surface air temperature. In general, the quantitative relationship to emissions and its uncertainty ranges are distinct for different individual target variables.

Climate projections are associated with two fundamentally distinct types of uncertainties (e.g. Hawkins and Sutton, 2009). First, the scenario uncertainty arises from the fact that future anthropogenic emissions are not known because they depend largely on human actions and decisions, such as climate policies, technological advances, and other socioeco- nomic factors. Second, limitations in our process understanding likely lead to differences between the simulated response to emissions and the response of the actual system the model is intended to describe. This constitutes an additional uncertainty, termed the model or response uncertainty.

Well-defined metrics that summarize the Earth system response to a given forcing by a single or a few values are useful in many aspects. They allow one to quantify the response uncertainty and to compare results from different sources, such as ensemble model simulations, model intercomparisons, or observation-based estimates. Due to their relative simplicity, metrics also ease the communication among scientists and between scientists, stakeholders, and the public. The transient climate response (TCR) and the equilibrium climate sensitivity (ECS) are such metrics, which are used to quantify the global mean surface air temperature (SAT) change associated with a doubling of atmospheric $\mathrm{CO}_{2}$ (e.g. Knutti and Hegerl, 2008). The TCR measures the short-term response (i.e., the temperature increase at the time of doubling atmospheric $\mathrm{CO}_{2}$ in a simulation with $1 \% \mathrm{yr}^{-1}$ increase), while the ECS quantifies the long-term response after reaching a new equilibrium of the system under the increased radiative forcing. TCR and ECS are metrics for the physical climate system and they do not depend on the carbon-cycle response (e.g. Huber and Knutti, 2014; Kummer and Dessler, 2014). TCR and ECS both depend on multiple physical feedbacks such as the water vapor, the icealbedo, or the cloud feedbacks. TCR also depends on the rate of ocean heat uptake. ECS itself does not depend on the rate of ocean heat uptake, while observationally constrained estimates of ECS do.

Certain metrics are helpful to reduce the scenario dependency of results, which may facilitate the communication in a mitigation policy context (Allen et al., 2009). One such metric is the response to a pulse-like emission of $\mathrm{CO}_{2}$ and other forcing agents as applied to compute global warming potentials used in the greenhouse gas basket approach of the Kyoto protocol (Joos et al., 2013; Myhre et al., 2013). Another metric is the transient climate response to cumulative $\mathrm{CO}_{2}$ emissions (TCRE), which links the global mean surface air temperature increase to the total amount of $\mathrm{CO}_{2}$ emissions. In addition to the physical climate response, these metrics also depend on the response of the carbon cycle. TCRE is a useful metric because it has been shown that global warming is largely proportional to cumulative $\mathrm{CO}_{2}$ emissions and almost independent of the emission pathway (Allen et al., 2009; Matthews et al., 2009; Zickfeld et al., 2009; IPCC, 2013; Gillett et al., 2013). It essentially represents the combination of the TCR and the cumulative airborne fraction of $\mathrm{CO}_{2}$ (Gregory et al., 2009; Collins et al., 2013). More recently, additional metrics, i.e., the equilibrium and multimillennial climate response to cumulative $\mathrm{CO}_{2}$ emission, have been proposed to evaluate the long-term link between global mean surface air temperature and emission (Frölicher and Paynter, 2015). 
There is an apparent discrepancy between the TCR estimated with the most recent set of Earth system models (ESMs) versus some recent studies that invoke observational constraints (Otto et al., 2013) and simplified models (Schwartz, 2012; Collins et al., 2013). These latter studies suggest the possibility of a TCR below $1{ }^{\circ} \mathrm{C}$, i.e., outside the very likely range given in the Fourth Assessment Report of the IPCC (Collins et al., 2013). Shindell (2014b, a) suggests that there are biases in simple models that do not adequately account for the spatial distribution of forcings. Shindell found by analyzing ESM output that the transient climate sensitivity to historical aerosol and ozone forcing is substantially greater than to $\mathrm{CO}_{2}$ forcing due to their spatial differences. Taking this into account resolves the discrepancies in TCR estimates. Stainforth (2014) concluded from the study by Shindell (2014b) that probabilistic 21 st century projections based on simple models and observational constraints under-weight the possibility of high impacts and over-weight low impacts on multi-decadal timescales. Huber and Knutti (2014) find that the TCR and ECS of the ESMs are consistent with recent climate observations when natural variability and updated forcing data are considered. Kummer and Dessler (2014) concluded that considering a $\approx 33 \%$ higher efficacy of aerosol and ozone forcing than for $\mathrm{CO}_{2}$ forcing would resolve the disagreement between estimates of ECS based on the 20th century observational record and those based on climate models, the paleoclimate record, and interannual variations. Van der Werf and Dolman (2014) applied a multiple regression approach using historical temperature and radiative forcing data to find that recent temperature trends are influenced by natural modes of variability such as the Atlantic Multidecadal Oscillation. They estimated TCR to be above $1{ }^{\circ} \mathrm{C}$ using century-long records. However, an updated probabilistic quantification of the TCR, ECS, and TCRE with a spatially explicit model and constrained by a broad set of observations is missing.

The goals of this study are (i) to establish the relation between cumulative $\mathrm{CO}_{2}$ emissions and changes in illustrative, impact-relevant Earth system variables; (ii) to quantify TCRE, TCR, and ECS; and (iii) to establish the response of different Earth system variables to an emission pulse, i.e., the impulse response function (IRF). In analogy to TCRE, we introduce a new metric, the transient response to cumulative $\mathrm{CO}_{2}$ emissions (TRE). TRE ${ }^{X}$ is the change in a climate variable, $X$, in response to cumulative $\mathrm{CO}_{2}$ emissions of $1000 \mathrm{Gt} \mathrm{C}$. To this end, we analyzed TRE for variables that we deemed impact-relevant and also reasonably well represented in our model including surface air temperature, sea surface temperature, steric sea level change, ocean acidity, carbon storage in soils, and ocean overturning.

The link and the linearity between the responses in the different variables and cumulative $\mathrm{CO}_{2}$ emissions is investigated in a structured way with an observation-constrained model ensemble and a large set of emissions scenarios. This allows us to address not only the scenario uncertainty but also the model uncertainty. We quantify uncertainties related to specific greenhouse gas emission trajectories, i.e., scenario uncertainty, by analyzing responses to $\mathrm{CO}_{2}$ emission pulses as well as to a set of 55 scenarios representing the evolution of carbon dioxide and other radiative agents. The response uncertainties for these scenarios are quantified with an $\sim 1000$-member model ensemble constrained by 26 observational data sets in a Bayesian, Monte Carlo-type framework with an ESM of intermediate complexity (EMIC). The model features spatially explicit representations of land-use forcing, vegetation, and carbon dynamics, as well as physically consistent surface-to-deep transport of heat and carbon by a 3-D, dynamic model ocean, thereby partly overcoming deficiencies identified for box-type models used in earlier probabilistic assessments (Shindell, 2014b, a). This allows us also to reassess the probability density distribution, including best estimates and confidence ranges, for the ECS, the TCR, and the TCRE.

This paper is structured in the following way. In the Methods section, first the modeling framework is introduced (Sect. 2.1). Specific subsections deal with model parameter selection and sampling (Sect. 2.1.1), observational constraints and the calculation of model skill scores (Sect. 2.1.2), the procedure for model spin-up (Sect. 2.1.3), and scenario choices and model simulations (Sect. 2.1.4). The following sections then cover the definition of TCRE and TRE ${ }^{X}$ (Sect. 2.2), the calculation of probability density functions (PDFs; Sect. 2.3), and how the linearity of the responses to cumulative $\mathrm{CO}_{2}$ emissions is tested (Sect. 2.4). Finally, we discuss the selection of the analyzed climate variables $(X)$ in Sect. 2.5. In the results section, we first discuss the response in various climate variables to $\mathrm{CO}_{2}$ emission pulses of various magnitude to gain insight regarding to what extent we may expect linearity in the response to emissions (Sect. 3.1). In Sect. 3.2, we present results for the TRE of the global mean surface air and surface ocean temperatures, steric sea level rise (SSLR), the Atlantic meridional overturning circulation (AMOC), global mean surface ocean $\mathrm{pH}$, the saturation of surface waters in the Southern Ocean and the tropics with respect to calcium carbonate, as used to build coral reefs and shells and other structures of marine organisms, and finally global soil carbon stocks. In Sect. 3.3, results for the transient and equilibrium climate sensitivity are presented. Discussion and conclusions complete the paper.

\section{Methods}

\subsection{Modeling framework}

We apply the Bern3D-LPJ model in a Bayesian, probabilistic, observation-constrained approach which is described in detail by Steinacher et al. (2013). Probabilistic assessments are widely used to determine probability distributions of model parameters, climate sensitivity, and many other cli- 
mate variables (e.g. Wigley and Raper, 2001; Knutti et al., 2002, 2003, 2005; Murphy et al., 2004; Schleussner et al., 2014; Bodman et al., 2013; Little et al., 2013; Harris et al., 2013; Holden et al., 2010, 2013; Bhat et al., 2012; Olson et al., 2012; Williamson et al., 2013). The Bern3D model was used in connection with an ensemble Kalman filter to constrain model parameters and regional air-sea carbon fluxes from observations (Gerber et al., 2009; Gerber and Joos, 2010, 2013). Bern3D-LPJ is an EMIC that consists of a threedimensional dynamic ocean component (Müller et al., 2006; Parekh et al., 2008) including sea ice (Ritz et al., 2011a); a two-dimensional energy and moisture balance model of the atmosphere (Ritz et al., 2011a, b); and a comprehensive terrestrial biosphere model with dynamic vegetation (Sitch et al., 2003), permafrost, peatland (Spahni et al., 2013), and land-use (Strassmann et al., 2008) modules.

We rely here on simulations presented by Steinacher et al. (2013) as described in the following subsections and illustrated in Fig. 1. Uncertainties in physical and carbon-cycle model parameters, radiative efficiencies, climate sensitivity, and carbon-cycle feedbacks are taken into account by varying 19 key model parameters to generate a model ensemble with 5000 members (Appendix Table A1). Each ensemble member is assigned a skill score based on how well the model version is able to represent the observational constraints. This skill score is used as a weight to compute PDFs and ensemble means for different model outcomes.

\subsubsection{Model parameter sampling}

Nineteen model parameters are sampled for the generation of the model ensemble (Table A1). The selection of these parameters has to balance computational costs vs. maximum coverage of the parameter space that is relevant for the model variables we are interested in.

Three parameters are sampled from the energy and moisture balance model of the atmosphere. Most importantly, the nominal ECS determines the equilibrium warming per change in radiative forcing. Technically, this is implemented by translating a given value for ECS to a value for the feedback parameter $\lambda$ (Ritz et al., 2011a, b) using a calibration curve. $\lambda$ accounts for all feedbacks in the model that are not explicitly resolved. Diffusivity coefficients, diff ${ }_{\text {zonal }}$ and diff $f_{\text {merid,scale, }}$ control the depth-integrated heat fluxes (Ritz et al., 2011a, b). The uniform zonal diffusivity is specified

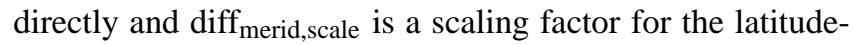
dependent meridional diffusivity.

The selection of the most relevant parameters for terrestrial photosynthesis, hydrology, vegetation dynamics, soil organic matter decomposition, and turnover is largely based on a previous study by Zaehle et al. (2005). They analyzed an earlier version of the model by sampling 36 parameters and identified the most important ones in controlling carbon fluxes and pool sizes. Perhaps not surprisingly, the most influential parameters directly govern either the input flux of carbon into a carbon pool or the timescale of carbon overturning for individual pools.

Four parameters are sampled that govern carbon assimilation and transpiration of water. These are a scaling parameter to upscale assimilation from the leaf to the canopy level $\left(\alpha_{\mathrm{a}}\right)$, the intrinsic quantum efficiency of $\mathrm{CO}_{2}$ uptake for $\mathrm{C} 3$ plants $\left(\alpha_{\mathrm{C} 3}\right)$, a shape parameter specifying the degree of colimitation by light and RuBisCO activity $(\theta)$, and a parameter that influences the link between canopy conductance and evapotranspiration $\left(g_{m}\right)$, and thereby soil hydrology and water limitation of photosynthesis. These parameters were identified as the four most important ones controlling net primary production and heterotrophic respiration and they are among the eight most important parameters controlling carbon pool sizes (Zaehle et al., 2005).

Two parameters are sampled that control the turnover of carbon in vegetation. These are the timescale governing the conversion of sapwood to heartwood $\left(\tau_{\text {sapwood }}\right)$ and the maximum mortality rate of trees (mort $\max _{\max }$ ). Four parameters are sampled that govern the carbon turnover in mineral soils. The fractions $f_{\text {soil }}$ and $f_{\text {slow }}$ determine how much decomposing litter enters the fast and slow overturning soil pools and how much is released directly to the atmosphere. $k_{\text {soil,scale }}$ is a global scaling factor applied to the spatial and temporal variable decomposition rates of organic carbon in the fast and slow soil pools. Litter and soil decomposition rates depend on soil temperature and thus are influenced by global warming. The parameter governing the temperature sensitivity of these rates is also sampled. Finally, $\mathrm{C}_{\text {peat,scale }}$ determines the initial amount of carbon stored in northern peatlands.

Three parameters are sampled from the Bern3D ocean component. diff dia $_{\text {and }}$ diff iso $_{\text {ise }}$ are diapycnal and isopycnal diffusivities that control the ocean circulation and thus the transport and vertical mixing of heat, carbon, and other tracers (Müller et al., 2006; Schmittner et al., 2009). $k_{\text {gas,scale }}$ is a scaling factor applied to the OCMIP-2 air-sea gas transfer velocity field (Müller et al., 2008) and affects the oceanic uptake of anthropogenic carbon. The ocean carbonate chemistry and marine biology parameters are not perturbed in this study in order to save computational costs. The ocean chemistry is very well understood and the relevant parameters are already well constrained (Dickson, 2002). The marine biology parameters are considered of secondary importance for this study, and when compared to the parameters affecting the physical transport and uptake of anthropogenic carbon (Joos et al., 1999; Plattner et al., 2001; Heinze, 2004; Gangstøet al., 2008; Kwon et al., 2009).

Finally, two parameters are sampled to modulate the radiative forcing from well-mixed greenhouse gases $\left(\mathrm{RF}_{\mathrm{GHG}, \text { scale }}\right)$ and aerosols $\left(\mathrm{RF}_{\text {aerosol,scale }}\right)$. They are applied as scaling factors to the prescribed time series (or to the simulated radiative forcing in the case of atmospheric $\mathrm{CO}_{2}$ ) and reflect the uncertainties given by Forster et al. (2007).

We generate a 5000-member ensemble from the prior distributions of those 19 key model parameters using the Latin 


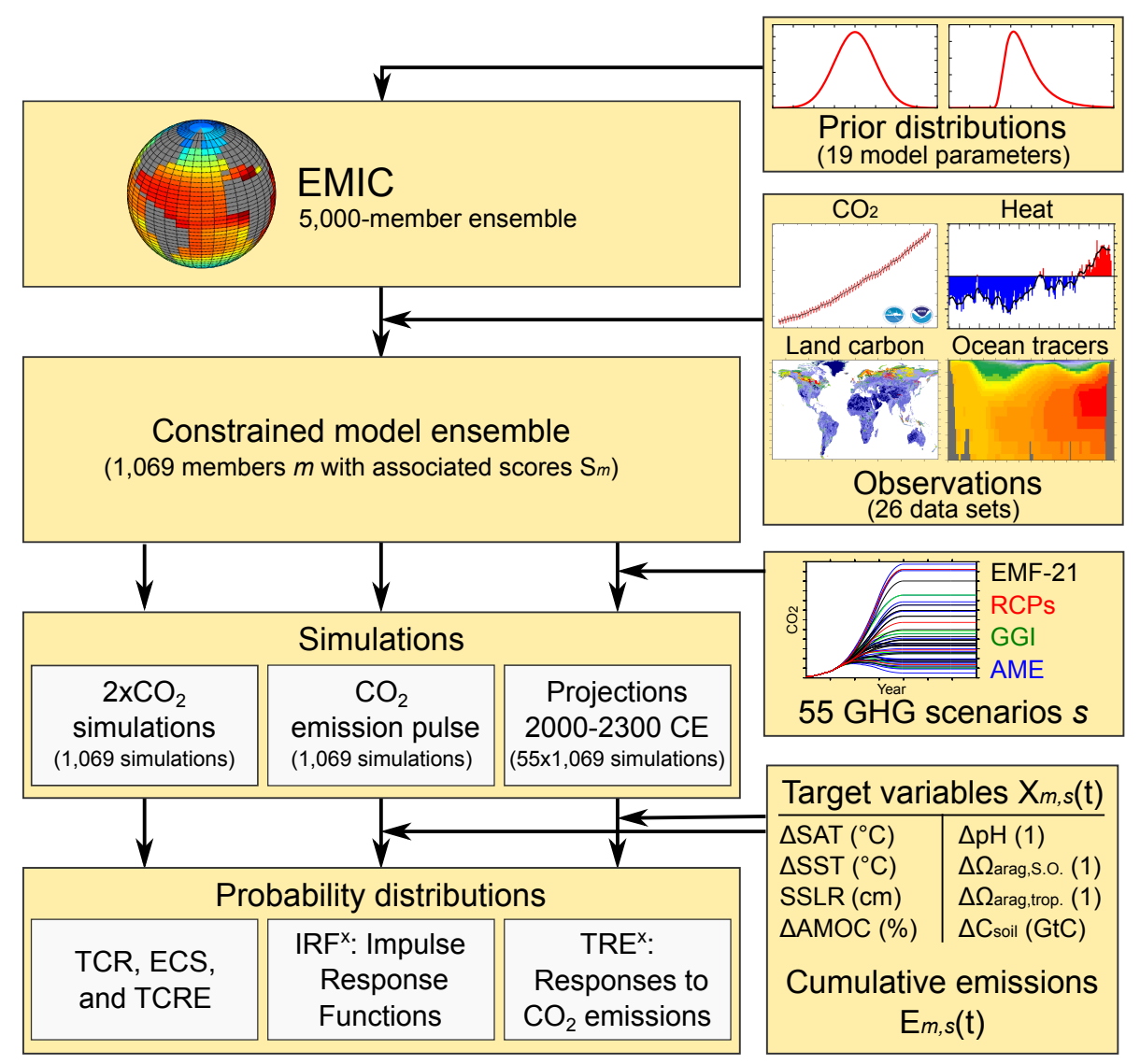

Figure 1. Flowchart illustrating the applied methodology. First, an ensemble of model configurations is generated from prior distributions of model parameters. Then the ensemble is constrained by 26 observational data sets by calculating a skill score $\left(S_{m}\right)$ for each ensemble member $(m)$. In the next step, the constrained model ensemble is run into the future under multiple greenhouse gas scenarios $(s)$ as well as for idealized $2 \mathrm{xCO}_{2}$ and $\mathrm{CO}_{2}$ emission pulse simulations. Finally, probability distributions are calculated from these simulations for TCR, ECS, and TCRE as well as for $\operatorname{TRE}^{X}$ and $\operatorname{IRF}^{X}$ and different climate variables, $X$.

Table 1. Response to a $100 \mathrm{GtC} \mathrm{CO}_{2}$ emission pulse on different timescales as simulated by the Bern3D-LPJ model (see also Fig. 2). The values (ensemble median and $90 \%$ range) indicate the difference to a baseline simulation without emission pulse after 20,50 , 100 , and 500 years for the atmospheric $\mathrm{CO}_{2}$ concentration $\left(\Delta p \mathrm{CO}_{2}\right)$, global annual mean surface temperature $(\Delta \mathrm{SAT})$, steric sea level rise (SSLR), Atlantic meridional overturning circulation ( $\triangle \mathrm{AMOC})$, global annual mean surface ocean $\mathrm{pH}(\Delta \mathrm{pH})$, annual mean surface aragonite saturation in the Southern Ocean $\left(\Delta \Omega_{\text {arag,S.O. }}\right)$ and in the tropics $\left(\Delta \Omega_{\text {arag, trop. }}\right)$, and global soil carbon stocks $\left(\Delta \mathrm{C}_{\text {soil }}\right)$.

\begin{tabular}{llrrrr}
\hline Variable & Units & 20 years & 50 years & 100 years & 500 years \\
\hline$\Delta p \mathrm{CO}_{2}$ & $\mathrm{ppm}$ & $30.6[26.9-33.8]$ & $25.6[21.0-29.6]$ & $22.0[17.3-26.6]$ & $15.0[11.2-21.9]$ \\
$\Delta \mathrm{SAT}$ & ${ }^{\circ} \mathrm{C}$ & $0.18[0.10-0.27]$ & $0.17[0.10-0.30]$ & $0.17[0.09-0.32]$ & $0.14[0.06-0.35]$ \\
SSLR & $\mathrm{cm}$ & $0.82[0.51-1.15]$ & $1.26[0.68-1.99]$ & $1.65[0.80-2.81]$ & $2.44[1.03-5.82]$ \\
$\Delta \mathrm{AMOC}$ & $\%$ & $-2.4[-4.0$ to -0.8$]$ & $-2.1[-4.5$ to -0.3$]$ & $-1.8[-4.5-0.0]$ & $-0.8[-3.9-0.7]$ \\
$\Delta \mathrm{pH}$ & $10^{-2}$ & $-2.6[-2.8$ to -2.2$]$ & $-2.3[-2.6$ to -1.9$]$ & $-2.0[-2.4$ to -1.6$]$ & $-1.4[-2.0$ to -1.0$]$ \\
$\Delta \Omega_{\text {arag,S.O. }}$ & $10^{-2}$ & $-7.7[-9.0$ to -5.8$]$ & $-6.8[-7.9$ to -5.4$]$ & $-5.9[-6.9$ to -4.7$]$ & $-4.1[-5.3$ to -3.1$]$ \\
$\Delta \Omega_{\text {arag,trop. }}$ & $10^{-2}$ & $-12.7[-13.9$ to -11.4$]$ & $-10.8[-12.2$ to -9.2$]$ & $-9.3[-10.8$ to -7.7$]$ & $-6.5[-8.5$ to -5.2$]$ \\
$\Delta \mathrm{C}_{\text {soil }}$ & $\mathrm{GtC}$ & $1.11[-1.03-5.22]$ & $1.38[-3.05-8.92]$ & $1.42[-6.82-12.01]$ & $1.73[-21.65-13.32]$ \\
\hline
\end{tabular}


hypercube sampling method (McKay et al., 1979). The prior distributions are selected such that the median matches the standard model configuration and the standard deviation is one-fourth of the plausible parameter range based on the literature and/or expert judgment (Table A1). Normal prior distributions are chosen for ranges that are basically symmetric with respect to the standard parameter value and log-normal priors are used for asymmetric ranges.

\subsubsection{Observational constraints and the computation of skill scores}

Twenty-six observation-based data sets are used to constrain the model results including projected Earth system changes, allowable carbon emissions to meet a climate target, or metrics such as the transient and equilibrium climate sensitivity. A single skill score is computed by comparing observations and model outcomes for each ensemble member and across all data sets. The data sets are organized in a hierarchical structure to balance the weight of individual data sets and groups of data. The skill scores are used to weight results from individual ensemble members for the computation of ensemble mean and uncertainties (PDF). Figure A1 summarizes the observation-based data sets and their hierarchical arrangement to compute skill scores (adapted from Fig. S3 and Table S2 in Steinacher et al., 2013).

The observational data sets combine information from satellite, ship-based, ice-core, and in situ measurements to probe both the mean state and transient responses in space and time. The energy balance and its change over time is probed by annual mean time series of Southern and Northern Hemisphere temperature from 1850 to 2010 (Brohan et al., 2006), upper (0-700 m) ocean heat content anomalies from 1955 to 2011 (Levitus et al., 2012) and from 1993 to 2008 (Lyman et al., 2010), and the ocean heat uptake over the period 2005 to 2010 (von Schuckmann and Le Traon, 2011). The atmospheric carbon balance is probed by the reconstructed atmospheric $\mathrm{CO}_{2}$ history from ice cores (1850 to 1958; Etheridge et al., 1996) and direct atmospheric measurements (1959 to 2010; Keeling and Whorf, 2005; Conway and Tans, 2011) as well as global and temporal means of net carbon uptake by the land and by the ocean for the periods 1959 to 2006, 1990 to 1999, and 2000 to 2006 (Canadell et al., 2007). Oceanic processes, which are key for the uptake of both heat and carbon, are probed using gridded data from the World Ocean Atlas (Locarnini et al., 2010; Antonov et al., 2010; Garcia et al., 2010) and the Global Ocean Analysis Project (GLODAP; Key et al., 2004); surface fields and whole ocean fields are considered separately for individual tracers. Ocean temperature $(T)$ and salinity $(S)$ fields probe the water mass distribution and $T$ and $S$ influences $\mathrm{CO}_{2}$ solubility and carbonate chemistry. The transient tracer CFC-11 (distribution for 1995) and radiocarbon (preindustrial) probe the ventilation timescales and thus the surface-to-deep transport rates for carbon, heat, and other tracers. The marine bio- logical cycle is probed by comparing modeled with observed fields of the major nutrient phosphate, as well as dissolved inorganic carbon (preindustrial) and alkalinity (1995). Temperature, salinity and phosphate fields from the World Ocean Atlas include seasonal variations in the upper ocean. Land biosphere processes are constrained by comparing modeled and observation-derived carbon stocks and fluxes. Vegetation carbon stock data include two different data sets for about 140 sites each (Luyssaert et al., 2007; Keith et al., 2009) and an estimate for the global preindustrial inventory $(550 \pm 200 \mathrm{Gt} \mathrm{C}$; Prentice et al., 2001). Gridded soil carbon fields for low and mid-latitudes (south of $50^{\circ} \mathrm{N}$; Global Soil Data Task Group, 2000) and high-latitude North America (Tarnocai et al., 2009, 2007) and an estimate for the global soil carbon content in the top $100 \mathrm{~cm}(1950 \pm 550 \mathrm{Gt} \mathrm{C}$; Batjes, 1996) are used for soil carbon pools. Net primary productivity is probed using observation-based estimates from around 80 sites (Olson et al., 2001) and 140 sites (Luyssaert et al., 2007), as well as a gridded seasonal climatology of the fraction of absorbed photosynthetic active radiation (Gobron et al., 2006). Finally, we probe the seasonal cycle of the net terrestrial carbon balance by prescribing modeled net landto-atmosphere fluxes in the TM2 transport model to compute the average seasonal cycle of atmospheric $\mathrm{CO}_{2}$ at nine sites as monitored by the GLOBALVIEW atmospheric $\mathrm{CO}_{2}$ network (GLOBALVIEW-CO2, 2011).

A hierarchical structuring of the data sets is applied for the computation of the skill scores. Individual data sets consist of single numbers, site data, time series, and gridded two- and three-dimensional fields. The number of values included in a data set ranges from one to many thousands. In addition, different data sets sometimes probe closely related quantities. It is thus necessary to implement a formalism to avoid that the data sets with the largest number of data dominate the outcome. The task is to attribute a weight to each individual data set that is appropriate in comparison with the other data sets. Here, this is done by organizing the data in a hierarchical structure for aggregating the scores of individual data sets to the total score. We consider four main data groups probing the energy balance, termed "heat" in Appendix Fig. A1; the atmospheric carbon balance, " $\mathrm{CO}_{2}$ "; ocean processes and inventories, "ocean"; and land biosphere fluxes and stocks, "land". Each of these groups has the same weight for the computation of the overall skill scores. The individual data sets are further arranged in additional subgroups.

From the simulation results over the historical period ("mod") and the set of observational constraints ("obs"), we assign a score to each ensemble member $m$ as $S_{m} \propto$ $\exp \left(-\frac{1}{2} \frac{\left({\left(\mathrm{X}_{m}^{\mathrm{mod}}-X^{\mathrm{obs}}\right)^{2}}_{\sigma^{2}}\right)}{\sigma^{2}}\right.$. This likelihood-type function basically corresponds to a Gaussian distribution of the datamodel discrepancy $\left(X_{m}^{\mathrm{mod}}-X^{\mathrm{obs}}\right)$ with zero mean and variance $\sigma^{2}$. The overbar indicates that the error-weighted datamodel discrepancy is first averaged over all data points of each observational variable (volume- or area-weighted) and 
then aggregated in the hierarchical structure by averaging variables belonging to the same group. Out of the 5000 ensemble members, 3931 contribute less than a percent to the cumulative skill $\sum_{m} S_{m}$ of all members $m$ and are not used any further.

The variance $\sigma^{2}$ represents the combined observational error and model discrepancy and needs to be specified. The model discrepancy is the inherent model error that cannot be eliminated even with the best parameter settings and input data. While most of the observational data sets come with estimates of the observational errors, the model discrepancy is difficult to specify. Here we estimate the combined observational and model error with the variance of the modeldata difference for the best fitting model realization (i.e., the model with the smallest mean squared error). In some few cases where the observational error is larger than this estimate (and thus the combined error is clearly underestimated), the observational error is taken as total error.

\subsubsection{Spin-up procedure}

The spin-up procedure for the 5000 ensemble members is tailored to keep computational costs low, while at the same time achieving small model drift after completion of the spinup. First, a very long spin-up over more than 20000 years is carried out with standard model parameters and preindustrial (year 1800) boundary conditions. The spin-up is then continued for all individual members from this initial steady state to adjust the model to the perturbed parameters. In this way, the new equilibrium for the perturbed parameter set is reached faster than when starting from scratch.

The adjustment spin-up is done in a sequence where not all model components are active in all steps to further decrease the computational costs. First, the physical ocean component is run stand-alone for 1500 years. Then, the atmospheric energy balance model is coupled again to the ocean and the model is run for 1000 more years. Next, the oceanic biogeochemistry module is activated with initial tracer fields from the standard model configuration. The model is run for another 1000 years to allow the biogeochemical fields to adjust to the new physics. In parallel, the terrestrial component is run stand-alone for 400 years with the perturbed parameter settings, including an instantaneous adjustment of the soil carbon pools after 200 years by calculating the new pool sizes analytically from the adjusted fluxes. Finally, the fully coupled model is run for another 200 years and all transient simulations are started from this state.

The reliability of the spin-up procedure is verified by performing a 500-year-long control run without additional forcing and checking for unacceptable drift. Slight drifts in deep ocean tracers are accepted.

Modern peat carbon stocks are not in equilibrium with the current climate and boreal peatlands still sequestered about $0.1 \mathrm{GtC} \mathrm{yr}^{-1}$ during the last millennium (Charman et al., 2013; Yu et al., 2010). Peat carbon distribution for our tran- sient simulations is initialized with the output from a transient simulation starting at the Last Glacial Maximum as described in Spahni et al. (2013). This initial pattern, and thus the total peat carbon inventory, is uniformly scaled with the value sampled for the parameter $C_{\text {peat,scale }}$.

After the spin-up, the 5000-member ensemble is run over the industrial period under prescribed $\mathrm{CO}_{2}$ and non- $\mathrm{CO}_{2}$ forcing. The model output is compared with the observational data and the ensemble is reduced to the 1069 simulations with the highest skill, as described in the previous section.

\subsubsection{Model simulations}

In a next step we run the constrained model ensemble for 55 greenhouse gas scenarios spanning from high businessas-usual to low-mitigation pathways. The set of scenarios consists of economically feasible multi-gas emission scenarios from the integrated assessment modeling community. In addition to the four RCP scenarios (Moss et al., 2010) that were selected for the Fifth Assessment Report (AR5) of the IPCC, we included 51 scenarios from the EMF-21 (Weyant et al., 2006), GGI (Grübler et al., 2007), and AME (Calvin et al., 2012) projects. For these simulations, we prescribe atmospheric $\mathrm{CO}_{2}$ and the non- $\mathrm{CO}_{2}$ radiative forcing derived from the emission scenarios (Fig. A2) as described in Joos et al. (2001) and Strassmann et al. (2009). We note that the AME scenarios are less complete than the others because they do not provide emission paths for aerosols and some minor greenhouse gases. We therefore make the conservative assumption of constant aerosol emissions at the level of the year $2005\left(-1.17 \mathrm{Wm}^{-2}\right)$, which implies a significant cooling effect continued into the future in those 23 (out of 55) scenarios (Fig. A2f). Note that this effect does not affect our estimates of TCR, ECS, and TCRE, which are based on the atmospheric $\mathrm{CO}_{2}$-only simulations described below, nor does it affect the constraining of the model ensemble with observation-based data over the historical period. The scenarios are extended from 2100 to 2300 by stabilizing atmospheric $\mathrm{CO}_{2}$ and the non- $\mathrm{CO}_{2}$ forcing by the year 2150 (see Steinacher et al., 2013, for details). Note that the extensions of the RCP scenarios beyond $2100 \mathrm{CE}$ as used in the AR5 (extended concentration pathways, ECPs; Meinshausen et al., 2011) are not identical to the extensions applied here. Our extensions of RCP4.5 and RCP6 are similar to ECP4.5 and ECP6, but ECP8.5 differs significantly from our extension of RCP8.5, where atmospheric $\mathrm{CO}_{2}$ is stabilized by 2150.

In addition to these multi-gas scenarios used by Steinacher et al. (2013), we run the model ensemble for an idealized " $2 \mathrm{xCO}_{2}$ " scenario to determine TCR, ECS, and TCRE and an emission pulse experiment. In the $2 \mathrm{xCO}_{2}$ simulation, atmospheric $\mathrm{CO}_{2}$ is increased by $1 \% \mathrm{yr}^{-1}$ from its preindustrial level until a doubling of the concentration is reached. After that, the atmospheric $\mathrm{CO}_{2}$ concentration is held fixed. 
All other forcings remain constant at preindustrial levels. The emission pulse simulations are conducted as described by Joos et al. (2013). A pulse input of $100 \mathrm{GtC}$ is added to a constant background atmospheric $\mathrm{CO}_{2}$ concentration of $389 \mathrm{ppm}$ in year 2010, while all other forcings are held constant at 2010 levels. The impulse response function (IRF) is then derived from the difference between simulations with and without emission pulse. Additionally, experiments with pulse sizes of 1000,3000 , and $5000 \mathrm{GtC}$ were performed to test the sensitivity of the response to the pulse size. These additional pulse experiments were run for a model configuration with median parameter settings, which is able to reproduce the median response of the ensemble for the $100 \mathrm{GtC}$ pulse (Fig. 2).

\subsection{Definition of TCRE and TRE}

There are slightly different definitions of the TCRE in the literature. Matthews et al. (2009) define it similarly to the TCR, i.e., as the ratio of warming to cumulative $\mathrm{CO}_{2}$ emissions in a simulation with prescribed $1 \% \mathrm{yr}^{-1}$ increase in atmospheric $\mathrm{CO}_{2}$ at the time when atmospheric $\mathrm{CO}_{2}$ reaches double its preindustrial concentration. In the AR5 of the IPCC, TCRE is defined more generally as the annual mean global surface temperature change per unit of cumulated $\mathrm{CO}_{2}$ emissions in a scenario with continuing emissions (Collins et al., 2013). In scenarios with non- $\mathrm{CO}_{2}$ forcings, such as the representative concentration pathways (RCPs), the diagnosed TCRE thus also depends on the non- $\mathrm{CO}_{2}$ forcing. Further, the transient response should be distinguished from the peak response to cumulative emissions as defined in Allen et al. (2009), although the TCRE is nearly identical to the peak climate response to cumulative $\mathrm{CO}_{2}$ emissions in many cases (Collins et al., 2013).

The responses, TCR and TCRE, are defined for surface air temperature in previous studies. Here, we extend the definition of TCRE to any climate variable $X(t)$. We define the transient response, $\operatorname{TRE}^{X}$, and peak response, $\mathrm{TRE}_{\text {peak }}^{X}$, per cumulative $\mathrm{CO}_{2}$ emissions at a given time $t$ as

$\operatorname{TRE}^{X}(t)=\frac{X(t)}{E(t)}$,
$\operatorname{TRE}_{\text {peak }}^{X}(t)=\frac{X\left(t_{\text {max }}\right)}{E(t)}$ with
$t_{\text {max }}:\left|X\left(t_{\text {max }}\right)\right|=\max _{t^{\prime} \leq t}\left(\left|X\left(t^{\prime}\right)\right|\right)$,

where $E(t)$ are the cumulative $\mathrm{CO}_{2}$ emissions (either total or fossil-fuel-only emissions; see Appendix A).

For the transient response analyses, $\operatorname{TRE}^{X}(t)$ is computed for every year $t$ in the range $2000<t \leq 2300$ (i.e., 300 data points per simulation). In contrast, the peak response is represented by only one data point per simulation. It is the value of $X(t)$ at the time $t_{\max }$, i.e., where the maximum change in the absolute value of $X(t)$ between the years 2000 and 2300 occurs, divided by the cumulative emissions in the year 2300 ,
$E(t=2300)$, and denoted $\operatorname{TRE}_{\text {peak }}^{X}(t=2300)$. Note that the actual peak response might occur after $2300 \mathrm{CE}$, in which case $\operatorname{TRE}_{\text {peak }}^{X}$ is only an approximation. Surface air temperature usually peaks before $2300 \mathrm{CE}$ in the applied scenarios. Steric sea level rise, on the other hand, continues to increase after $2300 \mathrm{CE}$ due to the large thermal inertia of the oceans.

TCRE is used in this study as defined by Gillett et al. (2013). Thus, TCRE is equivalent to TRE ${ }^{\triangle \mathrm{SAT}}$ derived from a simulation with prescribed $1 \% \mathrm{yr}^{-1}$ atmospheric $\mathrm{CO}_{2}$ increase and no other forcings.

\subsection{Calculation of PDFs}

Cumulative $\mathrm{CO}_{2}$ emissions $E_{m, s}(t)$ and climate response $X_{m, s}(t)$ are diagnosed for each model configuration $1 \leq$ $m \leq N_{m}\left(N_{m}=1069\right)$, greenhouse gas scenario $1 \leq s \leq N_{s}$ $\left(N_{s}=55\right)$, and simulation year $2000<t \leq 2300$. For a given model configuration $m$ and year $t$ we obtain 55 points in the two-dimensional $(E, X)$ space, representing the response under different scenarios $\left(E_{m, s}(t), X_{m, s}(t)\right)$. These points are considered to span the range of plausible emission-response combinations for this model configuration. Technically, we use the convex hull, which is the smallest region containing all points such that, for any pair of points within the region, the straight-line segment that joins the pair of points is also within the region.

By combining the convex hulls from all model configurations $m$ in the $(E, X)$ space we can derive a two-dimensional PDF, $p(E, X)$, of the plausible emission-response combinations. The model ensemble is constrained in this step by weighting the contribution of an individual model to the PDF with the model score $S_{m}$ :

$p(x, y)=\sum_{m} \theta_{m}(x, y) S_{m}$,
$\theta_{m}(x, y)= \begin{cases}1, & \text { if }(x, y) \in C\left(\left\{\left(E_{m, s}, X_{m, s}\right),\right.\right. \\ & \left.\left.s=1, \ldots, N_{s}\right\}\right) \\ 0, & \text { otherwise },\end{cases}$

where $C(P)$ denotes the convex hull of the set of points $P$. Finally, the resulting field is normalized for each emission $E$ to obtain the relative probability map $p_{\text {rel }}(E, X)$, as shown, for example, in Fig. 3a:

$p_{\text {rel }}(E, X)=\frac{p(E, X)}{\max _{X}(p(E, X))}$

Alternatively, $p(x, y)$, is normalized by its integral,

$p_{\text {norm }}(E, X)=\frac{p(E, X)}{\int_{-\infty}^{\infty} p(E, X) \mathrm{d} X}$,

which then represents the PDF of the response in $X$ for given emissions $E$. The probability that the change $X$ remains smaller than a target value, $X_{\text {target }}$, given emission $E$ 

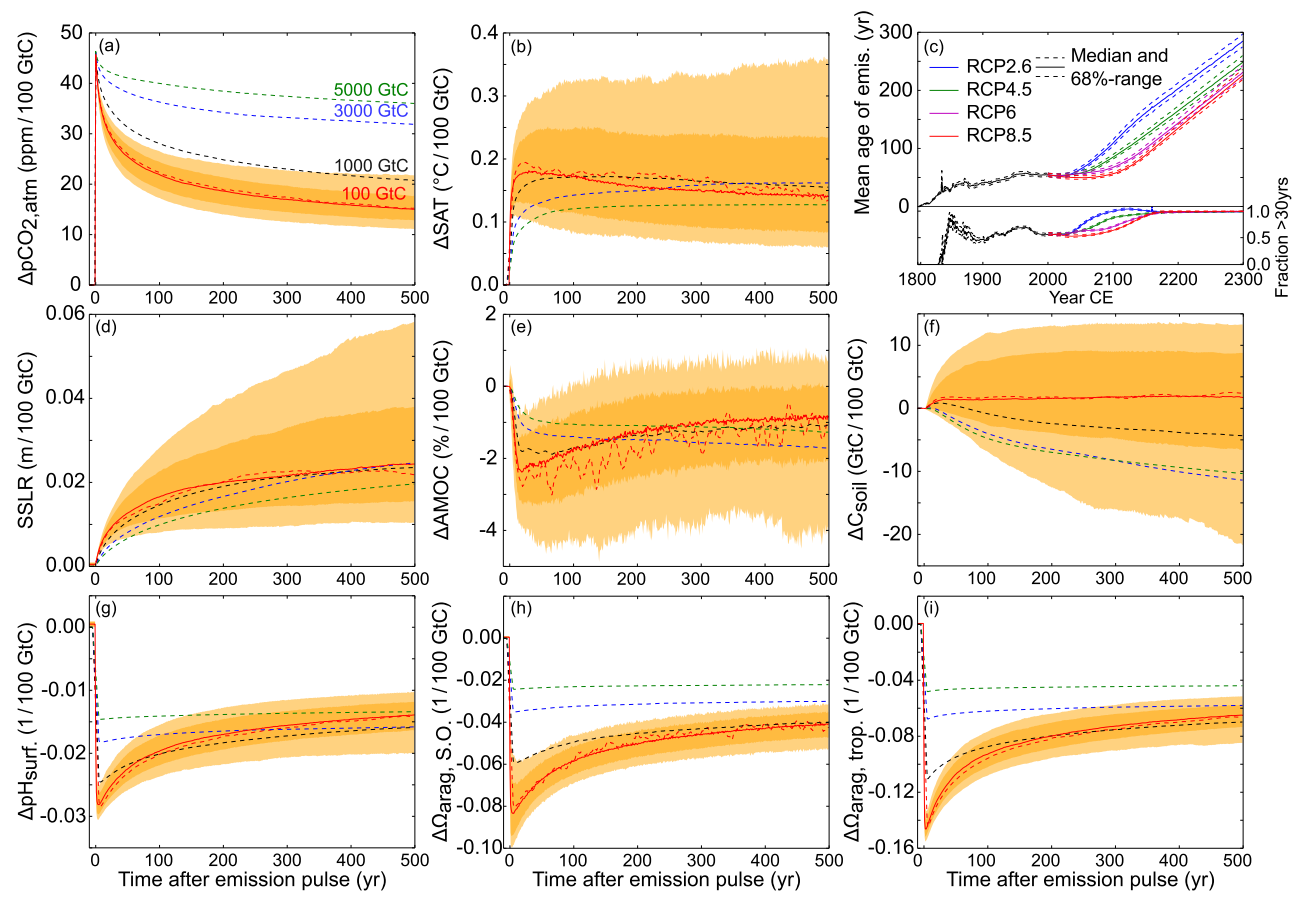

Figure 2. Response to an emission pulse of $100 \mathrm{Gt} \mathrm{C}$ added to an atmospheric concentration of 389 ppm. Ensemble median (solid red line) and 68/90\% ranges (dark/light orange) of changes in (a) atmospheric $\mathrm{CO}_{2}$, (b) surface air temperature, (d) steric sea level rise, (e) Atlantic meridional overturning circulation, (f) global soil carbon stocks, (g) global mean surface ocean pH, and (h) southern and (i) tropical ocean surface aragonite saturation are shown. The dashed lines show the response (per $100 \mathrm{Gt} \mathrm{C}$ ) for median parameters and pulse sizes of 100 (red), 1000 (black), 3000 (blue), and $5000 \mathrm{Gt} \mathrm{C} \mathrm{(green).} \mathrm{Panel} \mathrm{(c)} \mathrm{shows} \mathrm{the} \mathrm{mean} \mathrm{age} \mathrm{of} \mathrm{past} \mathrm{emissions} \mathrm{over} \mathrm{the} \mathrm{historical} \mathrm{period} \mathrm{and} \mathrm{for}$ the four RCP scenarios (left axis), and the fraction of the emissions older than 30 years (right axis) versus calendar years. More than half of the emissions are older than $\sim 30$ years. The bulk of the emissions at any calendar year is thus in the age range ( $x$ axis in the other panels) where the pulse response function varies within a limited range for surface air temperature (b), surface pH (g), steric sea level rise (d), and Atlantic meridional overturning (e). This implies an approximately linear relationship between cumulative emissions and responses in these variables.

is then in percent:

$$
p_{\text {cum }}\left(E, X_{\text {target }}\right)=\int_{-\infty}^{X_{\text {target }}} p_{\text {norm }}(E, X) \mathrm{d} X \cdot 100 \% .
$$

The allowable $\mathrm{CO}_{2}$ emissions, $E_{\text {allowable }}$, to not exceed the climate target $X_{\text {target }}$ with a probability of $68 \%$ are then implicitly given by $p_{\text {cum }}\left(E, X_{\text {target }}\right)=68 \%$.

\subsection{Testing the linearity of the response}

From the probability maps in the $(E, X)$ space, PDFs are extracted at $E=1000,2000$, and $3000 \mathrm{Gt} C$. To compare the response at different emission levels the PDFs at 2000 and $3000 \mathrm{Gt} \mathrm{C}$ are rescaled to the response per $1000 \mathrm{GtC}$. In a perfectly linear system we would expect that the rescaled PDFs are identical for the different emission levels. To test the linearity of the response further, we fit a linear function $\hat{X}(E)=a_{X, m} \cdot E$ to the points $\left(E_{m, s}(t), X_{m, s}(t)\right)$ for each model configuration $m$. The linear function is forced through zero because we require $X(E=0)=0$ at preindustrial $(t=1800)$. From the obtained coefficients $a_{X, m}$ of the model ensemble, we then calculate a PDF for the sensitivity $a_{X}$ of the response to cumulative emissions under the assumption that a linear fit is reasonable. The goodness of fit is quantified by the correlation coefficients, $r_{m}$, and standard errors of the regression, $\sigma_{m}=\sqrt{\frac{\sum_{s}\left(X_{m, s}-\hat{X}\left(E_{m, s}\right)\right)^{2}}{N_{s}}}$, for each model setup $m$. In Table 2, the ensemble median and $68 \%$ range of $a_{X}$, of $r_{m}$, as well as the ensemble median standard error (expressed as a percentage of the median linear slope), $\hat{\sigma}$, are reported.

\subsection{Selection of the climate variables for analysis and computation of TRE}

We compute TRE ${ }^{X}$ and IRFs (see Sect. 3.1) for eight climate variables. These are represented by the emission-driven changes in the model variables global mean surface air temperature $(\triangle \mathrm{SAT})$, surface ocean temperature $(\Delta \mathrm{SST})$, steric sea level rise (SSLR), the Atlantic meridional overturning circulation $(\triangle \mathrm{AMOC})$, global mean surface ocean $\mathrm{pH}$ $(\Delta \mathrm{pH})$, saturation of surface waters in the Southern Ocean $\left(\Delta \Omega_{\text {arag,S.O.; }}\right.$ south of $\left.50^{\circ} \mathrm{S}\right)$ and the tropics $\left(\Delta \Omega_{\text {arag,trop.; }}\right.$; 

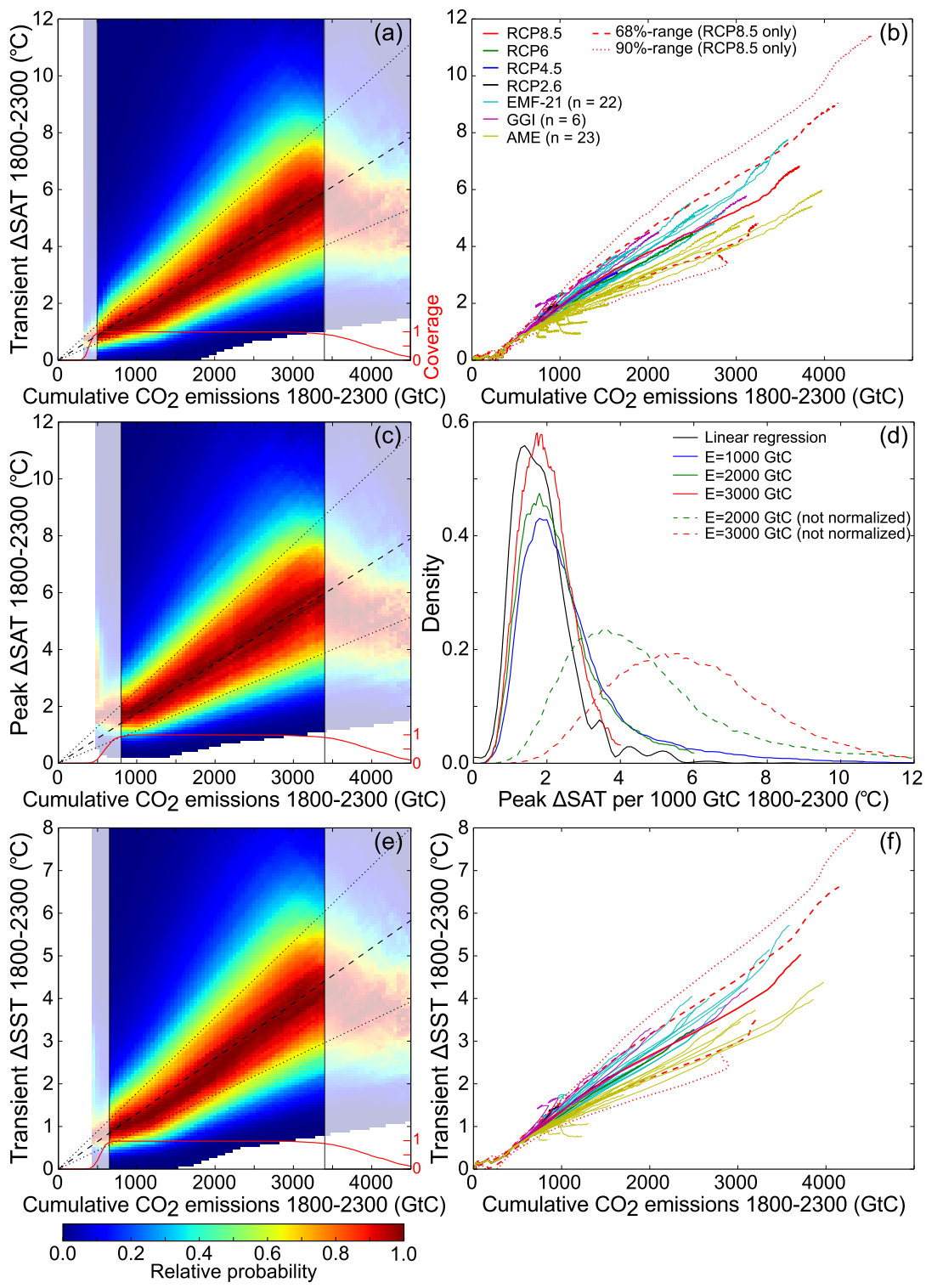

Figure 3. Transient and peak warming as a function of cumulative emissions: (a) relative probability of transient surface air temperature change $(\triangle \mathrm{SAT})$ for given cumulative $\mathrm{CO}_{2}$ emissions (fossil fuel and deforestation), derived from annual values from ensemble model simulations for 55 greenhouse gas emission scenarios. Black dashed lines show the median and $68 \%$ range of the linear regression slope. The red line indicates the coverage of the emission range by the model ensemble. High and low emission ranges with a coverage of less than $90 \%$ are shaded and considered not robust. (b) Transient $\Delta$ SAT response (ensemble median) for the 55 different scenarios. The dashed/dotted lines show the $68 / 90 \%$ range of the ensemble for the RCP8.5 scenario to indicate the model spread. Note that our extensions of the RCP scenarios beyond 2100 are not identical to the extended concentration pathways (ECPs; see Methods). (c) Same as (a) but for the peak warming for given total cumulative emissions. (d) PDFs of the peak warming for 1000 (blue), 2000 (green), and $3000 \mathrm{Gt}$ C (red) cumulative emissions, and for the linear regression (black). The dashed lines indicate the unscaled PDFs and solid lines the normalized response per $1000 \mathrm{GtC}$. (e, f) Same as (a, b) but for transient sea surface temperature change ( $\Delta \mathrm{SST})$.

$30^{\circ} \mathrm{N}$ to $30^{\circ} \mathrm{S}$ ) with respect to calcium carbonate in the mineral form of aragonite, and global soil carbon stocks $\left(\Delta \mathrm{C}_{\text {soil }}\right)$. These variables are deemed both impact-relevant and reasonably well represented in the Bern3D-LPJ EMIC. We stress the illustrative nature of this selection. $\mathrm{TRE}^{X}$ may be computed for other climate variables and regions in future work.
In particular the determination of $\operatorname{TRE}^{X}$ for extreme events, such as droughts, heat waves, and floods, or for food production and fishery may be relevant for policy makers and stakeholders.

Changes in SAT and sea level are known to impact biological and physical systems (e.g. IPCC, 2014; Sherwood 
Table 2. Transient $\left(\mathrm{TRE}^{X}\right)$ and peak $\left(\mathrm{TRE}_{\text {peak }}^{X}\right)$ response per $1000 \mathrm{GtC}$ total $\mathrm{CO}_{2}$ emissions estimated with different methods. Ensemble medians and $68 \%$ ranges (i.e., the 16th and 84th percentiles) are taken from the relative probability maps derived from all model configurations and scenarios at 1000, 2000, and $3000 \mathrm{GtC}$ total emissions as well as from the linear regression slope (see Methods). The correlation coefficient ( $r$, median, and $68 \%$ range) and the median standard error as a percentage of the median regression slope $(\hat{\sigma})$ are given for the linear fit of the peak response.

\begin{tabular}{|c|c|c|c|c|}
\hline Variable $X$ & Method & $\operatorname{TRE}^{X}$ & $\operatorname{TRE}_{\text {peak }}^{X}$ & Goodness of linear fit \\
\hline$\Delta \mathrm{SAT}$ & $1000 \mathrm{GtC}$ & $1.95[1.12-3.38]$ & $2.31[1.49-3.81]$ & \multirow[b]{4}{*}{$r=0.92 \pm 0.04, \hat{\sigma}=36 \%$} \\
\hline \multirow[t]{3}{*}{$\left({ }^{\circ} \mathrm{C}\right)$} & $2000 \mathrm{GtC}$ & $1.96[1.23-3.12]$ & $2.12[1.37-3.30]$ & \\
\hline & $3000 \mathrm{GtC}$ & $1.90[1.27-2.66]$ & $1.92[1.29-2.68]$ & \\
\hline & Lin. reg. & $1.75[1.18-2.48]$ & $1.76[1.14-2.56]$ & \\
\hline \multirow{4}{*}{$\begin{array}{l}\triangle \mathrm{SST} \\
\left({ }^{\circ} \mathrm{C}\right)\end{array}$} & $1000 \mathrm{GtC}$ & $1.47[0.89-2.45]$ & $1.68[1.11-2.68]$ & \multirow[b]{4}{*}{$r=0.92 \pm 0.04, \hat{\sigma}=35 \%$} \\
\hline & $2000 \mathrm{GtC}$ & $1.40[0.91-2.08]$ & $1.49[0.99-2.15]$ & \\
\hline & $3000 \mathrm{GtC}$ & $1.30[0.91-1.70]$ & $1.32[0.91-1.72]$ & \\
\hline & Lin. reg. & $1.30[0.87-1.78]$ & $1.31[0.85-1.86]$ & \\
\hline \multirow{4}{*}{$\begin{array}{l}\text { SSLR } \\
(\mathrm{cm})\end{array}$} & $1000 \mathrm{GtC}$ & $25[14-44]$ & $29[18-48]$ & \multirow[b]{4}{*}{$r=0.91 \pm 0.04, \hat{\sigma}=39 \%$} \\
\hline & $2000 \mathrm{GtC}$ & $23[14-38]$ & $27[17-42]$ & \\
\hline & $3000 \mathrm{GtC}$ & $21[13-32]$ & $25[17-36]$ & \\
\hline & Lin. reg. & $19[12-25]$ & $23[15-33]$ & \\
\hline \multirow{4}{*}{$\begin{array}{l}\triangle \mathrm{AMOC} \\
(\%)\end{array}$} & $1000 \mathrm{GtC}$ & $-16[-29$ to -7$]$ & $-24[-35$ to -15$]$ & \multirow[b]{4}{*}{$r=0.8 \pm 0.1, \hat{\sigma}=40 \%$} \\
\hline & $2000 \mathrm{GtC}$ & $-15[-23$ to -9$]$ & $-18[-26$ to -12$]$ & \\
\hline & $3000 \mathrm{GtC}$ & $-14[-19$ to -9$]$ & $-15[-20$ to -10$]$ & \\
\hline & Lin. reg. & $-15[-22$ to -9$]$ & $-15[-22$ to -10$]$ & \\
\hline \multirow{4}{*}{$\begin{array}{l}\Delta \mathrm{pH} \\
(1)\end{array}$} & $1000 \mathrm{GtC}$ & $-0.19[-0.22$ to -0.15$]$ & $-0.20[-0.23$ to -0.18$]$ & \multirow[b]{4}{*}{$r=0.98 \pm 0.01, \hat{\sigma}=12 \%$} \\
\hline & $2000 \mathrm{GtC}$ & $-0.18[-0.21$ to -0.16$]$ & $-0.18[-0.21$ to -0.15$]$ & \\
\hline & $3000 \mathrm{Gt} \mathrm{C}$ & $-0.17[-0.19$ to -0.15$]$ & $-0.17[-0.19$ to -0.15$]$ & \\
\hline & Lin. reg. & $-0.18[-0.20$ to -0.16$]$ & $-0.17[-0.19$ to -0.15$]$ & \\
\hline \multirow{4}{*}{$\begin{array}{l}\Delta \Omega_{\text {arag,S.O. }} \\
\text { (1) }\end{array}$} & $1000 \mathrm{GtC}$ & $-0.55[-0.66$ to -0.45$]$ & $-0.61[-0.68$ to -0.55$]$ & \multirow[b]{4}{*}{$r=0.87 \pm 0.05, \hat{\sigma}=30 \%$} \\
\hline & $2000 \mathrm{GtC}$ & $-0.46[-0.53$ to -0.39$]$ & $-0.46[-0.51$ to -0.41$]$ & \\
\hline & $3000 \mathrm{GtC}$ & $-0.40[-0.45$ to -0.35$]$ & $-0.40[-0.43$ to -0.35$]$ & \\
\hline & Lin. reg. & $-0.48[-0.53$ to -0.42$]$ & $-0.43[-0.48$ to -0.38$]$ & \\
\hline \multirow{4}{*}{$\begin{array}{l}\Delta \Omega_{\text {arag, trop. }} \\
\text { (1) }\end{array}$} & $1000 \mathrm{GtC}$ & $-0.87[-1.04$ to -0.71$]$ & $-0.96[-1.04$ to -0.89$]$ & \multirow[b]{4}{*}{$r=0.93 \pm 0.03, \hat{\sigma}=24 \%$} \\
\hline & $2000 \mathrm{GtC}$ & $-0.76[-0.86$ to -0.65$]$ & $-0.74[-0.82$ to -0.68$]$ & \\
\hline & $3000 \mathrm{GtC}$ & $-0.67[-0.73$ to -0.61$]$ & $-0.66[-0.70$ to -0.61$]$ & \\
\hline & Lin. reg. & $-0.78[-0.85$ to -0.71$]$ & $-0.71[-0.79$ to -0.65$]$ & \\
\hline \multirow{4}{*}{$\begin{array}{l}\Delta \mathrm{C}_{\text {soil }} \\
(\mathrm{GtC})\end{array}$} & $1000 \mathrm{GtC}$ & $-59[-234$ to +22$]$ & $-77[-268$ to -17$]$ & \multirow{4}{*}{$r=0.7_{-0.7}^{+0.1}, \hat{\sigma}=165 \%$} \\
\hline & $2000 \mathrm{GtC}$ & $-73[-201$ to -5$]$ & $-82[-217$ to -4$]$ & \\
\hline & $3000 \mathrm{GtC}$ & $-75[-162$ to -17$]$ & $-80[-170$ to -15$]$ & \\
\hline & Lin. reg. & $-26[-85$ to +24$]$ & $-39[-122$ to +25$]$ & \\
\hline
\end{tabular}

and Huber, 2010). Sea level rise is expected to affect coastal ecosystems such as mangroves, reduce coastal protection, and increase flood occurrence, possibly affecting hundreds of millions of people living in low-lying cities and along the coast.

The uptake of $\mathrm{CO}_{2}$ by the ocean fundamentally changes the chemical composition of ocean waters (Orr, 2011), generally referred to as "ocean acidification". The reaction of dissolved $\mathrm{CO}_{2}$ with $\mathrm{H}_{2} \mathrm{O}$ to $\mathrm{H}_{2} \mathrm{CO}_{3}$ and the dissociation of the latter lead to an increase in the hydrogen ion concentration $\left(\mathrm{H}^{+}\right)$; a decrease in $\mathrm{pH}\left(\mathrm{pH}=-\log \left[\mathrm{H}^{+}\right]\right)$; and, through shifting acid-base equilibria, a decrease in the concentration of carbonate ions, $\mathrm{CO}_{3}^{2-}$. The decrease in $\mathrm{CO}_{3}^{2-}$ is associated with a decrease in the saturation state of water with respect to calcium carbonate $\left(\mathrm{CaCO}_{3}\right)$.

Ocean acidification in conjunction with warming waters poses large risks to marine species, marine ecosystems such as corals, sea grass meadows, and marine ecosystem services such as tropical fisheries (e.g. Gattuso et al., 2015; Howes et al., 2015). Warming waters affect the aerobic scope of marine organisms and constrain marine habitats (Deutsch et al., 2015; Pörtner et al., 2011). The saturation state of water with respect to aragonite and other mineral forms of calcium carbonate determines whether water is corrosive (in the absence 

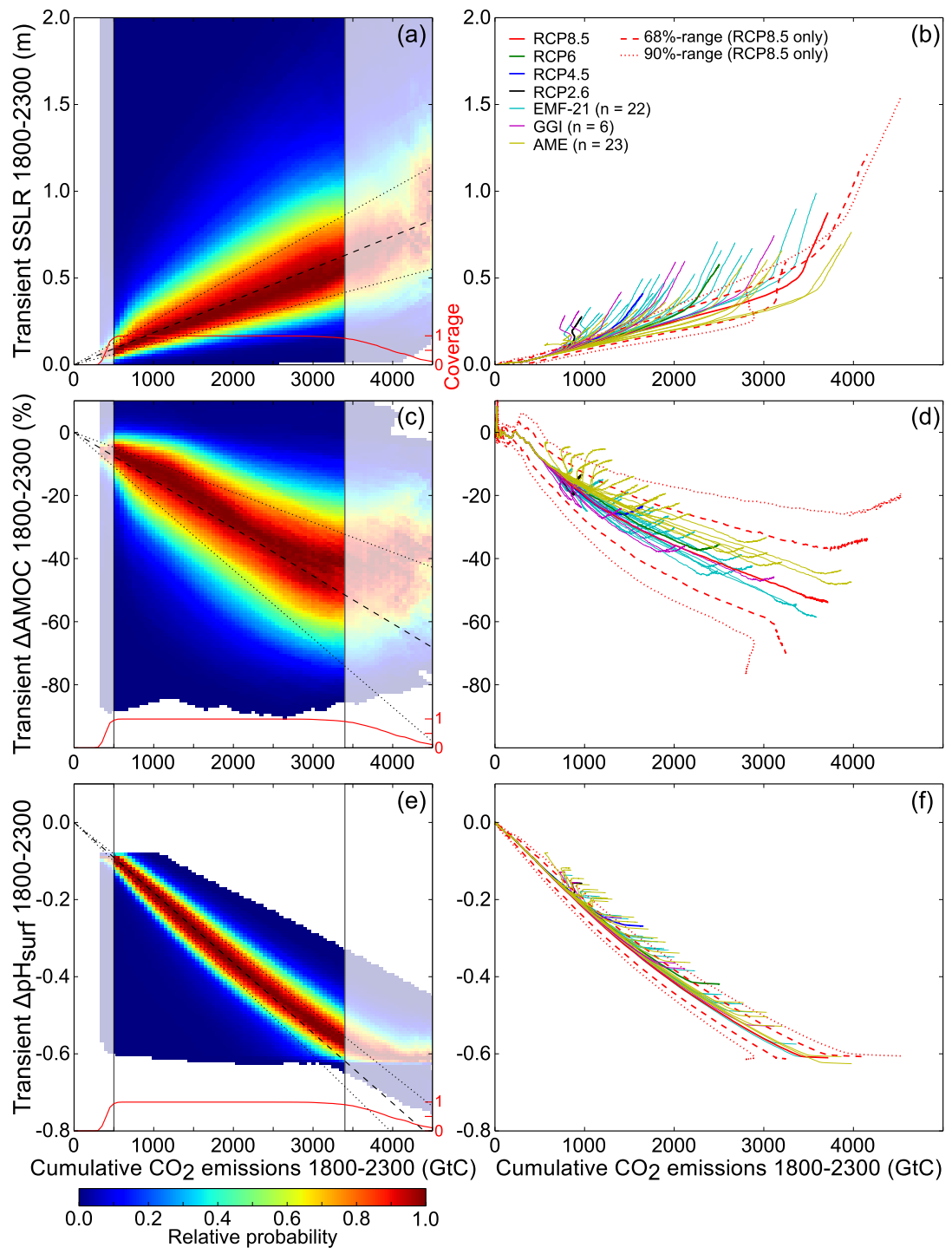

Figure 4. Response of SSLR, AMOC, and $\mathrm{pH}$ to cumulative $\mathrm{CO}_{2}$ emissions (including deforestation), similar to Fig. $3 \mathrm{a}$, b.

of protective mechanisms) to shells and structures made out of calcium carbonate. Model projections reveal large and sustained changes in the saturation state of surface and deep waters for a range of emission scenarios (Orr et al., 2005; Joos et al., 2011). Waters in the Arctic Ocean, coastal upwelling zones, and the Southern Ocean are becoming increasingly undersaturated with respect to aragonite (Steinacher et al., 2009; Gruber et al., 2012) and ongoing changes in saturation state are largest in the tropics, possibly adversely affecting net calcification rates of coral systems.

The AMOC contributes to the net heat transport into the North Atlantic region and changes in the AMOC may affect climate patterns in Europe and worldwide. Paleo-data reveal a southward shift of the Intertropical Convergence Zone linked to a decrease or collapse of the AMOC with related terrestrial ecosystem impacts (e.g. Bozbiyik et al., 2011). Fi- nally, changes in the global soil carbon inventory may be taken here as an indication of the strength of the land carbonclimate feedback.

\section{Results}

\subsection{Climate response to a $\mathrm{CO}_{2}$ emission pulse: testing the linearity of the emission-response relationship}

In a first step, we explore how different climatic variables respond to a pulse-like input of carbon into the atmosphere (Fig. 2) and determine the so-called IRF for the different climate variables. The IRF experiments provide a framework to discuss path dependency and linearity in responses without the need to run many independent scenarios. IRFs for atmospheric $\mathrm{CO}_{2}$, SAT, SSLR, and ocean and land carbon 
uptake are given elsewhere and we refer the reader to the literature for a general discussion on IRFs, underlying carboncycle and climate processes, and timescales (e.g. Archer et al., 1998; Joos et al., 2013; Maier-Reimer and Hasselmann, 1987; Shine et al., 2005).

A main goal of this section on IRF is to discuss to which extent one may expect a close-to-linear relationship between cumulative $\mathrm{CO}_{2}$ emissions and a climate variable of interest. A linear relationship between emissions and variable $X$ has the advantage that the determination of $\mathrm{TRE}^{X}$ depends on neither the choice of scenario nor the magnitude of $\mathrm{CO}_{2}$ emissions. In addition, $\operatorname{TRE}^{X}$ would, in the case of linearity, fully describe the response to any $\mathrm{CO}_{2}$ emissions. We start with a description of the model setup, followed by theoretical considerations. Then we discuss linearity in the context of $\mathrm{CO}_{2}$-only scenario uncertainty by analyzing median model responses. After that, we investigate the response uncertainty by relying on the full model ensemble and compare scenario and response uncertainty. Finally, we briefly address the scenario uncertainty due to non- $\mathrm{CO}_{2}$ forcing.

\subsubsection{Model simulations to determine IRFs}

$\mathrm{CO}_{2}$ is added instantaneously to the model atmosphere to determine IRFs. This results in a sudden increase in atmospheric $\mathrm{CO}_{2}$ and radiative forcing. Afterwards, the evolution in the perturbation of atmospheric $\mathrm{CO}_{2}$ and in any climate variable of interest, e.g., global mean surface air temperature, is monitored in the model. The resulting curve is the impulse response function (Fig. 2). Here, 1069 runs were carried out in different model configurations by adding emissions of $100 \mathrm{GtC}$ to an atmospheric $\mathrm{CO}_{2}$ background concentration of $389 \mathrm{ppm}$, which corresponds to the concentration in the year 2010. Additionally, simulations with emission pulses of 1000,3000 , and $5000 \mathrm{GtC}$ were run for a median model configuration (Methods). For comparability, all IRFs are normalized to a carbon input of $100 \mathrm{GtC}$.

\subsubsection{The link between IRF and TRE: theoretical considerations}

The motivation to analyze IRFs is twofold. First, the dynamic of a linear (or approximately linear) system is fully characterized by its response to a pulse-like perturbation - i.e., the response of variable $X$ at year $t$ to earlier annual emissions, $e$, at year $t^{\prime}$ can be represented as the weighted sum of all earlier annual emissions. The weights are the values of the IRF curve at emission age $t-t^{\prime}$ :

$X(t)=\sum_{t^{\prime}} e\left(t^{\prime}\right) \cdot \operatorname{IRF}\left(t-t^{\prime}\right)$,

where the sum runs over all years $t^{\prime}$ with annual emissions up to year $t$. IRFs thus provide a convenient and comprehensive quantitative characterization of the response of a model. IRFs form also the basis for the metrics used to compare different greenhouse gases in the Kyoto basket approach and to compute $\mathrm{CO}_{2}$ equivalent concentrations (Joos et al., 2013; Myhre et al., 2013) and are used to build substitute models of comprehensive models (Joos et al., 1996). Second, and relevant for the TRE and for this study, IRFs allow us to gauge whether there is a roughly linear relationship between cumulative $\mathrm{CO}_{2}$ emissions,

$E(t)=\sum_{t^{\prime}} e\left(t^{\prime}\right)$,

and the change in a climate variable of interest, $X(t)$. The transient response for variable $X$ to cumulative $\mathrm{CO}_{2}$ emissions is in this notation:

$\operatorname{TRE}^{X}(t)=\frac{X(t)}{E(t)}$.

We note that there is a close relationship between Eqs. (8) to (10) and thus between cumulative $\mathrm{CO}_{2}$ emissions $E(t)$, response $X(t)$, and $\operatorname{TRE}^{X}$. The IRF provides the link between these quantities.

Three conditions are to be met for a strict linear relationship between cumulative $\mathrm{CO}_{2}$ emissions $E$ and response $X$ for any emission pathway: (i) the response is independent of the magnitude of the emissions, (ii) the response is independent of the age of the emission, i.e., the time passed since emissions occurred (in this case the IRF and the response $\mathrm{TRE}^{X}$ is a constant and all emissions are weighted equally in Eq. 8), and (iii) non- $\mathrm{CO}_{2}$ forcing factors play no role a point that will be discussed later in Sect. 3.1.4. While these conditions are not fully met for climate variables, they may still approximately hold for plausible emission pathways. For the range of RCP scenarios, the mean age of the $\mathrm{CO}_{2}$ emissions varies from a few decades to about 100 years for the industrial period and up to year 2100, and then it increases up to 300 years until $2300 \mathrm{CE}$ (Fig. 2c). More than half of the cumulative $\mathrm{CO}_{2}$ emissions have typically an age older than 30 years (Fig. 2c). If the IRF curve is approximately flat after a few decades and independent of the pulse size, then the vast majority of emission is weighted by a similar value in Eq. (8). Consequently, the relationship between response $X(t)$ and cumulative emissions, $E(t)$, is approximately linear and path-independent. This response sensitivity per unit emission, $X(t) / E(t)$, corresponds to an "effective" (emission-weighted) mean value of the IRF and is the transient response to cumulative $\mathrm{CO}_{2}$ emissions $\mathrm{TRE}^{X}$. Indeed, the IRF for many variables varies within a limited range after a few decades (Fig. 2). Then, an approximately linear relationship between $E(t)$ and $X(t)$ holds and $\mathrm{TRE}^{X}$ is approximately scenario-independent.

\subsubsection{IRFs: median results}

The median values of the (normalized) IRFs (Fig. 2, solid and dashed lines; Table 1) vary within a limited range over the period from 30 years to the end of the simulation (500 years) and for the different pulse sizes of 100 to $3000 \mathrm{GtC}$ for 
global mean SAT, surface ocean $\mathrm{pH}$, AMOC, and to a somewhat lesser degree SSLR. Consequently, we expect a closeto-linear relationship between these variables and cumulative $\mathrm{CO}_{2}$ emissions.

For a given pulse size, the median of the IRF for the saturation with respect to aragonite in the tropical $\left(\Omega_{\text {arag, trop. }}\right.$ ) and Southern Ocean $\left(\Omega_{\text {arag,S.O. }}\right)$ surface waters and for the global soil carbon inventory varies within a limited range. However, the normalized IRFs for these variables vary substantially with the magnitude of the emission pulse. Thus, we expect a nonlinear relationship between the ensemble median responses and cumulative $\mathrm{CO}_{2}$ emissions for these quantities.

The atmospheric $\mathrm{CO}_{2}$ perturbation declines by about a factor of 2 within the first 100 years for an emission pulse of $100 \mathrm{Gt} \mathrm{C}$. This means that the atmospheric $\mathrm{CO}_{2}$ concentration at a specific time depends strongly on the emission path of the previous 100 years. In addition, the IRFs differ for different pulse sizes because the efficiency of the oceanic and terrestrial carbon sinks decreases with higher atmospheric $\mathrm{CO}_{2}$ concentrations and warming. The fraction remaining airborne after 500 years is about $75 \%$ for a pulse input of $3000 \mathrm{GtC}$, about 2.5 times larger than the fraction remaining for a pulse of $100 \mathrm{GtC}$ (Fig. 2a). Thus, we do not expect a scenario-independent, linear relationship between atmospheric $\mathrm{CO}_{2}$ and cumulative emissions.

At first glance, it may be surprising that the responses in SAT, SSLR, AMOC, and $\mathrm{pH}$ do not depend much on the size of the emission pulse given the strong sensitivity of the atmospheric $\mathrm{CO}_{2}$ response to the pulse size. For the physical variables, this is a consequence of near-cancellation of nonlinearity in the carbon cycle and in the relationship between radiative forcing and atmospheric $\mathrm{CO}_{2}$ (Joos et al., 2013). The long-term response in atmospheric $\mathrm{CO}_{2}$ (Fig. 2a) increases with increasing emissions and the fraction remaining airborne is substantially larger for large than for small emission pulses. On the other hand, radiative forcing depends logarithmically on atmospheric $\mathrm{CO}_{2}$ and the change in forcing per unit change in $\mathrm{CO}_{2}$ is smaller at high than at low atmospheric $\mathrm{CO}_{2}$ concentrations. As a consequence, the response in radiative forcing is rather insensitive to the magnitude of the emission pulse and so is the response in climate variables forced by $\mathrm{CO}_{2}$ radiative forcing. A similar effect applies for $\mathrm{pH}$. Changes in dissolved $\left[\mathrm{CO}_{2}\right]$ and $\left[\mathrm{H}^{+}\right]$in the surface ocean closely follow changes in atmospheric $\mathrm{CO}_{2}$ as the typical timescale to equilibrate the ocean mixed layer with an atmospheric $\mathrm{CO}_{2}$ perturbation is of the order of a year and because changes in $\left[\mathrm{H}^{+}\right]$are roughly proportional to $\left[\mathrm{CO}_{2}\right]$ (Orr, 2011). pH is by definition the (negative) logarithm of the $\mathrm{H}^{+}$concentration. As for radiative forcing, nonlinearities in the $\mathrm{CO}_{2}$ and thus $\mathrm{H}^{+}$response roughly cancel out when applying the logarithm to compute $\mathrm{pH}$.

\subsubsection{Response vs. scenario uncertainty}

The Monte Carlo IRF experiments allow us also to assess the response or model uncertainty (Fig. 2, orange range). The $90 \%$ confidence range in the IRF are substantially larger than the variation of the (normalized) median IRF for the variables SAT, SSLR, AMOC, and soil carbon inventory. Consequently, the model uncertainty will dominate the uncertainty in $\mathrm{TRE}^{X}$ and is larger than uncertainties arising from dependencies on the carbon emission pathway. On the other hand, the response uncertainty from our 1069 Monte Carlo model setups are more comparable to the variation in the median IRFs for atmospheric $\mathrm{CO}_{2}$, and surface water saturation with respect to aragonite in the tropical ocean and Southern Ocean.

In addition to the path dependency and the response uncertainty in $\mathrm{TRE}^{X}$ discussed above, forcing from non- $\mathrm{CO}_{2}$ agents will affect $\mathrm{TRE}^{X}$. We expect a notable influence of non- $\mathrm{CO}_{2}$ agents on the physical climate variables SAT, SSLR, and AMOC. For example, Strassmann et al. (2009) attributed simulated surface warming to individual forcing components for a range of mitigation and non-mitigation scenarios. They find that non- $\mathrm{CO}_{2}$ greenhouse gas forcing causes up to $50 \%$ as much warming as $\mathrm{CO}_{2}$ forcing and that the non- $\mathrm{CO}_{2}$ forcing is only partly offset by aerosol cooling by 2100 . On the other hand, we expect a small influence of non- $\mathrm{CO}_{2}$ forcing on $\mathrm{pH}$ and saturation state which is predominantly driven by the atmospheric $\mathrm{CO}_{2}$ perturbation (Steinacher et al., 2009; McNeil and Matear, 2007).

In summary, uncertainty in the response dominates over the uncertainty arising from path dependency for SAT, SSLR, AMOC, and soil carbon. For $\mathrm{CO}_{2}$-only or $\mathrm{CO}_{2}$-dominated scenarios, we expect close-to-linear relationship between cumulative $\mathrm{CO}_{2}$ emissions and SAT, surface ocean $\mathrm{pH}, \mathrm{AMOC}$, and to some extent for SSLR. In other words, the concept of $\mathrm{TRE}^{X}$ should work particularly well for these variables. On the other hand, less well expressed linear behavior is found for global soil carbon and surface water saturation with respect to aragonite. In the next section, we will elaborate on these findings and quantify $\operatorname{TRE}^{X}$.

\subsection{The transient response to cumulative $\mathrm{CO}_{2}$ emissions}

We investigate the response in multiple climate variables, $X(t)$, as a function of cumulative fossil or total $\mathrm{CO}_{2}$ emissions $E(t)$. We used the model ensemble presented in Steinacher et al. (2013) for 55 multi-gas emission scenarios from the integrated assessment modeling community which range from very optimistic mitigation to high business-asusual scenarios (Methods). From those simulations we determine the transient response to cumulative $\mathrm{CO}_{2}$ emissions $\operatorname{TRE}^{X}(t)=X(t) / E(t)$ (Tables 2 and A2; Figs. 3-5). In addition, we also present results for the peak response 
$\operatorname{TRE}_{\text {peak }}^{X}(t=2300)=\max _{t^{\prime}}\left(X\left(t^{\prime}\right) / E(t=2300)\right)($ Tables 2 and A2, Fig. 3).

The discussion of results is guided by the results shown in Figs. 3 to 5 . These show the relative probability of change in the variable $X$ for given cumulative $\mathrm{CO}_{2}$ emissions (e.g., colors in Fig. 3a) together with the linear regression slopes (black dashed lines). These graphs allow one to visually inspect the linearity in response to cumulative $\mathrm{CO}_{2}$ emissions and results include both scenario and response uncertainty. In accompanying panels (e.g., Fig. 3b), the focus is on scenario uncertainty versus response uncertainty. The relationship between change and cumulative emissions is plotted for the ensemble median and for the 55 scenarios (55 colored lines). In addition, the 68 and $90 \%$ confidence intervals for the response (or model) uncertainty are given for one scenario, RCP8.5, by red dashed and dotted lines, respectively. These graphs allow one to infer scenario and response uncertainty individually.

\subsubsection{TRE $^{\Delta \mathrm{SAT}}$}

We find a largely linear relationship between cumulative $\mathrm{CO}_{2}$ emissions and both transient and peak warming (Fig. 3a and c) for the set of emission scenarios considered here. These linear relationships confirm the finding from the pulse experiment above, i.e., that the response in the global SAT change is largely independent of the pathway of $\mathrm{CO}_{2}$ emissions in our model. We note, however, that some low-end scenarios show a nonlinear behavior due to non- $\mathrm{CO}_{2}$ forcing (Fig. 3b). Some AME scenarios show a decrease in temperature due to a strong reduction in the non- $\mathrm{CO}_{2}$ forcing while cumulative emissions continue to increase slightly. Other scenarios (mostly from GGI) deviate from the linear relationship when negative emissions decrease the cumulative emissions while the increased temperature is largely sustained. These nonlinearities are evident as large changes in the slope between SAT and cumulative emissions towards the end of the individual simulations - that is, after $\approx 2150 \mathrm{CE}$, when atmospheric $\mathrm{CO}_{2}$ is stabilized and emissions are low (Fig. 3b). Yet those deviations are not large enough to eliminate the generally linear relationship found for this set of scenarios.

The projected warming for a given amount of $\mathrm{CO}_{2}$ emissions is associated with a considerable uncertainty which increases with higher cumulative emissions. This uncertainty arises both from the response uncertainty of the model ensemble such as the uncertain climate sensitivity or oceanic carbon uptake and from the scenario uncertainty. The scenario uncertainty is mainly due to different assumptions for the non- $\mathrm{CO}_{2}$ forcing in the scenarios. The AME scenarios, for example, assume a relatively strong negative forcing from aerosols which leads to a consistently smaller warming than in the other scenarios (Fig. 3b). The response and scenario uncertainty appear to be of the same order of magnitude (Fig. 3b).
The median transient response is $2.0^{\circ} \mathrm{C}(\mathrm{TtC})^{-1}(1.1-$ $3.4^{\circ} \mathrm{C}(\mathrm{TtC})^{-1} 68 \%$ c.i.) evaluated at $1000 \mathrm{GtC}$ total emissions and similar for 2000 and $3000 \mathrm{GtC}$. The median peak warming response is slightly larger. It is $2.3^{\circ} \mathrm{C}(\mathrm{TtC})^{-1}$ $\left(1.5-3.8^{\circ} \mathrm{C}(\mathrm{TtC})^{-1} 68 \%\right.$ c.i. $)$ for scenarios with $1000 \mathrm{GtC}$ total emissions and decreases slightly to $1.9^{\circ} \mathrm{C}(\mathrm{TtC})^{-1}$ $\left(1.3-2.7^{\circ} \mathrm{C}(\mathrm{TtC})^{-1} 68 \%\right.$ c.i. $)$ for scenarios with $3000 \mathrm{GtC}$ total emissions (Fig. 3d; Table 2). The corresponding responses to fossil-fuel emissions only are accordingly somewhat higher, e.g., $2.2^{\circ} \mathrm{C}(\mathrm{TtC})^{-1}\left(1.3-3.8^{\circ} \mathrm{C}(\mathrm{TtC})^{-1}\right)$ for the transient response evaluated at $1000 \mathrm{GtC}$ fossil emissions (Fig. A3, Table A2).

We fitted a linear function through zero to the results of each ensemble member and then calculated the PDFs from the individual slopes. The median slope is $1.8^{\circ} \mathrm{C}(\mathrm{TtC})^{-1}$ $\left(1.1-2.6^{\circ} \mathrm{C}(\mathrm{TtC})^{-1}\right)$ for the peak response and values are similar for the transient response (Table 2). These slopes are somewhat lower than the direct results, but in general the linear regression approach is able to reproduce the distribution of the peak and transient warming response per $1000 \mathrm{GtC}$ $\mathrm{CO}_{2}$ emissions, although the confidence interval is narrower and the long tail of the distribution might be underestimated.

\subsubsection{TCRE}

Following Matthews et al. (2009) and Gillett et al. (2013), we also determined the TCRE for our model ensemble from a scenario where atmospheric $\mathrm{CO}_{2}$ is increasing by $1 \% \mathrm{yr}^{-1}$ until twice the preindustrial concentration is reached. No other forcing agents are included. Correspondingly, we find a slightly lower median TCRE of $1.7^{\circ} \mathrm{C}(\mathrm{TtC})^{-1}(1.3-$ $2.3^{\circ} \mathrm{C}(\mathrm{TtC})^{-1} 68 \%$ c.i.; $1.0-2.7^{\circ} \mathrm{C}(\mathrm{TtC})^{-1} 5-95 \%$ c.i. $)$ than for the SAT response in the multi-agent scenarios. The $68 \%$ c.i. includes the scenario uncertainty range in TCRE ( 1.5 to $2.0^{\circ} \mathrm{C}$ ) obtained by Herrington and Zickfeld (2014) with a single model setup and for a range of $\mathrm{CO}_{2}$-only scenarios (with constant future non- $\mathrm{CO}_{2}$ forcing). Gillett et al. (2013) report a TCRE of $0.8-2.4^{\circ} \mathrm{C}(\mathrm{TtC})^{-1}(5-95 \%$ range) from 15 models of the Coupled Model Intercomparison Project (CMIP5) for a $2 \mathrm{xCO}_{2}$ scenario and a range of $0.7-2.0^{\circ} \mathrm{C}(\mathrm{TtC})^{-1}$ estimated from observations. In IPCC AR5, TCRE is estimated to be likely in the range of $0.8^{\circ} \mathrm{C}$ to $2.5^{\circ} \mathrm{C}$ for cumulative emissions up to about $2000 \mathrm{GtC}$ (IPCC, 2013). Those ranges are somewhat lower than our $5-95 \%$ ranges of $0.9-3.1^{\circ} \mathrm{C}(\mathrm{TtC})^{-1}$ obtained by linear regression from the scenarios that include non- $\mathrm{CO}_{2}$ forcing and $1.0-2.7^{\circ} \mathrm{C}(\mathrm{TtC})^{-1}$ from the $2 \mathrm{xCO}_{2}$ simulations.

\subsubsection{TRE TRST $^{\Delta \mathrm{SST}}$}

The transient response in sea surface temperature (SST) shows the same characteristics as the response in SAT (Fig. 3e, f). The response is $1.5^{\circ} \mathrm{C}(\mathrm{TtC})^{-1}(0.9-$ $2.5^{\circ} \mathrm{C}(\mathrm{TtC})^{-1} 68 \%$ c.i.) evaluated at $1000 \mathrm{GtC}$ total emis- 

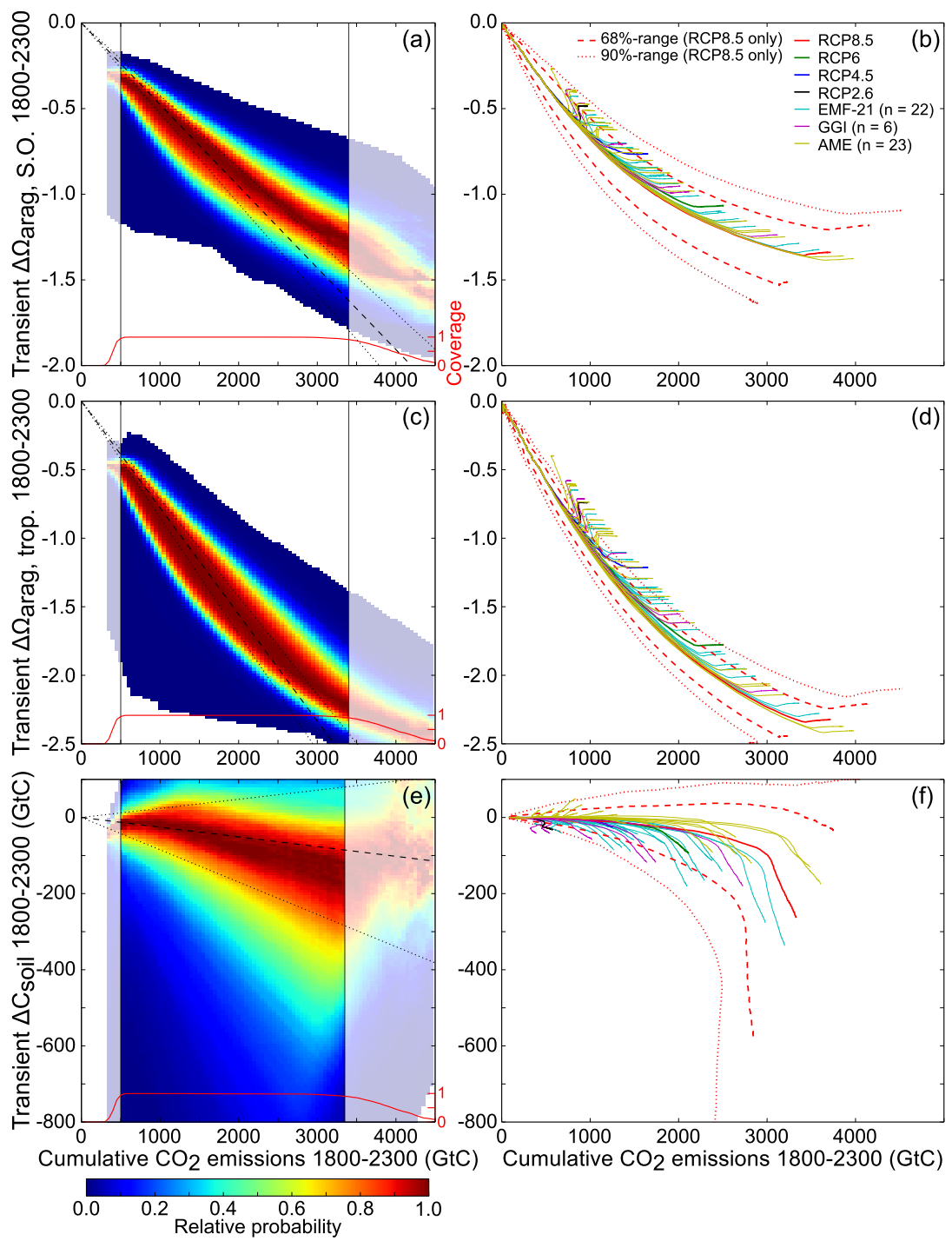

Figure 5. Same as Fig. 4 but for the transient response in surface aragonite saturation state in the Southern Ocean and in the tropics, as well as in global soil carbon stocks.

sions, and $1.3^{\circ} \mathrm{C}(\mathrm{TtC})^{-1}\left(0.9-1.8^{\circ} \mathrm{C}(\mathrm{TtC})^{-1}\right)$ for the linear regression approach.

\subsubsection{TRE ${ }^{\text {SSLR }}$ and TRE ${ }^{\triangle A M O C}$}

Compared to global mean warming, the responses in SSLR and in the strength of the AMOC are more emission-pathdependent (Fig. 4b, d). In all scenarios applied here, it is assumed that atmospheric $\mathrm{CO}_{2}$ and total radiative forcing is stabilized after 2150 . This yields a slow additional growth in cumulative emissions after 2150, whereas SSLR continues largely unabated and the AMOC continues to recover. This results in a steep slope in the relationship between cumulative $\mathrm{CO}_{2}$ emissions and these variables after 2150 as well visible in Fig. 4b. The path dependency also results in larger differences between transient and peak responses (Table 2).
The projected peak SSLR is described remarkably well by a linear regression (Table 2). However, these results for the peak SSLR response are somewhat fortuitous and influenced by our choice to stabilize atmospheric $\mathrm{CO}_{2}$ and forcings after 2150 in all scenarios and by the stopping of simulations in year 2300. We emphasize that SSLR would continue to increase beyond the end of the simulation and TRE ${ }^{\mathrm{SSLR}}$ are thus only indicative for the period from today to year 2300 .

For AMOC, the response is somewhat stronger for lowemission than high-emission paths (Fig. 4d). For $1000 \mathrm{GtC}$ total emissions, we find a peak reduction in AMOC of $-24 \%$ $(-35$ to $-15 \%)$ (Table 2). This sensitivity is larger than found by Herrington and Zickfeld (2014), but simulated changes in AMOC are known to be model-dependent. 


\subsection{5 $\mathrm{TRE}^{\mathrm{pH}}, \mathrm{TRE}^{\Delta \Omega_{\text {arag,S.o. }}}$ and $\mathrm{TRE}^{\Delta \Omega_{\text {arag,tropics }}}$}

Surface $\Delta \mathrm{pH}$ shows a very tight and linear relationship with cumulative $\mathrm{CO}_{2}$ emissions (Fig. 4e, f). This is consistent with a small influence of non- $\mathrm{CO}_{2}$ forcing agents, a small response uncertainty, and a relatively small dependency on the $\mathrm{CO}_{2}$ emission pathway as revealed by the IRF experiments. Both scenario uncertainty and response uncertainty are smaller than for other variables. $\mathrm{pH}$ decreases by about 0.2 unit per $1000 \mathrm{Gt} C$ emissions from fossil sources.

For $\Omega_{\text {arag, }}$, the nonlinearities are more pronounced than for the physical variables and $\mathrm{pH}$ with a proportionally stronger response at low total emissions $\left(\Delta \Omega_{\text {arag }}=-0.68\right.$ to $-0.54(\mathrm{TtC})^{-1}$ at $1000 \mathrm{GtC}$ total emissions) and weaker response at higher total emissions $\left(\Delta \Omega_{\mathrm{arag}}=-0.43\right.$ to $-0.35(\mathrm{TtC})^{-1}$ at $3000 \mathrm{GtC}$ total emissions, Fig. 5b, d). Again, results for fossil-fuel emissions only are provided in Fig. A3 and Table A2.

\subsection{6 $\operatorname{TRE}^{\Delta_{\mathrm{C}_{\text {soil }}}}$}

Finally, the change in global soil carbon (Fig. 5e, f) shows a similar response to SSLR, with continued carbon release from soils after stabilization of greenhouse gas concentrations in medium- to high-emission scenarios. Like the ocean heat uptake, the respiration of soil carbon can be slow, particularly in deep soil layers at high latitudes, and it takes some time to reach a new equilibrium at a higher temperature. The response uncertainty represented by the model spread for a given scenario, however, is even larger than the spread from the scenarios. For the same scenario, the $90 \%$ confidence interval ranges from a very high loss of up to $40 \%$ to increases in global soil carbon by a few percent (Fig. 5f).

In summary, we find that not only global mean surface air temperature but also the other target variables investigated here show a monotonic relationship with cumulative $\mathrm{CO}_{2}$ emissions in multi-gas scenarios. The relationship with cumulative $\mathrm{CO}_{2}$ emission is highly linear for $\mathrm{pH}$ as evidenced by the high correlation coefficient and the invariance in the ensemble median and confidence range from total emissions (Table 2). Changes in steric sea level, meridional overturning circulation, and aragonite saturation are generally less linearly related to cumulative emissions than global $\mathrm{pH}$ and surface air temperature. These variables show a substantial nonlinear response after stabilization of atmospheric $\mathrm{CO}_{2}$. Nevertheless, the PDF of the peak response for all these variables can be reproduced relatively well with a linear regression yielding correlations of $r=0.8-0.98$ and standard errors of $\hat{\sigma}=30-40 \%$ (Table 2).

\subsection{Transient and equilibrium climate sensitivity}

TCR is estimated from the ensemble simulations with $1 \% \mathrm{yr}^{-1}$ increase until doubling of atmospheric $\mathrm{CO}_{2}$ and in combination with the observational constraints (Methods).
TCR is constrained to a median value of $1.7^{\circ} \mathrm{C}$ with 68 and $90 \%$ c.i. of $1.3-2.2{ }^{\circ} \mathrm{C}$ and $1.1-2.6^{\circ} \mathrm{C}$, respectively. The $68 \%$ range is somewhat narrower than the corresponding IPCC AR5 range of $1.0-2.5^{\circ} \mathrm{C}$ (Collins et al., 2013). The CMIP5 model mean and $90 \%$ uncertainty range of 1.8 and $1.2-2.4^{\circ} \mathrm{C}$ (Flato et al., 2013) are fully consistent with our observation-constrained estimates.

ECS is estimated by extending the $2 \mathrm{xCO}_{2}$ simulations by 1500 years (at constant radiative forcing) and fitting a sum of exponentials to the resulting temperature response. Median ECS is $2.9^{\circ} \mathrm{C}$ with constrained 68 and $90 \%$ c.i. of $2.0-4.2^{\circ} \mathrm{C}$ and $1.5-6.0^{\circ} \mathrm{C}$. Again, the CMIP5 model mean and $90 \%$ range of 3.2 and $1.9-4.5^{\circ} \mathrm{C}$ are well within our observationconstrained estimates. However, our $68 \%$ confidence interval is narrower than the IPCC AR5 estimate of $1.5-4.5^{\circ} \mathrm{C}$, particularly on the low end.

\subsubsection{Influence of individual observational data on the probability distribution}

Twenty-six different observational data sets are applied to constrain carbon-cycle and physical climate responses. This raises the question of to what extent an individual data set or a group of data sets constrain the model responses and whether some data sets may unintentionally deteriorate estimates. Uncertainties in the carbon cycle are irrelevant for the physical metrics TCR and ECS. Correspondingly, data sets aimed at constraining the carbon-cycle response, e.g., land carbon inventory data, should not affect estimates of TCR and ECS.

The effect of the different observational constraints on the constrained, posterior distribution for TCR and ECS is estimated by applying only subsets of the observational data. First, the subsets of constraints is given the full weight as if they were the only available data (Fig. 6a, c). As expected, the data groups "land" and "ocean", targeted at carbon-cycle responses, do not influence the outcomes for TCR and ECS. The subgroups "heat" (SAT and ocean heat uptake records) and " $\mathrm{CO}_{2}$ " both constrain TCR and ECS and shift the prior PDF towards the fully constrained PDF when applied alone (Fig. 6a, c). The SAT record tends to constrain TCR and ECS to slightly higher values and the ocean heat uptake data to slightly lower values than the full constraint.

Interestingly, the " $\mathrm{CO}_{2}$ " subgroup also narrows the probability distribution for TCR and ECS, although less than the SAT and ocean heat records. The " $\mathrm{CO}_{2}$ " subgroup includes data sets of the atmospheric $\mathrm{CO}_{2}$ increase over the industrial period and observation-based estimates of the ocean and land carbon uptake for recent periods. Ocean carbon and heat uptake are governed by similar processes, namely the surfaceto-deep transport of excess carbon and heat from the surface to the deep ocean. Apparently, model members that are not able to describe the ocean carbon uptake and the evolution in atmospheric $\mathrm{CO}_{2}$ reasonably well, also fail to match observational records for SAT and ocean heat content. The PDF 
for the " $\mathrm{CO}_{2}$ " subgroup displays several maxima for ECS and similar for TCR. We are not in a position to provide a firm explanation for these maxima, but we speculate that this result may be related to the limited number of members in our ensemble and that the multi-dimensional model parameter space is not completely sampled.

Second, the subsets of constraints are added successively (Fig. 6b, d). Unlike above, weights associated with each subgroup are now set to correspond to the weights they will have in the fully constrained set (i.e., after adding all the subsets). Note that the fully constrained posterior distribution does not depend on the order of applying the individual constraints. When applied sequentially with their corresponding weights in the full constraint, ocean heat uptake represents the strongest constraint. In contrast, the SAT record changes the prior PDF only slightly (dashed magenta line in Fig. 6b, d) when applied with its corresponding weight in the full constraint. Similarly, adding the group " $\mathrm{CO}_{2}$ " after the ocean heat uptake data shifts the PDF only slightly (solid magenta vs. cyan line in Fig. 6b, d). This suggests that the $\mathrm{CO}_{2}$ data do not add substantial information with respect to TCR and ECS that is not already captured by the temperature data. In summary, the subgroup "heat" represents the strongest constraints for TCR and ECS. In particular, the ocean heat uptake data are important for constraining these metrics and exerts the dominant influence on the final PDFs.

\section{Discussion}

We have quantified the transient response to cumulative $\mathrm{CO}_{2}$ emissions, $\mathrm{TRE}^{X}$, for multiple Earth system variables, the responses to a $\mathrm{CO}_{2}$ emission pulse defining the IRF, and three other important climate metrics, the ECS, the TCR, and the TCRE. TRE ${ }^{X}$ and IRF are evaluated for global and regional changes in physical and biogeochemical variables. The linearity and path dependency in responses and scenario uncertainties as well as model response uncertainties are quantified. Our probabilistic results are derived with an observationally constrained $\sim 1000$-member ensemble of the Bern3D-LPJ model and for 55 different greenhouse gas scenarios and additional idealized simulations.

A caveat is that we apply a cost-efficient EMIC with limitations in spatial and temporal model resolution and mechanistic representation of important climate processes. However, and in contrast to reduced-form, box-type, twodimensional, linear response models; expert assumptions; or component models applied in many earlier probabilistic assessments (e.g. Wigley and Raper, 2001; Knutti et al., 2002, 2003, 2005; Schleussner et al., 2014; Bodman et al., 2013; Little et al., 2013; Harris et al., 2013; Holden et al., 2013; Bhat et al., 2012), Bern3D-LPJ features a dynamic threedimensional ocean with physically consistent formulations for the transport of heat, carbon, and other biogeochemical tracers, similar to work by Holden et al. (2010) and Olson et al. (2012), and includes a state-of-the-art dynamic global vegetation model, peat carbon, and anthropogenic land-use dynamics. The model is applied directly without using an emulator (Holden et al., 2010, 2015; Olson et al., 2012). Further, we note that no ocean carbonate chemistry or marine biology parameters were varied in this study. Results for changes in AMOC are known to vary considerably among different models and our ensemble may not represent the full uncertainty in AMOC response. Important processes are not represented in Bern3D-LPJ. Most notably, the melting of ice sheets and glacier and its impacts on sea level and AMOC are not included. Consequently, only results for the steric component of sea level rise are reported and results for changes in AMOC should be considered with caution. Potential climatic "surprises" such as the massive release of methane from clathrates or permafrost are also not considered.

\section{1 $\operatorname{TRE}^{X}$ : The emission-response relationship}

A main focus of this study is on $\mathrm{TRE}^{X}$ and thus on the probabilistic relationship between cumulative $\mathrm{CO}_{2}$ emissions and the transient or peak response in individual, illustrative climate variables. $\operatorname{TRE}^{X}$ was evaluated both by using the response and emission data for each year of a simulation and, in the case of $\mathrm{TRE}_{\text {peak }}^{X}$, by considering only the peak (or maximum) in response over a transient simulation. For simplicity, the term $\operatorname{TRE}^{X}$ is often used to refer to both quantities in the following discussion. In this study, probability distributions are always determined for the climate variable response for a fixed, given amount of emissions. For example, for $1000 \mathrm{Gt} \mathrm{C}$ of total emissions, the peak response in global mean surface temperature change $(\triangle \mathrm{SAT})$ is determined to $2.31^{\circ} \mathrm{C}$ and to be with a probability of $68 \%$ within 1.49 and $3.81{ }^{\circ} \mathrm{C}$ (Table 2).

The magnitude of the response is in general nonlinearly related to cumulative $\mathrm{CO}_{2}$ emissions. This may present no fundamental problem. Yet, nonlinearity in responses add to the scenario uncertainty and extrapolation beyond the considered scenario space may not provide reliable results. Non-linear relationships cannot be precisely summarized with one single number. For convenience, we have approximated responses for the investigated variables by linear fits (Tables 2 and A2). A close to linear relationship is found for $\mathrm{pH}$. Consistent with earlier studies, we also find an approximately linear relation between transient surface temperature increase and cumulative $\mathrm{CO}_{2}$ emissions of about $1-3^{\circ} \mathrm{C}(\mathrm{TtC})^{-1}$ over our set of multi-agent scenarios. There are some nonlinear temperature responses in strong mitigation scenarios (particularly those with negative emissions).

Within Bern3D-LPJ, TRE ${ }^{\triangle \mathrm{SAT}}$ is higher when evaluated at $1000 \mathrm{GtC}$ than when evaluated at 2000 or $3000 \mathrm{GtC}$ (see Table 2). This may be related to non- $\mathrm{CO}_{2}$ forcing as it potentially has a relatively smaller role in high-emission scenarios. It may also be model-specific as similar tendencies are found for not only the other physical variables but 

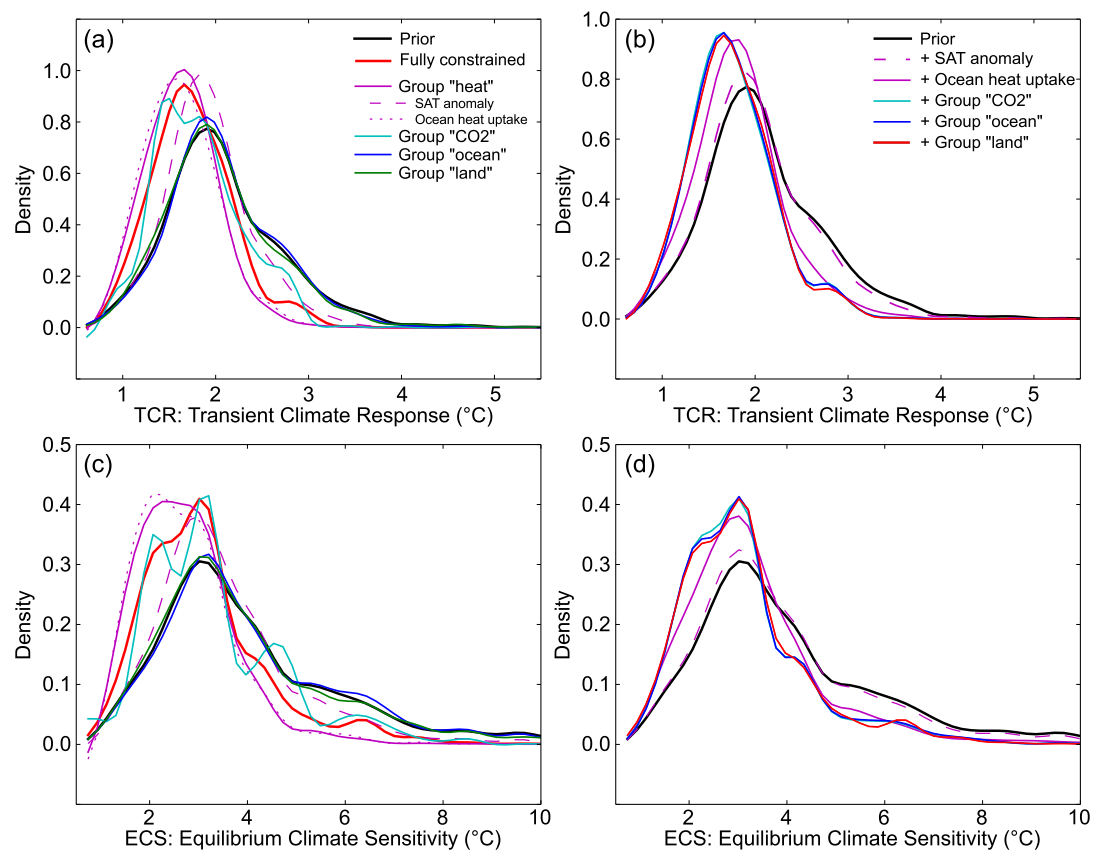

Figure 6. PDFs of transient climate response (a, b) and equilibrium climate sensitivity (c, d) derived from the model ensemble and for different observation-based constraints. In (a, c) the PDFs are shown for the ensemble without constraints (prior, black line), for the case when each of the constraint groups "heat" (magenta), " $\mathrm{CO}_{2}$ " (cyan), "ocean" (blue), and "land" (green) is applied alone with equal weights, and for all constraints (red). The group "heat" is split up further into SAT anomaly (dashed magenta) and ocean heat uptake observations (dotted magenta). In (b, d) the constraints are added sequentially with their corresponding weights in the full constraint in the following order: SAT anomaly (magenta dashed), ocean heat uptake (magenta solid), $\mathrm{CO}_{2}$ (cyan), ocean (blue), and land (red, corresponding to the full constraint).

also the ocean acidification variables which are hardly influenced by non- $\mathrm{CO}_{2}$ forcing. A tendency for the TCRE to decrease with increasing cumulative emissions is noted in earlier studies (Herrington and Zickfeld, 2014; Gillett et al., 2013; Matthews et al., 2009), while Krasting et al. (2014) find TCRE to be large for low and high emission rates and low for modern emission rates in idealized scenarios in the GFDL model.

\subsection{Climate targets, allowable emissions, and TRE ${ }^{X}$}

Next we address climate targets and allowable emissions, widely discussed in the literature for global mean surface temperature (e.g. Siegenthaler and Oeschger, 1978; Friedlingstein et al., 2011; Rogelj et al., 2011; Peters et al., 2013). The link between a climate target, e.g., the $2{ }^{\circ} \mathrm{C}$ target, and allowable emissions is closely related to $\mathrm{TRE}^{X}$ and $\mathrm{TRE}_{\text {peak }}^{X}$. The probabilistic, quantitative relationship between a climate variable of choice and cumulative $\mathrm{CO}_{2}$ emissions permits one to assess the ceiling in cumulative $\mathrm{CO}_{2}$ emissions if a specific individual limit is not to be exceeded with a given probability, $P$. This quantification of allowable emissions is possible irrespective of whether the emissionresponse relationship is linear or not. Estimates of allowable emissions may be inferred from the full model ensemble re- sults or approximated graphically from the Figs. 3 to 5. Even simpler, $\operatorname{TRE}^{X}(P)$ (or $\left.\operatorname{TRE}_{\text {peak }}^{X}(P)\right)$ is a convenient measure to link a given climate target with allowable fossil-fuel $\mathrm{CO}_{2}$ emissions, $E_{\text {allowable. }}$ It holds that

$E_{\text {allowable }}=\frac{X_{\text {target }}(P)}{\operatorname{TRE}^{X}(P)} \mathrm{TtC}$,

where $X_{\text {target }}(P)$ is a limit in variable $X$ not to be exceeded with probability $P . \operatorname{TRE}^{X}(P)$ is then the numerical value determined from the probability distribution (e.g., Fig. 3d) of $\mathrm{TRE}^{X}$ for a given cumulative probability $P($ or $(1-P)$ ). In the case of an approximately linear emission-response relationship, a single value of $\operatorname{TRE}^{X}(P)$ applies for different target levels. For example, $\mathrm{TRE}_{\text {peak }}^{\Delta \mathrm{SAT}}$ is $2.85^{\circ} \mathrm{C}(\mathrm{TtC})^{-1}$ at the 68th percentile (evaluated for total emissions of $1000 \mathrm{GtC}$ ). Then, allowable total carbon emissions to keep global mean surface temperature warming below $2{ }^{\circ} \mathrm{C}$ at any time with a $68 \%$ probability are estimated to $702 \mathrm{GtC}$ $\left(2{ }^{\circ} \mathrm{C} /\left(2.85^{\circ} \mathrm{C}(\mathrm{TtC})^{-1}\right)\right)$. Correspondingly, allowable total carbon emissions to meet the $1.5^{\circ} \mathrm{C}$ target mentioned in the Paris agreement (United Nations, 2015) are $526 \mathrm{Gt}$ C.

Numerical values of $\mathrm{TRE}^{X}$ vary with the magnitude of emissions (Tables 2 and A2) as mentioned above. Cumulative fossil and land-use emissions up to year 2100 are typically lower than $1500 \mathrm{GtC}$ for the mitigation scenarios of 
the Energy Modeling Forum Project 21 (Van Vuuren et al., 2008). Thus, in the context of emission mitigation, the numerical values (median and confidence interval) determined at $1000 \mathrm{GtC}$ cumulative fossil-fuel emissions appear best suited (Tables 2 and A2). For convenience, we provide the inverse values of $\operatorname{TRE}^{X}$ and $\mathrm{TRE}_{\text {peak }}^{X}$ for the different climate variables for the 68th and 90th percentiles of the cumulative, integrated probability distribution in Table 3. Multiplying the appropriate value by the climate target of choice yields the allowable emissions to meet this target with 68 and $90 \%$ probability, respectively.

Some aspects are not explicitly considered here. First, meeting a set of multiple targets requires lower cumulative $\mathrm{CO}_{2}$ emissions than required to meet the most stringent target within the set in probabilistic assessments (Steinacher et al., 2013). Thus, the evaluation of allowable cumulative emissions to meet multiple climate targets requires their joint evaluation. In practical terms, the joint evaluation of the $2{ }^{\circ} \mathrm{C}$ target and the Southern Ocean saturation target would yield lower allowable emissions than indicated in the above paragraph.

Second, inertia in the socioeconomic system limits the rate of carbon emission reduction. In other words, carbon emissions are committed for the future through existing infrastructure. The committed peak change in a climate variable $X$ (relative to preindustrial) under a limited, constant rate of emission reduction $s$ is easily evaluated using the tabulated values of $\operatorname{TRE}^{X}$ (Allen and Stocker, 2014):

$X_{\text {peak }}=\operatorname{TRE}^{X}\left(\frac{e(t)}{s}+E(t)\right)$

Here, $e(t)$ denotes the $\mathrm{CO}_{2}$ emissions at time $t$, e.g., today, $e(t) / s$ is the cumulative sum of future emissions (given exponentially decreasing emissions with rate $s$ ), and $E(t)$ is the cumulative emissions over the historical period up to time $t$. Economically feasible emission reduction rates are considered to be in the range of a few percent. In 2015, total $\mathrm{CO}_{2}$ emissions are about $10 \mathrm{Gt} C$ per year and realized emissions from fossil-fuel burning, land use, and cement production are about $600 \mathrm{Gt} C$. This yields a committed (median) change in SAT of $2.5\left(2.31^{\circ} \mathrm{C}(\mathrm{TtC})^{-1} \times(10 / 0.02+600) \mathrm{GtC}\right)$ and $1.8^{\circ} \mathrm{C}$ when assuming immediate emission reduction with a rate of 2 and $5 \%$, respectively. The corresponding commitments in $\mathrm{pH}$ decrease are 0.22 and 0.16 .

Climate targets may become out of reach when the transition to a decarbonized economy is delayed. This is quantitatively illustrated by the mitigation delay sensitivity (MDS; Stocker, 2013; Pfister and Stocker, 2016), a metric that captures the additional, committed increase in a climate variable due to a delay in emission reduction. Again, the values of $\mathrm{TRE}^{X}$ given in Tables 2 and A2 allow one to compute the median and the $68 \%$ confidence interval for the MDS following Allen and Stocker (2014).

\subsection{Impulse response functions (IRFs)}

The response to a pulse-like input of carbon into the atmosphere for atmospheric $\mathrm{CO}_{2}$, ocean and land carbon, surface air temperature, and steric sea level rise are discussed elsewhere (e.g. Archer et al., 1998; Frölicher et al., 2014; Joos et al., 2013; Shine et al., 2005). Here we provide, in addition, IRFs for surface ocean $\mathrm{pH}$ and calcium carbonate saturation states as well as soil carbon. A substantial fraction of carbon emitted today will remain airborne for centuries and millennia. The impact of today's carbon emissions on surface air temperature will accrue within about 20 years only but persists for many centuries. In Bern3D-LPJ, as in many other models, surface air temperature remains approximately constant after the first $\sim 20$ years after the pulse input. As found in earlier studies, the normalized IRF in SAT depends relatively weakly on the magnitude of the emission pulse. However, the peak warming is realized later for larger than for smaller emission pulses in Bern3D and in a range of other models (Joos et al., 2013; Zickfeld and Herrington, 2015). Interestingly, Frölicher et al. (2014) find that surface air temperature increases for several centuries in their $\mathrm{CO}_{2}$ pulse experiment with the GFDL model. Steric sea level rise accrues slowly on multi-decadal to century timescales. Similar to atmospheric $\mathrm{CO}_{2}$, peak impacts in surface ocean $\mathrm{pH}$ and saturation states occur almost immediately after emissions and these changes will persist for centuries to millennia. Thus, the environment and the socioeconomic system will experience the impact of our current carbon emissions more or less immediately and these impacts are irreversible on human timescales.

\subsection{Transient and equilibrium climate sensitivity}

Another focus of this study is to provide observationconstrained estimates of the TCR, the ECS, and the TCRE as determined from $\mathrm{CO}_{2}$-only scenarios. The recent slow-down in global surface air temperature warming (Hartmann et al., 2013; Roberts et al., 2015; Nieves et al., 2015; Karl et al., 2015; Marotzke and Forster, 2015), termed hiatus, has provoked discussions whether climate models react too sensitive to radiative forcing. Here, the observation-constrained TCR and ECS are quantified to 1.7 and $2.9^{\circ} \mathrm{C}$ (ensemble mean) with $68 \%$ uncertainty ranges of 1.3 to 2.2 and 2.0 to $4.2^{\circ} \mathrm{C}$, respectively. TCRE is estimated to $1.7^{\circ} \mathrm{C}(\mathrm{TtC})^{-1}$. Our results for ECS, TCR, and TCRE are consistent with the CMIP5 estimates in terms of multi-model mean and uncertainty ranges (Flato et al., 2013) and there is no apparent discrepancies between our observation-constrained TCR and CMIP5 models. On the other hand, our results do not confirm some recent studies (Otto et al., 2013; Schwartz, 2012; Collins et al., 2013) that suggest the possibility of a TCR below $1^{\circ} \mathrm{C}$. Such low values for TCR are outside the very likely range given in the Fourth Assessment Report of IPCC (discussed by Collins et al., 2013) and of this study. 
Table 3. Inverse values of $\operatorname{TRE}^{X}$ and $\mathrm{TRE}_{\text {peak }}^{X}$ for the different climate variables. The values are determined at $1000 \mathrm{Gt} \mathrm{C}$ total and fossil-fuel $\mathrm{CO}_{2}$ emissions, respectively, and are given for the 68th and 90th percentiles of the cumulative probability distribution. Under the assumption of linearity, the allowable emissions to meet a given target with 68 or $90 \%$ probability can be estimated by multiplying the corresponding value in the table with the target value of the climate variable. $\Delta \mathrm{C}_{\text {soil }}$ is omitted in this table due to its nonlinear response and large uncertainty.

\begin{tabular}{|c|c|c|c|c|c|}
\hline \multirow[b]{2}{*}{ Variable } & \multirow[b]{2}{*}{ Units } & \multicolumn{2}{|c|}{ Total emissions } & \multicolumn{2}{|c|}{ Fossil-fuel emissions } \\
\hline & & $P=68 \%$ & $P=90 \%$ & $P=68 \%$ & $P=90 \%$ \\
\hline$\left[\mathrm{TRE}^{\Delta \mathrm{SAT}}\right]^{-1}$ & \multirow{2}{*}{$\mathrm{GtC} /{ }^{\circ} \mathrm{C}$} & 402 & 245 & 360 & 219 \\
\hline$\left[\mathrm{TRE}_{\text {peak }}^{\Delta \mathrm{SAT}}\right]^{-1}$ & & 351 & 215 & 315 & 194 \\
\hline$\left[\mathrm{TRE}^{\Delta \mathrm{SST}}\right]^{-1}$ & \multirow{2}{*}{$\mathrm{GtC} /{ }^{\circ} \mathrm{C}$} & 532 & 329 & 479 & 296 \\
\hline$\left[\mathrm{TRE}_{\text {peak }}^{\Delta S S T}\right]^{-1}$ & & 479 & 294 & 426 & 262 \\
\hline$\left[\mathrm{TRE}^{\mathrm{SSLR}}\right]^{-1}$ & \multirow{2}{*}{$\mathrm{GtC} / \mathrm{cm}$} & 31.2 & 19.6 & 27.8 & 17.2 \\
\hline$\left[\mathrm{TRE}_{\text {peak }}^{\mathrm{SSLR}}\right]^{-1}$ & & 27.8 & 17.9 & 25.6 & 16.1 \\
\hline$\left[\mathrm{TRE}^{\triangle \mathrm{AMOC}}\right]^{-1}$ & \multirow{2}{*}{$\mathrm{GtC} / \%$} & -46.6 & -30.3 & -42.3 & -27.9 \\
\hline$\left[\mathrm{TRE}_{\mathrm{peak}}^{\Delta \mathrm{AMOC}}\right]^{-1}$ & & -35.3 & -25.1 & -33.4 & -23.8 \\
\hline$\left[\mathrm{TRE}^{\Delta \mathrm{pH}}\right]^{-1}$ & \multirow{2}{*}{$\mathrm{GtC}$} & -5000 & -4348 & -4348 & -3846 \\
\hline$\left[\mathrm{TRE}_{\text {peak }}^{\Delta \mathrm{pH}^{-1}}\right]^{-1}$ & & -4545 & -4000 & -4348 & -3704 \\
\hline$\left[\operatorname{TRE}^{\Delta \Omega_{\text {arag,S.O. }}}\right]^{-1}$ & \multirow{2}{*}{$\mathrm{GtC}$} & -1667 & -1449 & -1515 & -1316 \\
\hline$\left[\mathrm{TRE}_{\text {peak }}^{\Delta \Omega_{\text {arag,S.O. }}}\right]^{-1}$ & & -1563 & -1429 & -1471 & -1333 \\
\hline$\left[\mathrm{TRE}^{\Delta \Omega_{\text {arag, }} \text { trop. }}\right]^{-1}$ & \multirow{2}{*}{$\mathrm{GtC}$} & -1042 & -926 & -935 & -840 \\
\hline$\left[\mathrm{TRE}_{\text {peak }}^{\Delta \Omega_{\text {arag, trop. }}}\right]^{-1}$ & & -1010 & -926 & -943 & -870 \\
\hline
\end{tabular}

The choice and record length of observational constraints may bias results for TCR and ECS. In particular, internal climate variability, e.g., associated with the Atlantic Multidecadal Oscillation, may obscure the link between anthropogenic forcing and response (van der Werf and Dolman, 2014). Ocean heat content data provide the strongest constraint on ECS and TCR in our analysis. The influence of the applied long-term hemispheric SAT records is smaller. This is not surprising as ocean heat content represents the timeintegrated anthropogenic forcing signal both in the observations and in our model. Roemmich et al. (2015) analyzed a large set of ocean temperature measurements from floats covering the top $2000 \mathrm{~m}$ of the water column and concluded that ocean heat uptake continues steadily and unabated over the recent period 2006 and 2013. The significant variability in surface temperature and upper $100 \mathrm{~m}$ heat content was offset by opposing variability from 100 to $500 \mathrm{~m}$. The high variability in the SAT and SST records as evidenced by the hiatus serves to emphasize that these records are poor indicators of the steadier subsurface-ocean and climate warming signal on the decadal timescale. These findings appear to support our approach where ocean heat data provide the strongest constraint on TCR and ECS, complemented by hemispheric century-scale (1850 to 2010) SAT records. Studies that rely on decadal-scale SAT (or SST) changes as included in the most recent assessment by the IPCC may be affected by large and unavoidable uncertainties due to the chaotic nature of natural, internal variability (van der Werf and Dolman, 2014). These findings suggest that the downward revision of the ECS range from the IPCC's AR4 to AR5 may, in hindsight, appear perhaps somewhat cautious and that the AR4 range may be more reliable.

\section{Summary and conclusions}

We have quantified the transient response to cumulative $\mathrm{CO}_{2}$ emissions, $\mathrm{TRE}^{X}$, for multiple Earth system variables, the responses to a $\mathrm{CO}_{2}$ emission pulse defining the impulse response function (IRF), and three other important climate metrics, the equilibrium climate sensitivity (ECS), the transient climate response (TCR), and the transient climate response to cumulative $\mathrm{CO}_{2}$ emissions (TCRE). Our results are based on (i) a large number of simulations carried out in a probabilistic framework for the industrial period and for the future using 55 different greenhouse gas scenarios, different emission pulses, and an 1000-member model ensemble and (ii) a diverse and large set of observational data as constraints. The observation-constrained PDFs provide both best estimates and uncertainties ranges for risk analyses and for determining allowable emissions to meet a climate target.

The $68 \%$ confidence intervals for TCR and ECS are constrained to 1.3 to 2.2 and 2.0 to $4.2{ }^{\circ} \mathrm{C}$, respectively. This is 
fully consistent with the range found by the CMIP5 models, but in conflict with suggestions of the possibility of a TCR below $1^{\circ} \mathrm{C}$. Ocean heat content data provide the most stringent constraint on these estimates, while observation-based records of surface air temperature and of the atmospheric $\mathrm{CO}_{2}$ budget are of secondary importance in our analysis.

$\mathrm{TRE}^{X}$ and IRF are evaluated for changes in physical variables including surface air and ocean temperature, sea level, and Atlantic meridional overturning circulation and changes in ocean acidification variables and terrestrial soil carbon stocks. Path dependency in responses and scenario uncertainties as well as model response uncertainties are quantified.

The IRF analysis provides a theoretical framework to discuss path dependency and linearity in response without the need to run many independent scenarios. It reveals that a perfect linearity between cumulative $\mathrm{CO}_{2}$ emissions and Earth system variables is not to be expected. Nevertheless, the median values of the (normalized) IRFs vary within a limited range for an emission age range between 30 and 500 years and for pulse sizes between 100 and $3000 \mathrm{GtC}$ for global mean surface air temperature, surface ocean $\mathrm{pH}, \mathrm{AMOC}$, and to a somewhat lesser degree for SSLR. This implies a closeto-linear relationship between these variables and cumulative $\mathrm{CO}_{2}$ emissions and relatively little influence of the $\mathrm{CO}_{2}$ emission scenario choice for these variables. On the other hand, the IRFs for atmospheric $\mathrm{CO}_{2}$, global soil carbon inventory, and aragonite saturation in the tropics and Southern Ocean are shown to vary with the size of the emission pulse, implying some nonlinearity in the emission-response relationship.
$\mathrm{TRE}^{X}$ provides a convenient metric to characterize (i) responses of different climate variables to $\mathrm{CO}_{2}$ emissions and (ii) to estimate the link between an individual climate target and allowable emissions. A close to linear relationship between cumulative $\mathrm{CO}_{2}$ emissions and modeled change is found for the Earth system variables investigated here and when considering both scenario and response uncertainty and total emissions of up to $3000 \mathrm{Gt} \mathrm{C}$. These findings suggests that the emission-response and emission-climate target relationships described by $\mathrm{TRE}^{X}$ should be further evaluated and quantified for additional impact-relevant climate variables and using the full Earth system model hierarchy. 


\section{Appendix A: Total vs. fossil-fuel-only $\mathrm{CO}_{2}$ emissions}

Many studies report TCRE with respect to "cumulative total anthropogenic $\mathrm{CO}_{2}$ emissions" (e.g. IPCC, 2013; Allen et al., 2009; Meinshausen et al., 2009), not distinguishing between fossil-fuel emissions and emissions from land-use changes. Here, we use a model that explicitly simulates terrestrial carbon fluxes, including those from land-use changes. Thus the diagnosed $\mathrm{CO}_{2}$ emissions obtained by closing the global carbon budget to match the prescribed atmospheric concentration in the scenarios correspond to fossil-fuel emissions only. In order to estimate total emissions in our simulations, direct land-use emissions (i.e., carbon from vegetation that is removed due to land-use changes) are instantaneously added to the diagnosed fossil-fuel emissions. The delayed emission of carbon from deforestation via product and litter pools and the indirect land-use-change effects such as the losses of terrestrial sink capacity (Strassmann et al., 2008) or from the abandonment of land-use areas are simulated by the model, but they are not included in the estimate of total carbon emissions because this would require additional simulations. Shifting cultivation (Stocker et al., 2014) has not been considered in this study. Results in the present study are mostly given as a function of total (fossil fuel plus deforestation) and, where indicated, additionally as a function of fossil-fuel emissions. Results for fossil-fuel emissions only are provided in the appendix (Fig. A3 and Table A2).

Table A1. Sampled model parameters with plausible ranges based on the literature and/or expert judgment $\left(p_{\min }\right.$, $\left.p_{\max }\right)$. Normal prior distributions $N\left(x ; p_{\text {std }}, \sigma\right)=\frac{1}{(\sqrt{2 \pi} \sigma)} \exp \left(-\frac{\left(x-p_{\text {std }}\right)^{2}}{2 \sigma^{2}}\right)$ with $\sigma=\frac{p_{\max }-p_{\min }}{4}$ are chosen for ranges that are basically symmetric with respect to the standard parameter value $\left(p_{\text {std }}\right)$. Log-normal priors $L\left(x ; p_{\text {std }}, s, l\right)=\frac{1}{(\sqrt{2 \pi} s(x-l))} \exp \left(-\frac{\left(\ln (x-l)-\ln \left(p_{\text {std }}-l\right)\right)^{2}}{2 s^{2}}\right)$ are used for asymmetric ranges, with $s$ and $l$ chosen such that the median of the distribution matches $p_{\text {std }}$ and the standard deviation $\sigma$ is one-fourth of the parameter range, as for the normal distribution.

\begin{tabular}{|c|c|c|c|c|c|c|}
\hline Parameter & Description & $p_{\text {std }}$ & $p_{\min }$ & $p_{\max }$ & Prior & Refs. \\
\hline$\alpha_{a}$ & Photosynthesis scaling parameter (leaf to canopy) & 0.5 & 0.3 & 0.7 & $N\left(p_{\text {std }}, \sigma\right)$ & Zaehle et al. (2005); Haxeltine and Prentice (1996) \\
\hline$\alpha_{\mathrm{C}_{3}}$ & Intrinsic quantum efficiency of $\mathrm{CO}_{2}$ uptake ( $\mathrm{C}_{3}$ plants) & 0.08 & 0.02 & 0.125 & $N\left(p_{\text {std }}, \sigma\right)$ & Zaehle et al. (2005); Farquhar et al. (1980); Hallgren and Pitman (2000) \\
\hline$\theta^{\star}=1-\theta$ & Co-limitation shape parameter (light vs. RuBisCO act.) & 0.3 & 0.004 & 0.8 & $L\left(p_{\text {std }}, 0.54,0\right)$ & Zaehle et al. (2005); Collaty et al. (1990); Leverenz (1988) \\
\hline$g_{m}$ & Max. canopy conductance & 3.26 & 2.5 & 18.5 & $L\left(p_{\text {std }}, 1.05,1.5\right)$ & Zaehle et al. (2005); Magnani et al. (1998) \\
\hline$\tau_{\text {sapwood }}$ & Sapwood to heartwood turnover $(\mathrm{yr})$ & 20 & 5 & 100 & $L\left(p_{\text {std }}, 0.76,0\right)$ & Zaehle et al. (2005); Bartelink (1998) \\
\hline $\operatorname{mort}_{\max }$ & Asymptotic maximum mortality rate $\left(\mathrm{yr}^{-1}\right)$ & 0.01 & 0.005 & 0.1 & $L\left(p_{\text {std }}, 1.19,0\right)$ & Zaehle et al. (2005) \\
\hline $\operatorname{resp}_{\mathrm{Q}_{10}, \mathrm{eq}}$ & Temp. sensitivity of respiration and soil decomp. & 2.4 & 1.3 & 3.3 & $N\left(p_{\text {std }}, \sigma\right)$ & Lloyd and Taylor (1994); Raich and Schlesinger (1992) \\
\hline$k_{\text {soil,scale }}$ & Scaling factor for SOM decomp. rates at $10^{\circ} \mathrm{C}$ & 1.0 & 0.5 & 2.0 & $L\left(p_{\text {std }}, 0.41,0.2\right)$ & Trumbore (2000) \\
\hline$f_{\text {soil }}$ & Fraction of decomp. litter entering soil pools (\%) & 40 & 20 & 60 & $N\left(p_{\text {std }}, \sigma\right)$ & Zaehle et al. (2005); Jenkinson (1990) \\
\hline$f_{\text {slow }}$ & Fraction of soil-bound litter entering slow soil pool (\%) & 1.5 & 1.0 & 15 & $L\left(p_{\text {std }}, 1.05,0\right)$ & Zaehle et al. (2005); Kergoat (1998) \\
\hline $\mathrm{C}_{\text {peat,scale }}$ & Initial soil carbon in $\mathrm{NH}$ peatlands $(\mathrm{GtC})$ & 420 & 190 & 650 & $N\left(p_{\text {std }}, \sigma\right)$ & Tarnocai et al. (2009) \\
\hline $\mathrm{CS}$ & Nominal equilibrium climate sensitivity $\left({ }^{\circ} \mathrm{C}\right)$ & 3 & 1 & 10 & $L\left(p_{\text {std }}, 0.58,0\right)$ & Knutti et al. (2003); Meinshausen et al. (2009) \\
\hline diff $_{\text {zonal }}$ & Zonal atmospheric eddy diffusivity $\left(10^{6} \mathrm{~m}^{2} \mathrm{~s}^{-1}\right)$ & 1.0 & 0.1 & 10 & $L\left(p_{\text {std }}, 1.06,0\right)$ & Ritz et al. (2011a) \\
\hline diff merid,scale & Scaling factor for meridional atm. eddy diffusivity & 1.0 & 0.5 & 2.0 & $L\left(p_{\text {std }}, 0.34,0\right)$ & Ritz et al. (2011a) \\
\hline $\operatorname{diff}_{\text {dia }}$ & Ocean diapycnal diffusivity $\left(10^{-5} \mathrm{~m}^{2} \mathrm{~s}^{-1}\right)$ & 1.0 & 0.2 & 20 & $L\left(p_{\text {std }}, 1.35,0\right)$ & Edwards and Marsh (2005); Meinshausen et al. (2009) \\
\hline $\operatorname{diff}_{\text {iso }}$ & Ocean isopycnal diffusivity $\left(\mathrm{m}^{2} \mathrm{~s}^{-1}\right)$ & 1.000 & 300 & 9.000 & $L\left(p_{\text {std }}, 1.01,0\right)$ & Edwards and Marsh (2005); Huang et al. (2003) \\
\hline$k_{\text {gas,scale }}$ & Scaling factor for standard OCMIP gas transfer velocity & 0.81 & 0.65 & 0.97 & $N\left(p_{\text {std }}, \sigma\right)$ & Müller et al. (2008) \\
\hline $\mathrm{RF}_{\mathrm{GHG}, \text { scale }}$ & Scaling factor for total RF from well-mixed GHG & 1.0 & 0.92 & 1.12 & $L\left(p_{\text {std }}, 0.17,0.7\right)$ & Forster et al. (2007) \\
\hline $\mathrm{RF}_{\text {aerosol,scale }}$ & Scaling factor for total aerosol RF & 1.0 & 0.5 & 2.0 & $L\left(p_{\text {std }}, 0.35,0\right)$ & Forster et al. (2007) \\
\hline
\end{tabular}


Table A2. Same as Table 2 but for fossil-fuel $\mathrm{CO}_{2}$ emissions only - i.e., the gross emissions from deforestation are not included when regressing the responses against cumulative $\mathrm{CO}_{2}$ emissions (see Methods).

\begin{tabular}{|c|c|c|c|c|}
\hline Variable $X$ & Method & $\operatorname{TRE}^{X}$ & $\mathrm{TRE}_{\text {peak }}^{X}$ & Goodness of linear fit \\
\hline$\Delta \mathrm{SAT}$ & $1000 \mathrm{GtC}$ & $2.17[1.25-3.79]$ & $2.56[1.64-4.25]$ & \multirow[b]{4}{*}{$r=0.91 \pm 0.04, \hat{\sigma}=35 \%$} \\
\hline \multirow{3}{*}{$\left({ }^{\circ} \mathrm{C}\right)$} & $2000 \mathrm{GtC}$ & $2.12[1.36-3.32]$ & $2.26[1.47-3.47]$ & \\
\hline & $3000 \mathrm{GtC}$ & $1.94[1.33-2.68]$ & $1.96[1.34-2.70]$ & \\
\hline & Lin. reg. & $1.88[1.28-2.69]$ & $1.87[1.22-2.78]$ & \\
\hline \multirow{4}{*}{$\begin{array}{l}\Delta \mathrm{SST} \\
\left({ }^{\circ} \mathrm{C}\right)\end{array}$} & $1000 \mathrm{GtC}$ & $1.62[0.98-2.70]$ & $1.86[1.22-3.01]$ & \multirow[b]{4}{*}{$r=0.91 \pm 0.04, \hat{\sigma}=35 \%$} \\
\hline & $2000 \mathrm{GtC}$ & $1.50[1.00-2.19]$ & $1.58[1.06-2.25]$ & \\
\hline & $3000 \mathrm{GtC}$ & $1.33[0.95-1.72]$ & $1.35[0.94-1.73]$ & \\
\hline & Lin. reg. & $1.38[0.95-1.93]$ & $1.39[0.91-2.00]$ & \\
\hline \multirow{4}{*}{$\begin{array}{l}\text { SSLR } \\
(\mathrm{cm})\end{array}$} & $1000 \mathrm{GtC}$ & 29 [16-49] & 32 [19-52] & \multirow[b]{4}{*}{$r=0.90 \pm 0.04, \hat{\sigma}=36 \%$} \\
\hline & $2000 \mathrm{GtC}$ & $24[15-40]$ & $29[19-45]$ & \\
\hline & $3000 \mathrm{GtC}$ & 22 [14-33] & $26[18-37]$ & \\
\hline & Lin. reg. & 20 [13-27] & $25[16-35]$ & \\
\hline \multirow{4}{*}{$\begin{array}{l}\triangle \mathrm{AMOC} \\
(\%)\end{array}$} & $1000 \mathrm{GtC}$ & $-18[-31$ to -8$]$ & $-25[-37$ to -16$]$ & \multirow[b]{4}{*}{$r=0.8_{-0.2}^{+0.1}, \hat{\sigma}=41 \%$} \\
\hline & $2000 \mathrm{GtC}$ & $-16[-24$ to -10$]$ & $-19[-27$ to -12$]$ & \\
\hline & $3000 \mathrm{GtC}$ & $-14[-20$ to -9$]$ & $-15[-20$ to -11$]$ & \\
\hline & Lin. reg. & $-16[-23$ to -10$]$ & $-16[-24$ to -10$]$ & \\
\hline \multirow{4}{*}{$\begin{array}{l}\Delta \mathrm{pH} \\
(1)\end{array}$} & $1000 \mathrm{GtC}$ & $-0.21[-0.25$ to -0.18$]$ & $-0.22[-0.25$ to -0.20$]$ & \multirow[b]{4}{*}{$r=0.97 \pm 0.01, \hat{\sigma}=17 \%$} \\
\hline & $2000 \mathrm{GtC}$ & $-0.19[-0.22$ to -0.17$]$ & $-0.19[-0.22$ to -0.17$]$ & \\
\hline & $3000 \mathrm{GtC}$ & $-0.18[-0.19$ to -0.16$]$ & $-0.17[-0.19$ to -0.16$]$ & \\
\hline & Lin. reg. & $-0.19[-0.22$ to -0.18$]$ & $-0.18[-0.20$ to -0.16$]$ & \\
\hline \multirow{4}{*}{$\begin{array}{l}\Delta \Omega_{\text {arag,S.O. }} \\
\text { (1) }\end{array}$} & $1000 \mathrm{GtC}$ & $-0.61[-0.73$ to -0.50$]$ & $-0.65[-0.73$ to -0.59$]$ & \multirow[b]{4}{*}{$r=0.80 \pm 0.04, \hat{\sigma}=35 \%$} \\
\hline & $2000 \mathrm{GtC}$ & $-0.48[-0.56$ to -0.41$]$ & $-0.48[-0.53$ to -0.43$]$ & \\
\hline & $3000 \mathrm{GtC}$ & $-0.41[-0.46$ to -0.36$]$ & $-0.41[-0.45$ to -0.37$]$ & \\
\hline & Lin. reg. & $-0.51[-0.56$ to -0.46$]$ & $-0.46[-0.52$ to -0.41$]$ & \\
\hline \multirow{4}{*}{$\begin{array}{l}\Delta \Omega_{\text {arag, trop. }} \\
\text { (1) }\end{array}$} & $1000 \mathrm{GtC}$ & $-0.98[-1.15$ to -0.81$]$ & $-1.02[-1.11$ to -0.94$]$ & \multirow[b]{4}{*}{$r=0.89 \pm 0.03, \hat{\sigma}=28 \%$} \\
\hline & $2000 \mathrm{GtC}$ & $-0.80[-0.90$ to -0.70$]$ & $-0.78[-0.85$ to -0.72$]$ & \\
\hline & $3000 \mathrm{GtC}$ & $-0.70[-0.74$ to -0.64$]$ & $-0.68[-0.72$ to -0.64$]$ & \\
\hline & Lin. reg. & $-0.84[-0.91$ to -0.77$]$ & $-0.76[-0.84$ to -0.69$]$ & \\
\hline \multirow{4}{*}{$\begin{array}{l}\Delta \mathrm{C}_{\text {soil }} \\
(\mathrm{GtC})\end{array}$} & $1000 \mathrm{GtC}$ & $-66[-260$ to +25$]$ & $-81[-288$ to +24$]$ & \multirow[b]{4}{*}{$r=0.7_{-0.7}^{+0.1}, \hat{\sigma}=158 \%$} \\
\hline & $2000 \mathrm{GtC}$ & $-80[-212$ to -9$]$ & $-89[-228$ to -9$]$ & \\
\hline & $3000 \mathrm{GtC}$ & $-74[-154$ to -17$]$ & $-80[-163$ to -16$]$ & \\
\hline & Lin. reg. & $-28[-91$ to +26$]$ & $-42[-132$ to +27$]$ & \\
\hline
\end{tabular}




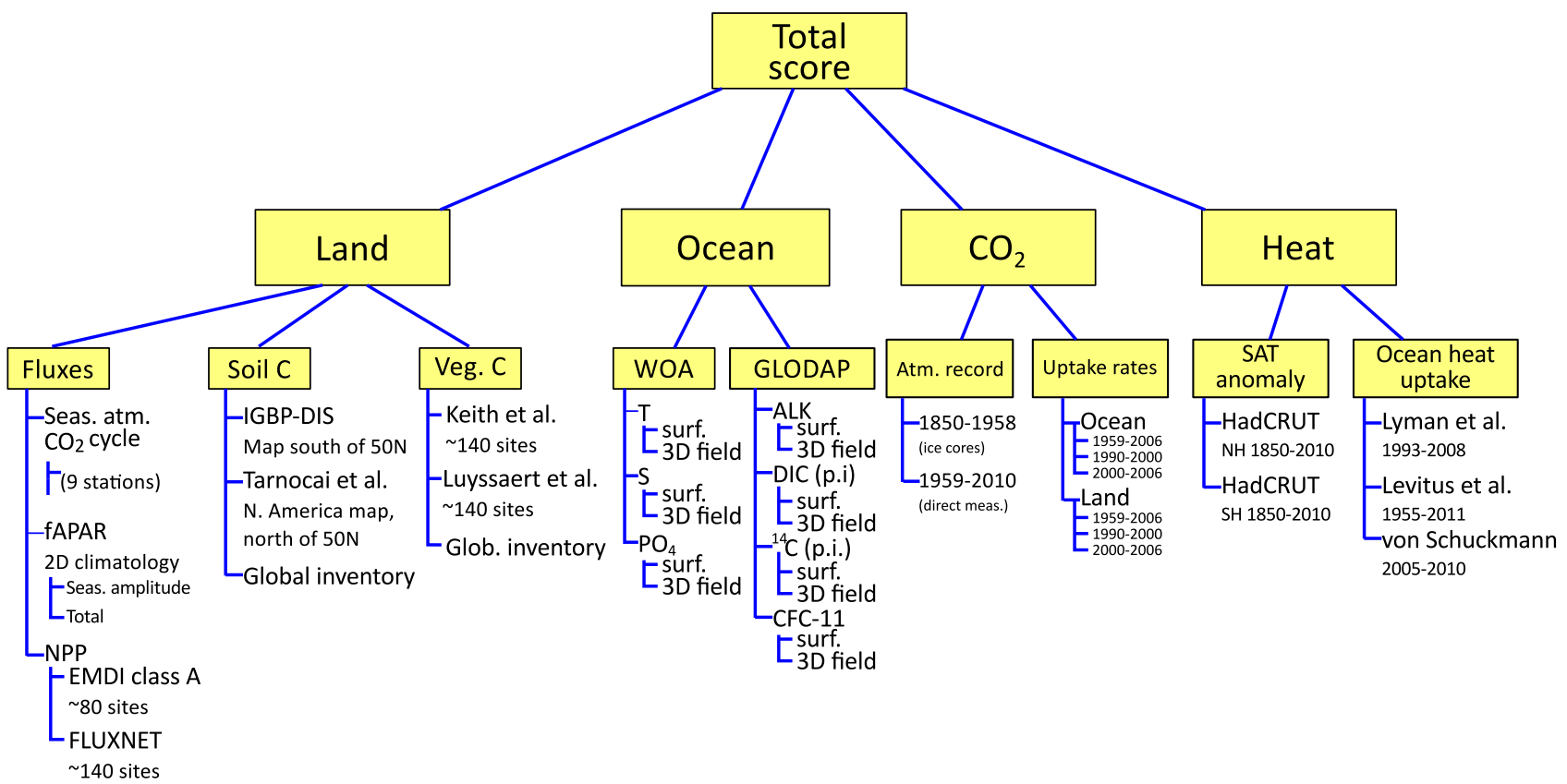

Figure A1. Observation-based data sets used to constrain the model ensemble. The data sets are organized in a hierarchical structure to balance the weight of individual data sets, and model skill scores are aggregated by averaging over the group of constraints at the same level in the hierarchy (Steinacher et al., 2013). 

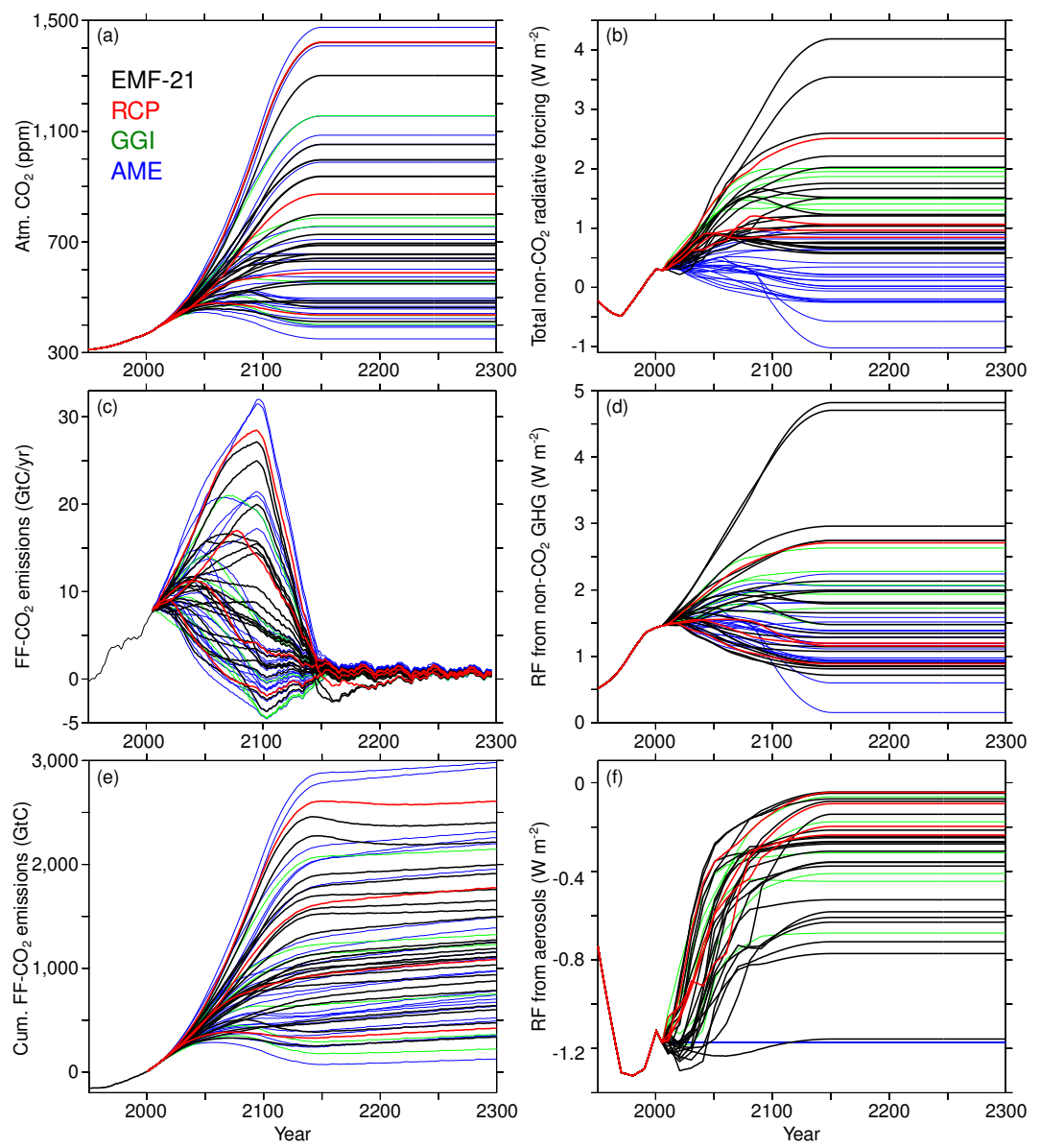

Figure A2. Time series of (a) atmospheric $\mathrm{CO}_{2}$ and (b) total non- $\mathrm{CO}_{2}$ radiative forcing prescribed in the scenario simulations. The forcings are derived from 22 EMF-21 (black), 4 RCPs (red), 6 GGI (green), and 23 AME (blue) scenarios. After 2100 the scenarios are extended to 2300 by stabilizing $\mathrm{CO}_{2}$ concentrations and non- $\mathrm{CO}_{2}$ radiative forcing by 2150 . The total non- $\mathrm{CO}_{2}$ radiative forcing is the sum of the forcing from (d) non- $\mathrm{CO}_{2}$ greenhouse gases and (f) aerosols. Note that for the AME scenarios the aerosol forcing is kept constant after 2005

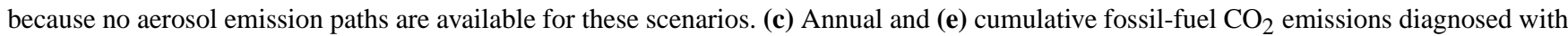
the standard model parameter settings are shown for reference. The annual emissions are smoothed with a 10-year moving average filter. The cumulative emissions are given relative to the year 2000 . 

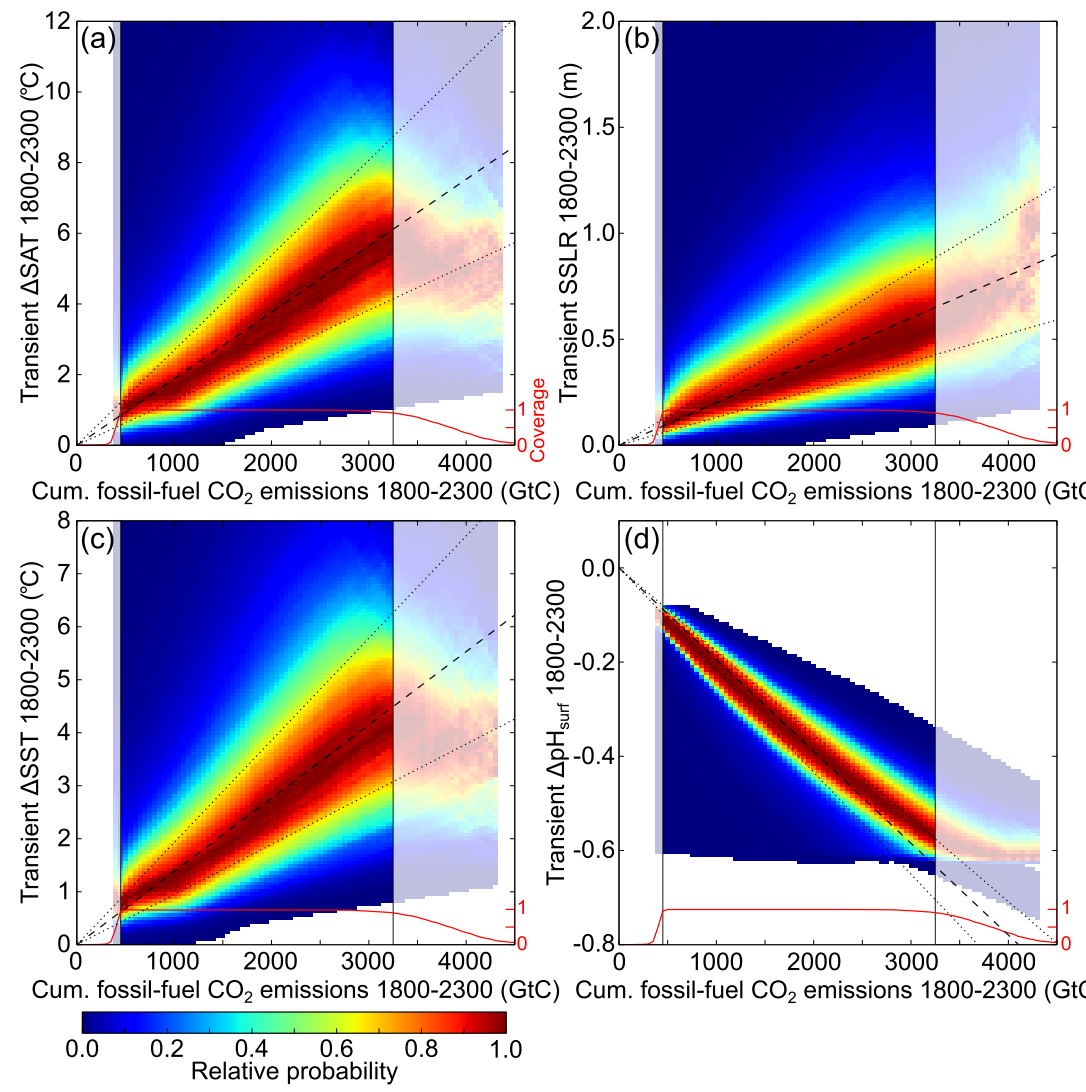

Cum. fossil-fuel $\mathrm{CO}_{2}$ emissions $1800-2300(\mathrm{GtC})$

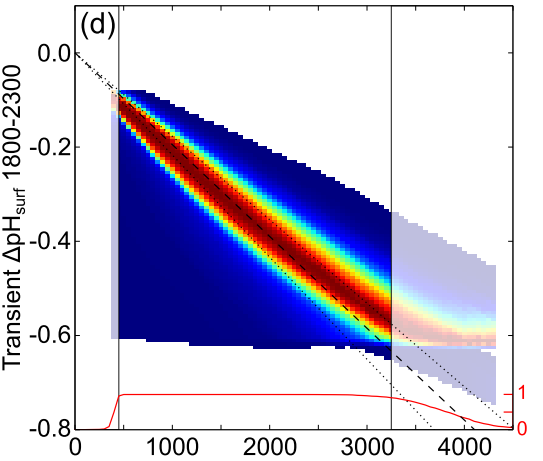

) Cum. fossil-fuel $\mathrm{CO}_{2}$ emissions $1800-2300(\mathrm{GtC})$

Figure A3. Response as function of fossil-fuel $\mathrm{CO}_{2}$ emissions: (a) same as Fig. 3a but for cumulative fossil-fuel emissions only - i.e., $\mathrm{CO}_{2}$ emissions from deforestation are not included in this figure (see Methods). (b-d) Same as (a) but for the transient SSLR, sea surface temperature change $(\Delta \mathrm{SST})$, and global annual mean surface ocean $\mathrm{pH}\left(\Delta \mathrm{pH}_{\text {surf }}\right)$. The response of the remaining variables to fossil-fuelonly $\mathrm{CO}_{2}$ emissions are given in Table A2. 
Acknowledgements. This study was funded by the Swiss National Science Foundation and the European Project CARBOCHANGE (264879), which received funding from the European Commission's Seventh Framework Programme (FP7/20072013). We also acknowledge the support from the International Space Science Institute (ISSI). This publication is an outcome of the ISSI's Working Group on "Carbon Cycle Data Assimilation: How to consistently assimilate multiple data streams".

Edited by: V. Brovkin

\section{References}

Allen, M. R. and Stocker, T. F.: Impact of delay in reducing carbon dioxide emissions, Nature Climate Change, 4, 23-26, doi:10.1038/nclimate2077, 2014.

Allen, M. R., Frame, D. J., Huntingford, C., Jones, C. D., Lowe, J. A., Meinshausen, M., and Meinshausen, N.: Warming caused by cumulative carbon emissions towards the trillionth tonne, $\mathrm{Na}-$ ture, 458, 1163-1166, doi:10.1038/nature08019, 2009.

Antonov, J. I., Seidov, D., Boyer, T. P., Locarnini, R. A., Mishonov, A. V., Garcia, H. E., Baranova, O. K., Zweng, M. M., and R., J. D.: World Ocean Atlas 2009, Volume 2: Salinity, NOAA Atlas NESDIS 69, US Government Printing Office, Washington, D.C., 184 pp., 2010.

Archer, D., Kheshgi, H., and Maier-Reimer, E.: Dynamics of fossil fuel $\mathrm{CO}_{2}$ neutralization by marine $\mathrm{CaCO}_{3}$, Global Biogeochem. Cy., 12, 259-276, doi:10.1029/98GB00744, 1998.

Bartelink, H. H.: A model of dry matter partitioning in trees, Tree Physiol., 18, 91-101, 1998.

Batjes, N. H.: Total carbon and nitrogen in the soils of the world, Eur. J. Soil Sci., 47, 151-163, doi:10.1111/j.13652389.1996.tb01386.x, 1996.

Bhat, K. S., Haran, M., Olson, R., and Keller, K.: Inferring likelihoods and climate system characteristics from climate models and multiple tracers, Environmetrics, 23, 345-362, doi:10.1002/env.2149, 2012.

Bodman, R. W., Rayner, P. J., and Karoly, D. J.: Uncertainty in temperature projections reduced using carbon cycle and climate observations, Nature Climate Change, 3, 725-729, doi:10.1038/NCLIMATE1903, 2013.

Bozbiyik, A., Steinacher, M., Joos, F., Stocker, T. F., and Menviel, L.: Fingerprints of changes in the terrestrial carbon cycle in response to large reorganizations in ocean circulation, Clim. Past, 7, 319-338, doi:10.5194/cp-7-319-2011, 2011.

Brohan, P., Kennedy, J. J., Harris, I., Tett, S. F. B., and Jones, P. D.: Uncertainty estimates in regional and global observed temperature changes: A new data set from 1850, J. Geophys. Res.Atmos., 111, D12106, doi:10.1029/2005JD006548, 2006.

Calvin, K., Clarke, L., Krey, V., Blanford, G., Jiang, K., Kainuma, M., Kriegler, E., Luderer, G., and Shukla, P. R.: The role of Asia in mitigating climate change: Results from the Asia modeling exercise, Energ. Econ., 34, Supplement 3, S251-S260, doi:10.1016/j.eneco.2012.09.003, 2012.

Canadell, J. G., Le Quere, C., Raupach, M. R., Field, C. B., Buitenhuis, E. T., Ciais, P., Conway, T. J., Gillett, N. P., Houghton, R. A., and Marland, G.: Contributions to accelerating atmospheric $\mathrm{CO}_{2}$ growth from economic activity, carbon intensity, and efficiency of natural sinks, P. Natl. Acad. Sci. USA, 104, 18866-18870, doi:10.1073/pnas.0702737104, 2007.

Charman, D. J., Beilman, D. W., Blaauw, M., Booth, R. K., Brewer, S., Chambers, F. M., Christen, J. A., Gallego-Sala, A., Harrison, S. P., Hughes, P. D. M., Jackson, S. T., Korhola, A., Mauquoy, D., Mitchell, F. J. G., Prentice, I. C., van der Linden, M., De Vleeschouwer, F., Yu, Z. C., Alm, J., Bauer, I. E., Corish, Y. M. C., Garneau, M., Hohl, V., Huang, Y., Karofeld, E., Le Roux, G., Loisel, J., Moschen, R., Nichols, J. E., Nieminen, T. M., MacDonald, G. M., Phadtare, N. R., Rausch, N., Sillasoo, Ü., Swindles, G. T., Tuittila, E.-S., Ukonmaanaho, L., Väliranta, M., van Bellen, S., van Geel, B., Vitt, D. H., and Zhao, Y.: Climaterelated changes in peatland carbon accumulation during the last millennium, Biogeosciences, 10, 929-944, doi:10.5194/bg-10929-2013, 2013.

Collaty, G. J., Berry, J. A., Farquhar, G. D., and Pierce, J.: The relationship between the rubisco reaction-mechanism and models of photosynthesis, Phys. Chem. Earth, 13, 219-225, doi:10.1111/j.1365-3040.1990.tb01306.x, 1990.

Collins, M., Knutti, R., Arblaster, J., Dufresne, J.-L., Fichefet, T., Friedlingstein, P., Gao, X. Gutowski, W. J., Johns, T., Krinner, G., Shongwe, M., Tebaldi, C., Weaver, A., and Wehner, M.: Climate Change 2013: The Physical Science Basis. Contribution of Working Group I to the Fifth Assessment Report of the Intergovernmental Panel on Climate Change, chap. 12: Long-term Climate Change: Projections, Commitments and Irreversibility, Cambridge University Press, Cambridge, United Kingdom and New York, NY, USA., 1029-1136, 2013.

Conway, T. and Tans, P.: Trends in Atmospheric Carbon Dioxide, Data set, NOAA/ESRL, available at: http://www.esrl.noaa.gov/ gmd/ccgg/trends/ (last access: 31 January 2012), 2011.

Deutsch, C., Ferrel, A., Seibel, B., Poertner, H.-O., and Huey, R. B.: Climate change tightens a metabolic constraint on marine habitats, Science, 348, 1132-1135, doi:10.1126/science.aaa1605, 2015.

Dickson, A.: Handbook of methods of the analysis of the various parameters of the carbon dioxide system in seawater, US Dep. of Energy, Washington, D.C., available at: http://cdiac.ornl.gov/ oceans/DOE_94.pdf (last access: 25 May 2015), 187 pp., 2002.

Edwards, N. and Marsh, R.: Uncertainties due to transportparameter sensitivity in an efficient 3-D ocean-climate model, Clim. Dynam., 24, 415-433, doi:10.1007/s00382-004-0508-8, 2005.

Etheridge, D. M., Steele, L. P., Langenfelds, R. L., Francey, R. J., Barnola, J. M., and Morgan, V. I.: Natural and anthropogenic changes in atmospheric $\mathrm{CO}_{2}$ over the last 1000 years from air in Antarctic ice and firn, J. Geophys. Res.-Atmos., 101, 41154128, doi:10.1029/95JD03410, 1996.

Farquhar, G. D., Caemmerer, S. V., and Berry, J. A.: A biochemicalmodel of photosynthetic $\mathrm{CO}_{2}$ assimilation in leaves of C-3 species, Planta, 149, 78-90, doi:10.1007/BF00386231, 1980.

Flato, G., Marotzke, J., Abiodun, B., Braconnot, P., Chou, S. C., Collins, W., Cox, P., Driouech, F., Emori, S., Eyring, V., Forest, C., Gleckler, P., Guilyardi, E., Jakob, C., Kattsov, V., C., R., and Rummukainen, M.: Climate Change 2013: The Physical Science Basis. Contribution of Working Group I to the Fifth Assessment Report of the Intergovernmental Panel on Climate Change, chap. 9: Evaluation of Climate Models, Cambridge University Press, 
Cambridge, United Kingdom and New York, NY, USA, 741866, 2013.

Forster, P., Ramaswamy, V., Artaxo, P., Berntsen, T., Betts, R., Fahey, D. W., Haywood, J., Lean, J., Lowe, D. C., Myhre, G., Nganga, J., Prinn, R., Raga, G., Schulz, M., and Dorland, R. V.: Climate Change 2007: The Physical Science Basis. Contribution of Working Group I to the Fourth Assessment Report of the Intergovernmental Panel on Climate Change, chap. 2: Changes in Atmospheric Constituents and in Radiative Forcing, Cambridge University Press, Cambridge, United Kingdom and New York, NY, USA, 129-234, 2007.

Friedlingstein, P., Solomon, S., Plattner, G.-K., Knutti, R., Ciais, P., and Raupach, M. R.: Long-term climate implications of twenty-first century options for carbon dioxide emission mitigation, Nature Climate Change, 1, 457-461, doi:10.1038/NCLIMATE1302, 2011.

Frölicher, T. L. and Paynter, D. J.: Extending the relationship between global warming and cumulative carbon emissions to multi-millennial timescales, Environ. Res. Lett., 10, 075002, doi:10.1088/1748-9326/10/7/075002, 2015.

Frölicher, T. L., Winton, M., and Sarmiento, J. L.: Continued global warming after $\mathrm{CO}_{2}$ emissions stoppage, Nature Climate Change, 4, 40-44, doi:10.1038/nclimate2060, 2014.

Gangst $\varnothing$, R., Gehlen, M., Schneider, B., Bopp, L., Aumont, O., and Joos, F.: Modeling the marine aragonite cycle: changes under rising carbon dioxide and its role in shallow water $\mathrm{CaCO}_{3}$ dissolution, Biogeosciences, 5, 1057-1072, doi:10.5194/bg-5-10572008, 2008.

Garcia, H. E., Locarnini, R. A., Boyer, T. P., Antonov, J. I., Zweng, M. M., Baranova, O. K., and Johnson, D. R.: World Ocean Atlas 2009, Volume 4: Nutrients (phosphate, nitrate, silicate), NOAA Atlas NESDIS 71, US Government Printing Office, Washington, D.C., 398 pp., 2010.

Gattuso, J.-P., Magnan, A., Bille, R., Cheung, W. W. L., Howes, E. L., Joos, F., Allemand, D., Bopp, L., Cooley, S. R., Eakin, C. M., Hoegh-Guldberg, O., Kelly, R. P., Poertner, H.-O., Rogers, A. D., Baxter, J. M., Laffoley, D., Osborn, D., Rankovic, A., Rochette, J., Sumaila, U. R., Treyer, S., and Turley, C.: Contrasting futures for ocean and society from different anthropogenic $\mathrm{CO}_{2}$ emissions scenarios, Science, 349, aac4722, doi:10.1126/science.aac4722, 2015.

Gerber, M. and Joos, F.: Carbon sources and sinks from an Ensemble Kalman Filter ocean data assimilation, Global Biogeochem. Cy., 24, GB3004, doi:10.1029/2009GB003531, 2010.

Gerber, M. and Joos, F.: An Ensemble Kalman Filter multi-tracer assimilation: Determining uncertain ocean model parameters for improved climate-carbon cycle projections, Ocean Model., 64, 29-45, doi:10.1016/j.ocemod.2012.12.012, 2013.

Gerber, M., Joos, F., Vazquez-Rodriguez, M., Touratier, F., and Goyet, C.: Regional air-sea fluxes of anthropogenic carbon inferred with an Ensemble Kalman Filter, Global Biogeochem. Cy., 23, GB1013, doi:10.1029/2008GB003247, 2009.

Gillett, N. P., Arora, V. K., Matthews, D., and Allen, M. R.: Constraining the Ratio of Global Warming to Cumulative $\mathrm{CO}_{2}$ Emissions Using CMIP5 Simulations, J. Climate, 26, 6844-6858, doi:10.1175/JCLI-D-12-00476.1, 2013.

Global Soil Data Task Group: Global Gridded Surfaces of Selected Soil Characteristics (IGBP-DIS), Data set, Oak Ridge National
Laboratory Distributed Active Archive Center, Oak Ridge, Tennessee, USA, doi:10.3334/ORNLDAAC/569, 2000.

GLOBALVIEW-CO2: Cooperative Atmospheric Data Integration Project - Carbon Dioxide, CD-ROM, NOAA ESRL, Boulder, Colorado, available at: http://ftp.cmdl.noaa.gov (last access: 23 March 2011), path: ccg/co2/GLOBALVIEW, 2011.

Gobron, N., Pinty, B., Aussedat, O., Chen, J. M., Cohen, W. B., Fensholt, R., Gond, V., Huemmrich, K. F., Lavergne, T., Melin, F., Privette, J. L., Sandholt, I., Taberner, M., Turner, D. P., Verstraete, M. M., and Widlowski, J.-L.: Evaluation of fraction of absorbed photosynthetically active radiation products for different canopy radiation transfer regimes: Methodology and results using Joint Research Center products derived from SeaWiFS against ground-based estimations, J. Geophys. Res.-Atmos., 111, D13110, doi:10.1029/2005JD006511, 2006.

Gregory, J. M., Jones, C. D., Cadule, P., and Friedlingstein, P.: Quantifying Carbon Cycle Feedbacks, J. Climate, 22, 52325250, doi:10.1175/2009JCLI2949.1, 2009.

Gruber, N., Hauri, C., Lachkar, Z., Loher, D., Froelicher, T. L., and Plattner, G.-K.: Rapid Progression of Ocean Acidification in the California Current System, Science, 337, 220-223, doi:10.1126/science.1216773, 2012.

Grübler, A., Nakicenovic, N., Riahi, K., Wagner, F., Fischer, G., Keppo, I., Obersteiner, M., O’Neill, B., Rao, S., and Tubiello, F.: Integrated assessment of uncertainties in greenhouse gas emissions and their mitigation: Introduction and overview, Technol. Forecast. Soc., 74, 873-886, doi:10.1016/j.techfore.2006.07.009, 2007.

Hallgren, W. S. and Pitman, A. J.: The uncertainty in simulations by a Global Biome Model (BIOMES) to alternative parameter values, Glob. Change Biol., 6, 483-495, doi:10.1046/j.13652486.2000.00325.x, 2000.

Harris, G. R., Sexton, D. M. H., Booth, B. B. B., Collins, M., and Murphy, J. M.: Probabilistic projections of transient climate change, Clim. Dynam., 40, 2937-2972, doi:10.1007/s00382012-1647-y, 2013.

Hartmann, D. L., Klein Tank, A. M. G., Rusticucci, M., Alexander, L. V., Brönnimann, S., Charabi, Y. A., Dentener, F., Dlugokencky, E., Easterling, D. R., Kaplan, A., Soden, J., Thorne, P. W., Wild, M., and Zhai, P.: Climate Change 2013: The Physical Science Basis. Contribution of Working Group I to the Fifth Assessment Report of the Intergovernmental Panel on Climate Change, chap. 2: Observations: Atmosphere and Surface, Cambridge University Press, Cambridge, United Kingdom and New York, NY, USA, 159-254, 2013.

Hawkins, E. and Sutton, R.: The potential to narrow uncertainty in regional climate predictions, B. Am. Meteorol. Soc., 90, 10951107, doi:10.1175/2009BAMS2607.1, 2009.

Haxeltine, A. and Prentice, I. C.: A general model for the lightuse efficiency of primary production, Funct. Ecol., 10, 551-561, doi:10.2307/2390165, 1996.

Heinze, C.: Simulating oceanic $\mathrm{CaCO}_{3}$ export production in the greenhouse, Geophys. Res. Lett., 31, L16308, doi:10.1029/2004GL020613, 2004.

Herrington, T. and Zickfeld, K.: Path independence of climate and carbon cycle response over a broad range of cumulative carbon emissions, Earth Syst. Dynam., 5, 409-422, doi:10.5194/esd-5409-2014, 2014. 
Holden, P. B., Edwards, N. R., Oliver, K. I. C., Lenton, T. M., and Wilkinson, R. D.: A probabilistic calibration of climate sensitivity and terrestrial carbon change in GENIE-1, Clim. Dynam., 35, 785-806, doi:10.1007/s00382-009-0630-8, 2010.

Holden, P. B., Edwards, N. R., Gerten, D., and Schaphoff, S.: A model-based constraint on $\mathrm{CO}_{2}$ fertilisation, Biogeosciences, 10 , 339-355, doi:10.5194/bg-10-339-2013, 2013.

Holden, P. B., Edwards, N. R., Garthwaite, P. H., and Wilkinson, R. D.: Emulation and interpretation of high-dimensional climate model outputs, J. Appl. Stat., 42, 2038-2055, doi:10.1080/02664763.2015.1016412, 2015.

Howes, E. L., Joos, F., Eakin, M., and Gattuso, J.-P.: An updated synthesis of the observed and projected impacts of climate change on the chemical, physical and biological processes in the oceans, Front. Mar. Sci., 2, 36, doi:10.3389/fmars.2015.00036, 2015.

Huang, B. Y., Stone, P. H., Sokolov, A. P., and Kamenkovich, I. V.: Ocean heat uptake in transient climate change: Mechanisms and uncertainty due to subgrid-scale eddy mixing, J. Climate, 16, 3344-3356, doi:10.1175/15200442(2003)016<3344:OHUITC>2.0.CO;2, 2003.

Huber, M. and Knutti, R.: Natural variability, radiative forcing and climate response in the recent hiatus reconciled, Nat. Geosci., 7, 651-656, doi:10.1038/NGEO2228, 2014.

IPCC: Climate Change 1995: The Science of Climate Change, Technical Summary, 11-34, Press Syndicate of the University of Cambridge, Cambridge, United Kingdom and New York, NY, USA, 1995.

IPCC: Summary for Policymakers, in: Climate Change 2013: The Physical Science Basis, Contribution of Working Group I to the Fifth Assessment Report of the Intergovernmental Panel on Climate Change, 3-32, Cambridge University Press, Cambridge, United Kingdom and New York, NY, USA, 2013.

IPCC: Climate Change 2014: Impacts, Adaptation, and Vulnerability. Contribution of Working Group I to the Fifth Assessment Report of the Intergovernmental Panel on Climate Change, Cambridge University Press, Cambridge, United Kingdom and New York, NY, USA, 1132 pp., 2014.

Jenkinson, D. S.: The turnover of organic-carbon and nitrogen in soil, Philos. T. Roy. Soc. B, 329, 361-368, doi:10.1098/rstb.1990.0177, 1990.

Joos, F., Bruno, M., Fink, R., Siegenthaler, U., Stocker, T. F., and Le Quéré, C.: An efficient and accurate representation of complex oceanic and biospheric models of anthropogenic carbon uptake, Tellus B, 48, 397-417, doi:10.1034/j.1600-0889.1996.t012-00006.x, 1996.

Joos, F., Plattner, G.-K., Stocker, T. F., Marchal, O., and Schmittner, A.: Global warming and marine carbon cycle feedbacks and future atmospheric $\mathrm{CO}_{2}$, Science, 284, 464-467, 1999.

Joos, F., Prentice, I. C., Sitch, S., Meyer, R., Hooss, G., Plattner, G.K., Gerber, S., and Hasselmann, K.: Global warming feedbacks on terrestrial carbon uptake under the Intergovernmental Panel on Climate Change (IPCC) emission scenarios, Global Biogeochem. Cy., 15, 891-907, doi:10.1029/2000GB001375, 2001.

Joos, F., Frölicher, T. L., Steinacher, M., and Plattner, G.-K.: Ocean Acidification, chap. 14: Impact of climate change mitigation on ocean acidification projections, Oxford University Press, New York, USA, 319-338, 2011.
Joos, F., Roth, R., Fuglestvedt, J. S., Peters, G. P., Enting, I. G., von Bloh, W., Brovkin, V., Burke, E. J., Eby, M., Edwards, N. R., Friedrich, T., Frölicher, T. L., Halloran, P. R., Holden, P. B., Jones, C., Kleinen, T., Mackenzie, F. T., Matsumoto, K., Meinshausen, M., Plattner, G.-K., Reisinger, A., Segschneider, J., Shaffer, G., Steinacher, M., Strassmann, K., Tanaka, K., Timmermann, A., and Weaver, A. J.: Carbon dioxide and climate impulse response functions for the computation of greenhouse gas metrics: a multi-model analysis, Atmos. Chem. Phys., 13, 2793 2825, doi:10.5194/acp-13-2793-2013, 2013.

Karl, T. R., Arguez, A., Huang, B., Lawrimore, J. H., McMahon, J. R., Menne, M. J., Peterson, T. C., Vose, R. S., and Zhang, H.-M.: Possible artifacts of data biases in the recent global surface warming hiatus, Science, 348, 1469-1472, doi:10.1126/science.aaa5632, 2015.

Keeling, C. D. and Whorf, T. P.: Atmospheric $\mathrm{CO}_{2}$ records from sites in the SIO air sampling network, Trends Online: A compendium of Data on Global Change, Carbon Dioxide Information Analysis Center, Oak Ridge National Laboratory, US Department of Energy, Oak Ridge, Tenn., USA, 2005.

Keith, H., Mackey, B. G., and Lindenmayer, D. B.: Re-evaluation of forest biomass carbon stocks and lessons from the world's most carbon-dense forests, P. Natl. Acad. Sci. USA, 106, 1163511640, doi:10.1073/pnas.0901970106, 2009.

Kergoat, L.: A model for hydrological equilibrium of leaf area index on a global scale, J. Hydrol., 212, 268-286, doi:10.1016/S00221694(98)00211-X, 1998.

Key, R. M., Kozyr, A., Sabine, C. L., Lee, K., Wanninkhof, R., Bullister, J., Feely, R. A., Millero, F., Mordy, C., and Peng, T.H.: A global ocean carbon climatology: Results from Global Data Analysis Project (GLODAP), Global Biogeochem. Cy., 18, GB4031, doi:10.1029/2004GB002247, 2004.

Knutti, R. and Hegerl, G. C.: The equilibrium sensitivity of the Earth's temperature to radiation changes, Nat. Geosci., 1, 735743, doi:10.1038/ngeo337, 2008.

Knutti, R., Stocker, T. F., Joos, F., and Plattner, G. K.: Constraints on radiative forcing and future climate change from observations and climate model ensembles, Nature, 416, 719-723, doi:10.1038/416719a, 2002.

Knutti, R., Stocker, T. F., Joos, F., and Plattner, G. K.: Probabilistic climate change projections using neural networks, Clim. Dynam., 21, 257-272, doi:10.1007/s00382-003-0345-1, 2003.

Knutti, R., Joos, F., Muller, S. A., Plattner, G. K., and Stocker, T. F.: Probabilistic climate change projections for $\mathrm{CO}_{2}$ stabilization profiles, Geophys. Res. Lett., 32, L20707, doi:10.1029/2005GL023294, 2005.

Krasting, J. P., Dunne, J. P., Shevliakova, E., and Stouffer, R. J.: Trajectory sensitivity of the transient climate response to cumulative carbon emissions, Geophys. Res. Lett., 41, 2520-2527, doi:10.1002/2013GL059141, 2014.

Kummer, J. R. and Dessler, A. E.: The impact of forcing efficacy on the equilibrium climate sensitivity, Geophys. Res. Lett., 41, 3565-3568, doi:10.1002/2014GL060046, 2014.

Kwon, E. Y., Primeau, F., and Sarmiento, J. L.: The impact of remineralization depth on the air-sea carbon balance, Nat. Geosci., 2, 630-635, doi:10.1038/NGEO612, 2009.

Leverenz, J. W.: The effects of illumination sequence, $\mathrm{CO}_{2}$ concentration, temperature and acclimation on the convexity of the pho- 
tosynthetic light response curve, Physiol. Plantarum, 74, 332341, doi:10.1111/j.1399-3054.1988.tb00639.x, 1988.

Levitus, S., Antonov, J. I., Boyer, T. P., Baranova, O. K., Garcia, H. E., Locarnini, R. A., Mishonov, A. V., Reagan, J. R., Seidov, D., Yarosh, E. S., and Zweng, M. M.: World ocean heat content and thermosteric sea level change (0-2000 m), 1955-2010, Geophys. Res. Lett., 39, L10603, doi:10.1029/2012GL051106, 2012.

Little, C. M., Oppenheimer, M., and Urban, N. M.: Upper bounds on twenty-first-century Antarctic ice loss assessed using a probabilistic framework, Nature Climate Change, 3, 654-659, doi:10.1038/NCLIMATE1845, 2013.

Lloyd, J. and Taylor, J. A.: On the temperature-dependence of soil respiration, Funct. Ecol., 8, 315-323, doi:10.2307/2389824, 1994.

Locarnini, R. A., Mishonov, A. V., Antonov, J. I., Boyer, T. P., Garcia, H. E., Baranova, O. K. Zweng, M. M., and Johnson, D. R.: World Ocean Atlas 2009, Volume 1: Temperature, NOAA Atlas NESDIS 68, US Government Printing Office, Washington, D.C., 184 pp., 2010.

Luyssaert, S., Inglima, I., Jung, M., Richardson, A. D., Reichstein, M., Papale, D., Piao, S. L., Schulzes, E.-D., Wingate, L., Matteucci, G., Aragao, L., Aubinet, M., Beers, C., Bernhoffer, C., Black, K. G., Bonal, D., Bonnefond, J.-M., Chambers, J., Ciais, P., Cook, B., Davis, K. J., Dolman, A. J., Gielen, B., Goulden, M., Grace, J., Granier, A., Grelle, A., Griffis, T., Gruenwald, T., Guidolotti, G., Hanson, P. J., Harding, R., Hollinger, D. Y., Hutyra, L. R., Kolar, P., Kruijt, B., Kutsch, W., Lagergren, F., Laurila, T., Law, B. E., Le Maire, G., Lindroth, A., Loustau, D., Malhi, Y., Mateus, J., Migliavacca, M., Misson, L., Montagnani, L., Moncrieff, J., Moors, E., Munger, J. W., Nikinmaa, E., Ollinger, S. V., Pita, G., Rebmann, C., Roupsard, O., Saigusa, N., Sanz, M. J., Seufert, G., Sierra, C., Smith, M.-L., Tang, J., Valentini, R., Vesala, T., and Janssens, I. A.: $\mathrm{CO}_{2}$ balance of boreal, temperate, and tropical forests derived from a global database, Glob. Change Biol., 13, 2509-2537, doi:10.1111/j.1365-2486.2007.01439.x, 2007.

Lyman, J. M., Good, S. A., Gouretski, V. V., Ishii, M., Johnson, G. C., Palmer, M. D., Smith, D. M., and Willis, J. K.: Robust warming of the global upper ocean, Nature, 465, 334-337, doi:10.1038/nature09043, 2010.

Magnani, F., Leonardi, S., Tognetti, R., Grace, J., and Borghetti, M.: Modelling the surface conductance of a broad-leaf canopy: effects of partial decoupling from the atmosphere, Phys. Chem. Earth, 21, 867-879, doi:10.1046/j.1365-3040.1998.00328.x, 1998.

Maier-Reimer, E. and Hasselmann, K.: Transport and storage of $\mathrm{CO}_{2}$ in the ocean - an inorganic ocean-circulation carbon cycle model, Clim. Dynam., 2, 63-90, doi:10.1007/BF01054491, 1987.

Marotzke, J. and Forster, P. M.: Forcing, feedback and internal variability in global temperature trends, Nature, 517, 565-570, doi:10.1038/nature14117, 2015.

Matthews, H. D., Gillett, N. P., Stott, P. A., and Zickfeld, K.: The proportionality of global warming to cumulative carbon emissions, Nature, 459, 829-832, doi:10.1038/nature08047, 2009.

McKay, M. D., Beckman, R. J., and Conover, W. J.: A comparison of three methods for selecting values of input variables in the analysis of output from a computer code, Technometrics, 21, 239-245, doi:10.2307/1268522, 1979.
McNeil, B. I. and Matear, R. J.: Climate change feedbacks on future oceanic acidification, Tellus B, 59, 191-198, doi:10.1111/j.16000889.2006.00241.x, 2007.

Meinshausen, M., Meinshausen, N., Hare, W., Raper, S. C. B., Frieler, K., Knutti, R., Frame, D. J., and Allen, M. R.: Greenhouse-gas emission targets for limiting global warming to $2{ }^{\circ} \mathrm{C}$, Nature, 458, 1158-1162, doi:10.1038/nature08017, 2009.

Meinshausen, M., Smith, S. J., Calvin, K. V., Daniel, J. S., Kainuma, M., Lamarque, J.-F., Matsumoto, K., Montzka, S. A., Raper, S. C. B., Riahi, K., Thomson, A. M., Velders, G. J. M., and van Vuuren, D.: The RCP Greenhouse Gas Concentrations and their Extension from 1765 to 2300, Climatic Change, 109, 213-241, doi:10.1007/s10584-011-0156-z, 2011.

Moss, R. H., Edmonds, J. A., Hibbard, K. A., Manning, M. R., Rose, S. K., van Vuuren, D. P., Carter, T. R., Emori, S., Kainuma, M., Kram, T., Meehl, G. A., Mitchell, J. F. B., Nakicenovic, N., Riahi, K., Smith, S. J., Stouffer, R. J., Thomson, A. M., Weyant, J. P., and Wilbanks, T. J.: The next generation of scenarios for climate change research and assessment, Nature, 463, 747-756, doi:10.1038/nature08823, 2010.

Müller, S. A., Joos, F., Edwards, N. R., and Stocker, T. F.: Water mass distribution and ventilation time scales in a cost-efficient, three-dimensional ocean model, J. Climate, 19, 5479-5499, doi:10.1175/JCLI3911.1, 2006.

Müller, S. A., Joos, F., Plattner, G.-K., Edwards, N. R., and Stocker, T. F.: Modeled natural and excess radiocarbon: Sensitivities to the gas exchange formulation and ocean transport strength, Global Biogeochem. Cy., 22, GB3011, doi:10.1029/2007GB003065, 2008.

Murphy, J. M., Sexton, D. M. H., Barnett, D. N., Jones, G. S., Webb, M. J., and Stainforth, D. A.: Quantification of modelling uncertainties in a large ensemble of climate change simulations, Nature, 430, 768-772, doi:10.1038/nature02771, 2004.

Myhre, G., Shindell, D., Bréon, F.-M., Collins, W., Fuglestvedt, J., Huang, J., Koch, D., Lamarque, J.-F., Lee, D., Mendoza, B., Nakajima, T., Robock, A., Stephens, G., Takemura, T., and Zhang, H.: Climate Change 2013: The Physical Science Basis, Contribution of Working Group I to the Fifth Assessment Report of the Intergovernmental Panel on Climate Change, chap. 8: Anthropogenic and Natural Radiative Forcing, Cambridge University Press, Cambridge, United Kingdom and New York, NY, USA, 659-740, 2013.

Nieves, V., Willis, J. K., and Patzert, W. C.: Recent hiatus caused by decadal shift in Indo-Pacific heating, Science, 349, 532-535, doi:10.1126/science.aaa4521, 2015.

Olson, R., Sriver, R., Goes, M., Urban, N. M., Matthews, H. D., Haran, M., and Keller, K.: A climate sensitivity estimate using Bayesian fusion of instrumental observations and an Earth System model, J. Geophys. Res.-Atmos., 117, D04103, doi:10.1029/2011JD016620, 2012.

Olson, R. J., Scurlock, J. M. O., Prince, S. D., Zheng, D. L., and Johnson, K. R.: NPP Multi-Biome: NPP and Driver Data for Ecosystem Model-Data Intercomparison., Data set, Oak Ridge National Laboratory Distributed Active Archive Center, Oak Ridge, Tennessee, USA, available at: http://www.daac.ornl.gov (last access: 29 July 2010), 2001.

Orr, J. C.: Ocean Acidification, chap. 3: Recent and future changes in ocean carbonate chemistry, Oxford University Press, New York, USA, 41-66, 2011. 
Orr, J. C., Fabry, V. J., Aumont, O., Bopp, L., Doney, S. C., Feely, R. A., Gnanadesikan, A., Gruber, N., Ishida, A., Joos, F., Key, R. M., Lindsay, K., Maier-Reimer, E., Matear, R., Monfray, P., Mouchet, A., Najjar, R. G., Plattner, G.-K., Rodgers, K. B., Sabine, C. L., Sarmiento, J. L., Schlitzer, R., Slater, R. D., Totterdell, I. J., Weirig, M. F., Yamanaka, Y., and Yool, A.: Anthropogenic ocean acidification over the twenty-first century and its impact on calcifying organisms, Nature, 437, 681-686, doi:10.1038/nature04095, 2005.

Otto, A., Otto, F. E. L., Boucher, O., Church, J., Hegerl, G., Forster, P. M., Gillett, N. P., Gregory, J., Johnson, G. C., Knutti, R., Lewis, N., Lohmann, U., Marotzke, J., Myhre, G., Shindell, D., Stevens, B., and Allen, M. R.: Energy budget constraints on climate response, Nat. Geosci., 6, 415-416, doi:10.1038/ngeo1836, 2013.

Parekh, P., Joos, F., and Müller, S. A.: A modeling assessment of the interplay between aeolian iron fluxes and ironbinding ligands in controlling carbon dioxide fluctuations during Antarctic warm events, Paleoceanography, 23, PA4202, doi:10.1029/2007PA001531, 2008.

Peters, G. P., Andrew, R. M., Boden, T., Canadell, J. G., Ciais, P., Le Quere, C., Marland, G., Raupach, M. R., and Wilson, C.: COMMENTARY: The challenge to keep global warming below 2 degrees C, Nature Climate Change, 3, 4-6, doi:10.1038/nclimate1783, 2013.

Pfister, P. L. and Stocker, T. F.: Earth system commitments due to delayed mitigation, Environ. Res. Lett., 11, 014010, doi:10.1088/1748-9326/11/1/014010, 2016.

Plattner, G.-K., Joos, F., Stocker, T. F., and Marchal, O.: Feedback mechanisms and sensitivities of ocean carbon uptake under global warming, Tellus B, 53, 564-592, doi:10.1034/j.16000889.2001.530504.x, 2001.

Pörtner, H.-O., Gutowska, M., Ishimatsu, A., Lucassen, M., Meizner, F., and Seibel, B. A.: Ocean Acidification, chap. 8: Effects of ocean acidification on nektonic organisms, Oxford University Press, New York, USA, 154-175, 2011.

Prentice, I. C., Farquhar, G. D., Fasham, M. J. R., Goulden, M. L., Heimann, M., Jaramillo, V. J., Kheshgi, H. S., Le Quéré, C., Scholes, R. J., and Wallace, D. W. R.: Climate Change 2001: The Scientific Basis, Contribution of Working Group I to the Third Assessment Report of the Intergovernmental Panel on Climate Change, chap.: The Carbon Cycle and Atmospheric Carbon Dioxide, Cambridge University Press, Cambridge, United Kingdom and New York, NY, USA, 183-237, 2001.

Raich, J. W. and Schlesinger, W. H.: The global carnon-dioxide flux in soil respiration and its relationship to vegetation and climate, Tellus B, 44, 81-99, doi:10.1034/j.1600-0889.1992.t01-100001.x, 1992.

Ritz, S. P., Stocker, T. F., and Joos, F.: A Coupled Dynamical OceanEnergy Balance Atmosphere Model for Paleoclimate Studies, J. Climate, 24, 349-375, doi:10.1175/2010JCLI3351.1, 2011a.

Ritz, S. P., Stocker, T. F., and Severinghaus, J. P.: Noble gases as proxies of mean ocean temperature: sensitivity studies using a climate model of reduced complexity, Quaternary Sci. Rev., 30, 3728-3741, doi:10.1016/j.quascirev.2011.09.021, 2011 b.

Roberts, C. D., Palmer, M. D., McNeall, D., and Collins, M.: Quantifying the likelihood of a continued hiatus in global warming, Nature Climate Change, 5, 337-342, doi:10.1038/nclimate2531, 2015.
Roemmich, D., Church, J., Gilson, J., Monselesan, D., Sutton, P., and Wijffels, S.: Unabated planetary warming and its ocean structure since 2006, Nature Climate Change, 5, 240-245, doi:10.1038/NCLIMATE2513, 2015.

Rogelj, J., Hare, W., Lowe, J., van Vuuren, D. P., Riahi, K., Matthews, B., Hanaoka, T., Jiang, K., and Meinshausen, M.: Emission pathways consistent with a 2 degrees $\mathrm{C}$ global temperature limit, Nature Climate Change, 1, 413-418, doi:10.1038/NCLIMATE1258, 2011.

Schleussner, C.-F., Levermann, A., and Meinshausen, M.: Probabilistic projections of the Atlantic overturning, Climatic Change, 127, 579-586, doi:10.1007/s10584-014-1265-2, 2014.

Schmittner, A., Urban, N. M., Keller, K., and Matthews, D.: Using tracer observations to reduce the uncertainty of ocean diapycnal mixing and climate-carbon cycle projections, Global Biogeochem. Cy., 23, GB4009, doi:10.1029/2008GB003421, 2009.

Schwartz, S. E.: Determination of Earth's Transient and Equilibrium Climate Sensitivities from Observations Over the Twentieth Century: Strong Dependence on Assumed Forcing, Surv. Geophys., 33, 745-777, doi:10.1007/s10712-012-9180-4, 2012.

Sherwood, S. C. and Huber, M.: An adaptability limit to climate change due to heat stress, P. Natl. Acad. Sci. USA, 107, 95529555, doi:10.1073/pnas.0913352107, 2010.

Shindell, D.: Reply to "Questions of bias in climate models", Nature Climate Change, 4, 742-743, doi:10.1038/nclimate2346, 2014a.

Shindell, D. T.: Inhomogeneous forcing and transient climate sensitivity, Nature Climate Change, 4, 274-277, doi:10.1038/NCLIMATE2136, 2014b.

Shine, K. P., Fuglestvedt, J. S., Hailemariam, K., and Stuber, N.: Alternatives to the global warming potential for comparing climate impacts of emissions of greenhouse gases, Climatic Change, 68, 281-302, doi:10.1007/s10584-005-1146-9, 2005.

Siegenthaler, U. and Oeschger, H.: Predicting future atmospheric carbon-dioxide levels, Science, 199, 388-395, doi:10.1126/science.199.4327.388, 1978.

Sitch, S., Smith, B., Prentice, I. C., Arneth, A., Bondeau, A., Cramer, W., Kaplan, J. O., Levis, S., Lucht, W., Sykes, M. T., Thonicke, K., and Venevsky, S.: Evaluation of ecosystem dynamics, plant geography and terrestrial carbon cycling in the LPJ dynamic global vegetation model, Glob. Change Biol., 9, 161-185, doi:10.1046/j.1365-2486.2003.00569.x, 2003.

Spahni, R., Joos, F., Stocker, B. D., Steinacher, M., and Yu, Z. C.: Transient simulations of the carbon and nitrogen dynamics in northern peatlands: from the Last Glacial Maximum to the 21st century, Clim. Past, 9, 1287-1308, doi:10.5194/cp-9-1287-2013, 2013.

Stainforth, D. A.: Climate projection: Testing climate assumptions, Nature Climate Change, 4, 248-249, doi:10.1038/nclimate2172, 2014.

Steinacher, M., Joos, F., Frölicher, T. L., Plattner, G.-K., and Doney, S. C.: Imminent ocean acidification in the Arctic projected with the NCAR global coupled carbon cycle-climate model, Biogeosciences, 6, 515-533, doi:10.5194/bg-6-515-2009, 2009.

Steinacher, M., Joos, F., and Stocker, T. F.: Allowable carbon emissions lowered by multiple climate targets, Nature, 499, 197-201, doi:10.1038/nature12269, 2013.

Stocker, B. D., Feissli, F., Strassmann, K. M., Spahni, R., and Joos, F.: Past and future carbon fluxes from land use change, 
shifting cultivation and wood harvest, Tellus B, 66, 23188, doi:10.3402/tellusb.v66.23188, 2014.

Stocker, T. F.: The Closing Door of Climate Targets, Science, 339, 280-282, doi:10.1126/science.1232468, 2013.

Strassmann, K. M., Joos, F., and Fischer, G.: Simulating effects of land use changes on carbon fluxes: past contributions to atmospheric $\mathrm{CO}_{2}$ increases and future commitments due to losses of terrestrial sink capacity, Tellus B, 60, 583-603, doi:10.1111/j.1600-0889.2008.00340.x, 2008.

Strassmann, K. M., Plattner, G.-K., and Joos, F.: $\mathrm{CO}_{2}$ and non$\mathrm{CO}_{2}$ radiative forcings in climate projections for twenty-first century mitigation scenarios, Clim. Dynam., 33, 737-749, doi:10.1007/s00382-008-0505-4, 2009.

Tarnocai, C., Swanson, D., Kimble, J., and Broll, G.: Northern Circumpolar Soil Carbon Database, Digital database, Research Branch, Agriculture and Agri-Food Canada, Ottawa, Canada, available at: http://wms1.agr.gc.ca/NortherCircumpolar/ northercircumpolar.zip (last access: 31 May 2010), 2007.

Tarnocai, C., Canadell, J. G., Schuur, E. A. G., Kuhry, P., Mazhitova, G., and Zimov, S.: Soil organic carbon pools in the northern circumpolar permafrost region, Global Biogeochem. Cy., 23, GB2023, doi:10.1029/2008GB003327, 2009.

Trumbore, S. E.: Age of soil organic matter and soil respiration: radiocarbon constraints on belowground $\mathrm{C}$ dynamics, Ecol. Appl., 10, 399-411, doi:10.1890/10510761(2000)010[0399:AOSOMA]2.0.CO;2, 2000.

United Nations: United Nations Framework Convention on Climate Change, Document FCCC/INFORMAL/84 GE.05-62220 (E) 200705, United Nations, available at: http://unfccc.int/resource/ docs/convkp/conveng.pdf (last access: 29 September 2013), 1992.

United Nations: Report of the Conference of the Parties on its sixteenth session, held in Cancun from 29 November to 10 December 2010, document FCCC/CP/2010/7/Add.1, United Nations, available at: http://unfccc.int/resource/docs/2010/cop16/ eng/07a01.pdf (last access: 29 September 2013), 2010.

United Nations: Conference of the Parties. ADOPTION OF THE PARIS AGREEMENT, Proposal by the President, document FCCC/CP/2015/L.9/Rev.1, United Nations, available at: https: //unfccc.int/resource/docs/2015/cop21/eng/109r01.pdf (last access: 14 January 2016), 2015.

van der Werf, G. R. and Dolman, A. J.: Impact of the Atlantic Multidecadal Oscillation (AMO) on deriving anthropogenic warming rates from the instrumental temperature record, Earth Syst. Dynam., 5, 375-382, doi:10.5194/esd-5-375-2014, 2014.
Van Vuuren, D. P., Meinshausen, M., Plattner, G.-K., Joos, F., Strassmann, K. M., Smith, S. J., Wigley, T. M. L., Raper, S. C. B., Riahi, K., de la Chesnaye, F., den Elzen, M., Fujino, J., Jiang, K., Nakicenovic, N., Paltsev, S., and Reilly, J. M.: Temperature increase of 21 st century mitigation scenarios, P. Natl. Acad. Sci. USA, 105, 15258-15262, doi:10.1073/pnas.0711129105, 2008.

von Schuckmann, K. and Le Traon, P.-Y.: How well can we derive Global Ocean Indicators from Argo data?, Ocean Sci., 7, 783791, doi:10.5194/os-7-783-2011, 2011.

Weyant, J. R., de la Chesnaye, F. C., and Blanford, G. J.: Overview of EMF-21: Multigas mitigation and climate policy, Energ. J., 27, 1-32, 2006.

Wigley, T. M. L. and Raper, S. C. B.: Interpretation of high projections for global-mean warming, Science, 293, 451-454, doi:10.1126/science.1061604, 2001.

Williamson, D., Goldstein, M., Allison, L., Blaker, A., Challenor, P., Jackson, L., and Yamazaki, K.: History matching for exploring and reducing climate model parameter space using observations and a large perturbed physics ensemble, Clim. Dynam., 41, 1703-1729, doi:10.1007/s00382-013-1896-4, 2013.

Yu, Z., Loisel, J., Brosseau, D. P., Beilman, D. W., and Hunt, S. J.: Global peatland dynamics since the Last Glacial Maximum, Geophys. Res. Lett., 37, L13402, doi:10.1029/2010GL043584, 2010.

Zaehle, S., Sitch, S., Smith, B., and Hatterman, F.: Effects of parameter uncertainties on the modeling of terrestrial biosphere dynamics, Global Biogeochem. Cy., 19, GB3020, doi:10.1029/2004GB002395, 2005.

Zickfeld, K. and Herrington, T.: The time lag between a carbon dioxide emission and maximum warming increases with the size of the emission, Environ. Res. Lett., 10, 031001, doi:10.1088/1748-9326/10/3/031001, 2015.

Zickfeld, K., Eby, M., Matthews, H. D., and Weaver, A. J.: Setting cumulative emissions targets to reduce the risk of dangerous climate change, P. Natl. Acad. Sci. USA, 106, 16129-16134, doi:10.1073/pnas.0805800106, 2009.

Zickfeld, K., Arora, V. K., and Gillett, N. P.: Is the climate response to $\mathrm{CO}_{2}$ emissions path dependent?, Geophys. Res. Lett., 39, L05703, doi:10.1029/2011GL050205, 2012. 